ACCEPTED MANUSCRIPT

\title{
High-power gyrotrons for electron cyclotron heating and current drive
}

To cite this article before publication: Manfred Thumm et al 2019 Nucl. Fusion in press https://doi.org/10.1088/1741-4326/ab2005

\section{Manuscript version: Accepted Manuscript}

Accepted Manuscript is "the version of the article accepted for publication including all changes made as a result of the peer review process, and which may also include the addition to the article by IOP Publishing of a header, an article ID, a cover sheet and/or an 'Accepted

Manuscript' watermark, but excluding any other editing, typesetting or other changes made by IOP Publishing and/or its licensors"

This Accepted Manuscript is () EURATOM 2019.

During the embargo period (the 12 month period from the publication of the Version of Record of this article), the Accepted Manuscript is fully protected by copyright and cannot be reused or reposted elsewhere.

As the Version of Record of this article is going to be / has been published on a subscription basis, this Accepted Manuscript is available for reuse under a CC BY-NC-ND 3.0 licence after the 12 month embargo period.

After the embargo period, everyone is permitted to use copy and redistribute this article for non-commercial purposes only, provided that they adhere to all the terms of the licence https://creativecommons.org/licences/by-nc-nd/3.0

Although reasonable endeavours have been taken to obtain all necessary permissions from third parties to include their copyrighted content within this article, their full citation and copyright line may not be present in this Accepted Manuscript version. Before using any content from this article, please refer to the Version of Record on IOPscience once published for full citation and copyright details, as permissions will likely be required. All third party content is fully copyright protected, unless specifically stated otherwise in the figure caption in the Version of Record.

View the article online for updates and enhancements. 


\title{
High-Power Gyrotrons for Electron Cyclotron Heating and Current Drive
}

\author{
M K A Thumm ${ }^{1}$, G G Denisov ${ }^{2}$, K Sakamoto $^{3}$ and M Q Tran ${ }^{4}$ \\ ${ }^{1}$ Karlsruhe Institute of Technology (KIT), IHM and IHE, D-76131 Karlsruhe, Germany \\ ${ }^{2}$ Institute of Applied Physics (IAP) of the Russian Academy of Sciences (RAS), \\ Nizhny Novgorod 603950, Russia \\ ${ }^{3}$ National Institutes for Quantum and Radiological Science and Technology (QST), \\ Naka, Ibaraki, 311-0193, Japan \\ ${ }^{4}$ Swiss Plasma Center (SPC), Ecole Polytechnique Fédérale de Lausanne (EPFL), \\ CH-1015 Lausanne, Switzerland
}

E-mail: manfred.thumm@kit.edu

\begin{abstract}
In many tokamak and stellarator experiments around the globe that are investigating energy production via controlled thermonuclear fusion, electron cyclotron heating and current drive (ECH\&CD) are used for plasma start-up, heating, non-inductive current drive and MHD stability control. ECH will be the first auxiliary heating method used on ITER. Megawatt-class, continuous wave $(\mathrm{CW})$ gyrotrons are employed as high-power millimeter $(\mathrm{mm})$-wave sources. The present review reports on the worldwide state-of-the-art of high-power gyrotrons. Their successful development during the past years changed ECH from a minor to a major heating method. After a general introduction of the various functions of ECH\&CD in fusion physics, especially for ITER, Section 2 will explain the fast-wave gyrotron interaction principle. Section 3 discusses innovations on the components of modern long-pulse fusion gyrotrons (magnetron injection electron gun (MIG), beam tunnel, cavity, quasi-optical output coupler, synthetic diamond output window, single-stage depressed collector) and auxiliary components (superconducting magnets, gyrotron diagnostics, high-power calorimetric dummy loads). Section 4 deals with present megawatt-class gyrotrons for ITER, W7-X, LHD, EAST, KSTAR and JT-60SA, and also includes tubes for moderate pulse length machines as, ASDEX-U, DIII-D, HL-2A, TCV, QUEST and GAMMA-10. In Section 5 the development of future advanced fusion gyrotrons is discussed. These are tubes with higher frequencies for DEMO, multi-frequency (multi-purpose) gyrotrons, stepwise frequency tunable tubes for plasma stabilization, injection-locked and coaxial-cavity multi-megawatt gyrotrons, as well as sub-THz gyrotrons for collective Thomson scattering (CTS). Efficiency enhancement via multi-stage depressed collectors, fast oscillation recovery methods and reliability, availability, maintainability and inspectability (RAMI) will be discussed at the end of this section.
\end{abstract}

Keywords: Gyrotron, tokamak, stellarator, electron cyclotron heating and current drive (ECH\&CD), collective Thomson scattering (CTS), ITER, DEMO

\section{Introduction}

It is well known that to reach thermonuclear fusion conditions, magnetically confined plasmas require external heating up to 100-200 million Kelvin [1]. While the considerations presented in [1] show the need for additional heating power, it is important to note that each specific heating method has specific features. For example, ref. [2] is a study of the heating mix for ITER: $20 \mathrm{MW}$ of electron cyclotron wave heating (ECH), $20 \mathrm{MW}$ of ion cyclotron wave heating (ICH) and $33 \mathrm{MW}$ of $1 \mathrm{MeV}$ neutral beam injection heating (NBI). References on radio frequency (RF) heating can be found for example in $[3,4$, 5]. In the present section, the missions, which can be covered by ECH and non-inductive Electron Cyclotron Wave Current Drive (ECCD) are outlined.

Here the role of electron cyclotron waves (ECWs) in magnetically confined fusion plasmas is briefly summarized. ECWs are absorbed at the plasma location, where the following resonance relation is fulfilled 


$$
\omega=n \Omega_{c o}(r)+k_{\|} v_{\|} \quad, \quad n=1,2, \ldots
$$

where $\omega$ and $k_{\|}$are the angular frequency and wave vector along the toroidal direction, respectively, $v_{\|}$ is the toroidal electron drift velocity, $\Omega_{c o}(r)$ is the local electron cyclotron frequency and $n$ is the cyclotron harmonic number.

The local non-relativistic electron cyclotron frequency $\Omega_{c o}(r)$ is given by

$$
\Omega_{c o}(r)=e B_{T}(r) / m_{o}
$$

where $e$ and $m_{o}$ are the charge and rest mass, respectively, of an electron and $B_{T}(r)$ is the magnitude of the local toroidal magnetic field.

The relativistic version of the resonance condition (1) is given by

$$
n \Omega_{c o}(r) / \omega=\gamma-N_{\|} u_{\|}
$$

where $u$ is the normalized relativistic momentum $u=p / m_{o} c$, with $c$ being the free-space velocity of light, $\gamma$ is the relativistic Lorentz factor

$$
\gamma=\left[1+u^{2}\right]^{1 / 2}
$$

and $N_{\|}$is the component of the vector refractive index $N=\boldsymbol{k} c / \omega$ parallel to $B_{\mathrm{T}}$.

When $k_{\|}$is zero (perpendicular injection), absorption occurs at the plasma location where the local cyclotron frequency $(n=1)$ or its harmonics $(n>1)$ matches the wave frequency. The term $k_{\|} v_{\|}$denotes the Doppler shift for an obliquely launched wave.

The physics of ECH\&CD, such as mode of propagation, cut-off and resonance, absorption coefficient, and current drive efficiency can be found in [1,5]. Clearly, since the toroidal magnetic field $B_{\mathrm{T}}$ in a tokamak depends on the radial location in the plasma ( $B_{\mathrm{T}}$ decreases inversely with the major radius), the required frequency of the ECWs will be dependent on the desired localization of the heating or current drive region in the plasma. The relation between the non-relativistic EC frequency $f_{c 0}$ and the local toroidal magnetic field is simply $f_{c 0}[\mathrm{GHz}]=\Omega_{c 0} / 2 \pi=28 * B_{\mathrm{T}}$, when $B_{\mathrm{T}}$ is expressed in Tesla. In the case of current drive, the waves are obliquely launched and therefore there will be an upshift of the resonance frequency compared to the local $f_{c 0}$. The value of this upshift is discussed in the paper by Poli et al. [6]. The application of formulas (3) and (4) of ref. [6] yields an upshift factor in the range of 1.2-1.4, depending on the launching angle and the plasma parameters (the local electron temperature). Therefore the $\mathrm{CD}$ frequency is given by $f_{\mathrm{CD}}[\mathrm{GHz}]=(1.2-1.4) * 28^{*} B_{\mathrm{T}}$. The selection of the optimum frequency for a specific $\mathrm{CD}$ function for a given plasma configuration (density profile, temperature profiles) and machine parameters (magnetic field, possible launching points), requires a full optimization calculation. Trade-off may be needed, taking into account the optimally determined frequency and what could be achieved technically. Often, as discussed below, an ECW system will combine both heating and current drive functions. Space and cost constraints lead to the selection of a compromise between the optimum frequency for each function.) As described later, the availability of gyrotrons operating at 2 or 3 frequencies (determined by the resonant frequencies of the dielectric window at the output of the tube) or step-tunable (in step of 2-3 GHz over a bandwidth of approx. $\pm 10 \mathrm{GHz}$ ) with a broadband output window opens up new domains of flexibility in the design and implementation of ECH\&CD systems.

ECWs can be used in magnetically confined plasmas for various functions from the plasma start-up to ramp down. They encompass: a) the plasma breakdown including the start of the tokamak current, b) the so-called ramp-up phase in which the current is ramped up to the nominal current and the plasma brought into the $\mathrm{H}$ mode, c) plasma control and MHD control during the burn phase and d) the ramp down of the plasma current. ECWs can even be used for vessel cleaning [7]. 
The necessity of using ECWs for the plasma breakdown in tokamaks arises due to the limitation of the toroidal $E$-field during this phase to a value of around $0.3 \mathrm{~V} / \mathrm{m}$. The requirements on frequency are relatively flexible. For example, in ITER, the same $170 \mathrm{GHz}$ gyrotrons will be used for breakdown as well as heating, current drive and control of the MHD instabilities [8].

The next phase is to bring the plasma into the $\mathrm{H}$ mode. The scaling law used most often (the so-called "Martin scaling law") is described in [9]. For this function, heating is the main point. For large devices like ITER and DEMO, the total power can be relatively high $[9,10]$, depending on the scenarios which will be adopted. For DEMO, where the required power is in the range of $150 \mathrm{MW}$, an optimization of the ramp-up scenarios is still under way in view of minimizing the required power during this phase. A second point to be noted is that this function can be fulfilled with other heating methods, provided that the power can be absorbed by the plasma during its trajectory from low-plasma current $I_{\mathrm{P}}$ to the flat top phase. In this sense, ECWs can be used at low plasma density, as noted in [10].

In subsequent phases of a fusion plasma, ECWs can fulfil various control functions, such as sawtooth period control [11], neo classical tearing mode (NTM) control [12], as well the control of the H to L mode transition during the ramp-down phases. In each case, the requirements for the gyrotrons (power, frequency) and for the launchers at the torus must be determined based on the plasma scenarios and plasma profiles. Examples of such calculations can be found in $[6,13]$. Optimization of the frequency for the current drive function is described in [6].

Before concluding on the physics requirements from the gyrotron side, it is worth mentioning a few trends, which are often driven by the users:

(a) even in present devices in operation, both tokamaks and stellarators, the power per gyrotron is at the $1 \mathrm{MW}$ level. This brings some cost reduction on the ancillary system (superconducting gyrotron magnets) as well as on the transmission lines and launchers. For future devices such as DEMO, a total required power of $50 \mathrm{MW}$ [13] or more is considered: this leads to a desirable gyrotron unit power of $2 \mathrm{MW}$;

(b) as already mentioned above, to fulfil the different functions required by physics, the ECW power is deposited at different locations in the plasma, with different upshift ( $=1$ for heating, between 1.2-1.4 for functions linked to current drive physics). In some medium size tokamaks such as $\mathrm{TCV}$, the low value of $B_{\mathrm{T}}$ leads to the use of ECWs at the second harmonic or even the third harmonic to allow access to high plasma density [14]. In both cases, the possibility of having gyrotrons operating at two or more frequencies (determined by the transmission frequencies of the output window), or which can be magnetically tuned over the different resonant frequencies of the gyrotron cavity is a strong asset, since it allows a reduction in the investment cost of the ancillary system. The former type of gyrotron is implemented in many present experiments. The second approach requires the development of large broadband synthetic diamond windows, which is now under way;

(c) in a reactor, two additional requirements may play an important role. First, the total power delivered to the plasma may be large (e.g. on the order of many tens of MW in continuous wave (CW) operation, implying a power per gyrotron in excess of $1 \mathrm{MW}$ (in the range of $2 \mathrm{MW}$ ) as discussed above. Secondly, in a reactor the electrical efficiency (defined as the ratio of the RF output power to the electrical power to the tube) must be as high as possible to minimize the recirculating power from the power plant. This consideration should also be a driver for the $\mathrm{R} \& \mathrm{D}$ in the field of multi-stage depressed collectors, where an overall balance should be performed by considering the electrical efficiency and the complexity of the collector design and operation, the high-voltage power supply and reliability-availability-maintainabilityinspectability (RAMI) aspects. However, at the present state of EC systems, the data available renders true RAMI studies difficult. At the end, the important point is the "expect" opinion on the reliability and availability of gyrotrons, which will determine the number of gyrotrons to be installed to deliver the required power (assuming a $100 \%$ availability of a certain function).

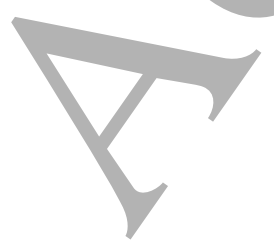




\section{Gyrotron interaction principle}

In electron cyclotron masers (ECMs), the electromagnetic (EM) energy is radiated by relativistic electrons gyrating in an external longitudinal magnetic field with a perpendicular velocity $v_{\llcorner}$. The resonance condition between the periodic rotation of the electrons and the EM wave (TE mode) in the interaction circuit is according to eqs. (1) and (2)

$$
\omega-k_{\|} v_{\|}=n \Omega_{c}, \quad n=1,2, \ldots
$$

where $k_{\|}$is the characteristic axial wavenumber of the EM wave in the interaction structure, $v_{\|}$is the longitudinal electron drift velocity and $\Omega_{c}=\Omega_{c o} / \gamma$ is the relativistic electron cyclotron frequency. The relativistic Lorentz factor $\gamma$ (eq. (4)) can be simply calculated from

$$
\gamma=1+e V_{b} / m_{o} c^{2} \approx 1+V_{b} / 511
$$

where $V_{b}$ is the acceleration voltage of the electron beam in $\mathrm{kV}$.

Gyrotrons are ECM oscillators, which mainly employ weakly relativistic electron beams $\left(V_{b}<100 \mathrm{kV}\right.$, $\gamma<1.2$ ) with high transverse momentum (velocity ratio $\left.\alpha=v_{\perp} / v_{\|}=1.2-1.5\right)$ [15-21]. The wave vector of the EM wave in the cavity is almost transverse to the direction of the longitudinal magnetic field $\left(k_{\perp} \gg k_{\|}\right.$and the Doppler shift is small), resulting, according to eq. (5), in radiation near the electron cyclotron frequency or one of its harmonics:

$$
\omega \cong n \Omega_{c}, \quad n=1,2, \ldots
$$

In cylindrical waveguide cavity gyrotrons the operating TE mode is close to cutoff $\left(v_{p h}=\omega k_{z}>c\right)$ and the frequency mismatch $\omega-n \Omega_{\mathrm{c}}$ is small but positive in order to achieve correct phasing, i.e. keeping the azimuthal electron bunches in the retarding phase to transfer energy to the TE wave. The Doppler term $k\|v\|$ is of the order of the gain width and is small compared to the radiation frequency. The interaction efficiency is between $35 \%$ and $40 \%$. The finite value of the minimum electron energy after the cavity allows the application of a retarding potential to the spent electron beam for recovery of beam power and thus for efficiency improvement (see Section 3.5).

The frequency of a gyrotron is approximately given by the cutoff frequency $f_{\text {cut }}$ of the cavity mode:

$$
f_{\text {cut }}(\mathrm{GHz})=95.4269 \chi_{m, n} / D(\mathrm{~mm})
$$

where $\chi_{m, n}$ is the $n^{\text {th }}$ root of the derivative of the corresponding Bessel function $J_{m}{ }_{m}$ ( $\mathrm{TE}_{\mathrm{mn}}$ mode) and $D$ is the cavity diameter. For millimeter $(\mathrm{mm})$-wave gyrotron cavities (e.g. $170 \mathrm{GHz})$ with a diffraction quality factor $Q$ of approximately 1000 , the exact operating frequency is only about $250 \mathrm{MHz}$ higher than the cutoff frequency $f_{\text {cut }}[22]$.

Gyrotrons are capable of producing very high-power radiation at $\mathrm{cm}, \mathrm{mm}$ and sub-mm wavelengths [1521], since the use of large cavity and output waveguide cross sections reduces wall losses as well as the danger of breakdown and permits the passage of large, high-power electron beams. In contrast to klystrons, the resonance frequency of a gyrotron cavity is not determined by the characteristic size, but by the strength of the magnetic field (see eqs. (2) and (7)). According to eq. (8), for a given frequency, operation in a high-order mode (determined by its eigenvalue $\chi_{m, n}$ ) with low Ohmic attenuation can be selected just by the cavity diameter. Since the Ohmic skin losses are proportional to $1 /\left(\chi_{m, n}{ }^{2}-m^{2}\right)$, volume modes with $0.3 \leqq m / \chi_{m, n} \leqq 0.5$ are preferable. 


\section{Components of modern fusion gyrotrons}

The schematic layout of a typical megawatt-class fusion gyrotron installation is shown in figure 1 . The gyrotron tube is inserted into the warm bore hole of a superconducting magnet (SCM). The following sections briefly describe the functions of the various components and innovations that have been introduced during recent years [19-21].

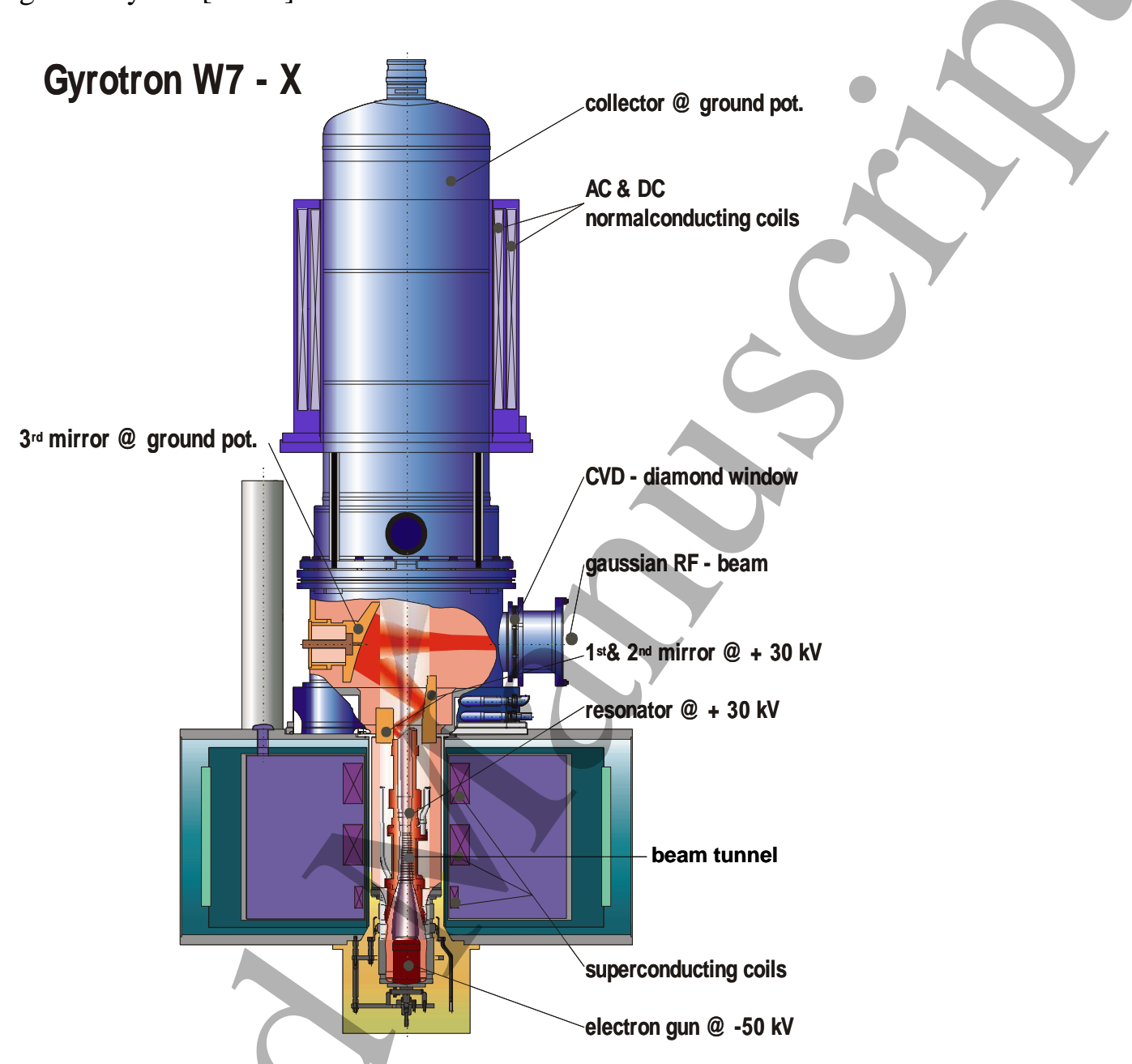

Figure 1. Schematic view of the $140 \mathrm{GHz}, 1 \mathrm{MW}, \mathrm{CW}$ Thales gyrotron with superconducting magnet (SCM) utilized in the ECH system of the stellarator W7-X (@ 2007 IEEE. Reprinted, with permission from [21] Thumm M 2014, IEEE Trans. on Plasma Science 42, 3, 590).

\subsection{Magnetron injection gun and beam tunnel}

In high-power fusion gyrotrons thermionic magnetron injection guns (MIGs) operating in the temperature limited (TL) current regime (Richardson-Dushman Law) with different electron flows (quasi-laminar, intermediate and regularly intersecting) have thus far been used most successfully $[15,23]$. This is in contrast to other types of microwave tubes such as klystrons and travelling-wave tubes, where electron guns operated under space-charge limited (SCL) conditions (Child-Langmuir Law) are used. In TL operation a non-zero electric field exists at the emitting surface and accelerates all electrons towards the anode. In this case the electron beam current $I_{\text {beam }}$ is only weakly dependent on the acceleration voltage $V_{\mathrm{b}}$ as a result of the Schottky effect, but the properties of the beam sensitively depend on the conditions of the emitting surface. The beam current is then adjusted by the temperature of the emitter. The characteristic feature of such MIGs is the emission of electrons in crossed electric and magnetic fields, forming an electron beam, which contains cyclotron motion. Impregnated tungsten dispenser or lanthanum hexaboride $\left(\mathrm{LaB}_{6}\right)$ cathodes are being employed in diode-type (two electrodes) or triode-type (three electrodes) guns (see figure 2). Triode guns with a modulation anode offer the possibility of variation of the electron beam velocity ratio $\alpha$ (pitch factor) in the interaction cavity and 
of requiring only a low power high-voltage (HV) modulator for efficient modulation of the output power. Simulation calculations on the interaction in gyrotron cavities show that the efficiency of RF generation decreases as the distribution of the velocity components of the electrons in the electron beam broadens. Various measurements showed velocity spreads $\delta v_{\perp}=\left(v_{\perp \max }-v_{\perp \min }\right) / 2 v_{\perp}=15-30 \%\left(\delta v_{\perp \mathrm{rms}} \cong 6-12 \%\right)$ $[15,24]$.

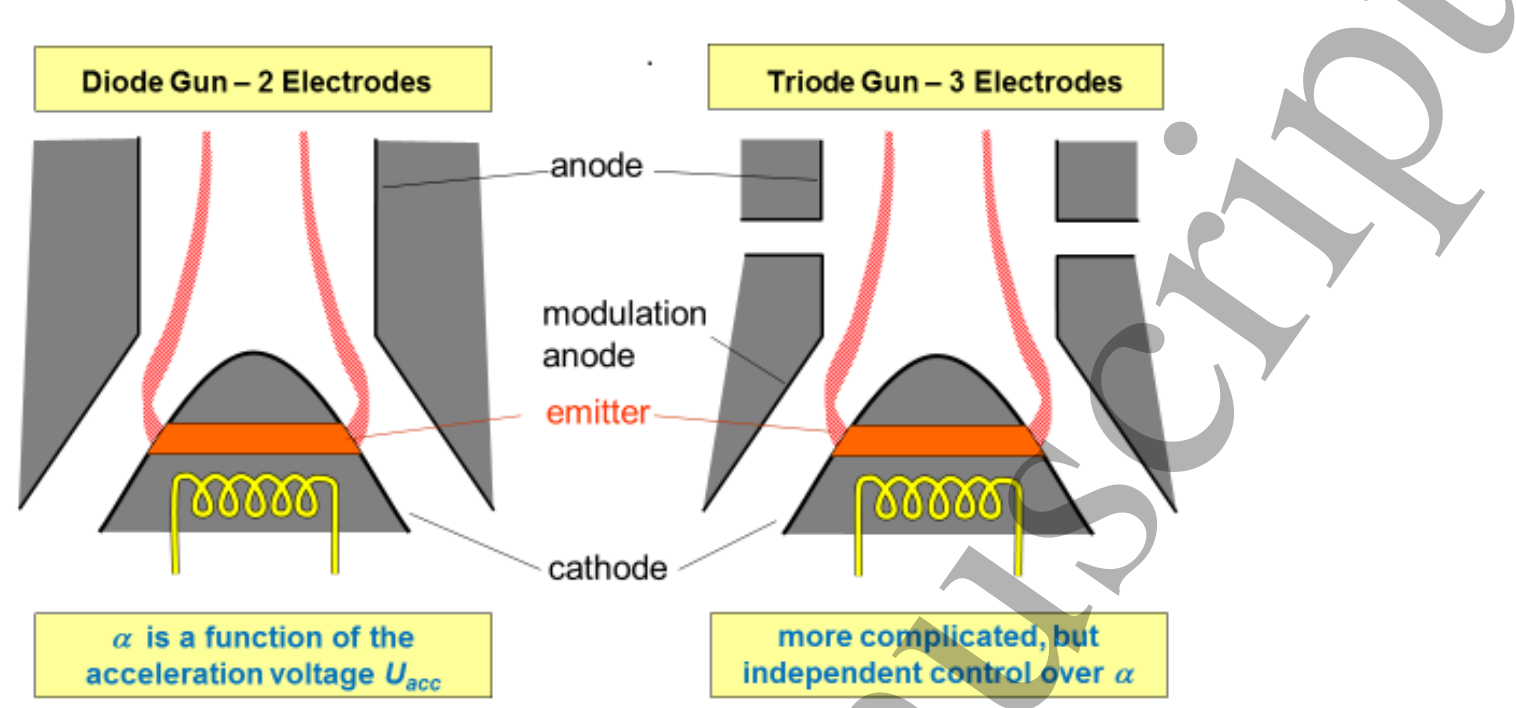

Figure 2. Two different types of magnetron injection guns (MIGs) for gyrotrons, diode gun (left) and triode gun (right). The pitch factor $\alpha$ of the electron beam in the cavity is determined by the magnetic mirror ratio between the MIG and the cavity, and the acceleration voltage. The triode MIG has the merit that $\alpha$ is controlled by the modulation-anode voltage, independently with respect to other parameters.

The possible sources of velocity spread, which have been suggested include: roughness of the emitter surface, spread of initial electron velocity at the cathode (both energy and direction), non-axisymmetric behaviour (non-uniform work function around the emitter ring, thermal inhomogeneities, misalignment of electrodes and magnetic field), non-adiabatic behavior, instabilities during transport of the electron beam through the beam tunnel (compression zone) to the cavity and space charge effects due to reflected electrons trapped between the magnetic mirror and the cathode, which also may raise the average pitch factor $[25,26]$. Proper shaping of the neighboring parts of the emitter ring or/and anti-emission coatings are necessary. The angle between the emitter surface and the magnetic field determines the characteristics of the trajectories. Quasi-laminar beams show the lowest values of velocity spread. For clean excitation of the operating mode, the thickness of the electron beam in the cavity should be smaller than approximately $\lambda / 5$, where $\lambda$ is the free-space wavelength. Optimum MIG designs are being achieved using advanced trajectory and particle-in-cell (PIC) codes.

The beam tunnel is especially prone to parasitic gyrotron-type oscillations, since the perpendicular energy of the electrons increases on the way from the emitter ring to the cavity. Azimuthally symmetric high-order $\mathrm{TE}_{0 \mathrm{n}}$ gyro-backward waves are the most dangerous source of parasitic oscillations, since it is difficult to attenuate them, especially in high-electron-current MW gyrotrons [27,28]. Several improved beam-tunnel damping structures have been developed to avoid unwanted oscillations:

- Non-axisymmetric conical metallic structures (IAP) [19]

- Conical silicon carbide (pure $\mathrm{SiC}$ ) structures. $\mathrm{SiC}$ is a good mm-wave absorber and a weak semiconductor to avoid static charges (QST) [29]

- Conical alternating stack of $\mathrm{BeO} / \mathrm{SiC}(60 / 40)$ ceramic damping rings and copper rings. The copper rings are indented with a slot depth of about $\lambda / 4$ in order to cut off azimuthal RF currents and to break the azimuthal symmetry. The number, width and periodicity of the indentations can vary irregularly (KIT). Such a structure can also be considered as a grating with many different grating constants. This complicates the formation of a resonant field structure and effectively damps $\mathrm{TE}_{\mathrm{m}, \mathrm{n}}$ modes, in particular, symmetric $\mathrm{TE}_{0 \mathrm{n}}$ modes [27]. 


\subsection{Cavity}

The gyrotron interaction circuit, the cavity, is a straight cylindrical resonator with a radius down taper below the cutoff radius of the operating mode at the input of the electron beam and a non-linear up taper as mm-wave output [15-22]. Mode conversion to unwanted spurious modes is strongly reduced by the use of curved transitions between the cylindrical and taper sections and an optimized radius contour of the output taper (see figure 3). The cavity is placed at the position of the maximum magnetic field. In order to raise the gyrotron power to the MW level, the cavity modes have changed over the past 35 years from low-order modes (e.g. $\mathrm{TE}_{02}$, with cavity radius $\approx \lambda$ ) to very high-order volume modes, e.g. $\mathrm{TE}_{25,10}, \mathrm{TE}_{31,11}$ and $\mathrm{TE}_{32,9}$, with cavity radius $\approx 10 \lambda$, for the Russian, Japanese and European ITER gyrotrons, respectively (see figure 4), rotating in the same direction as the gyrating electrons

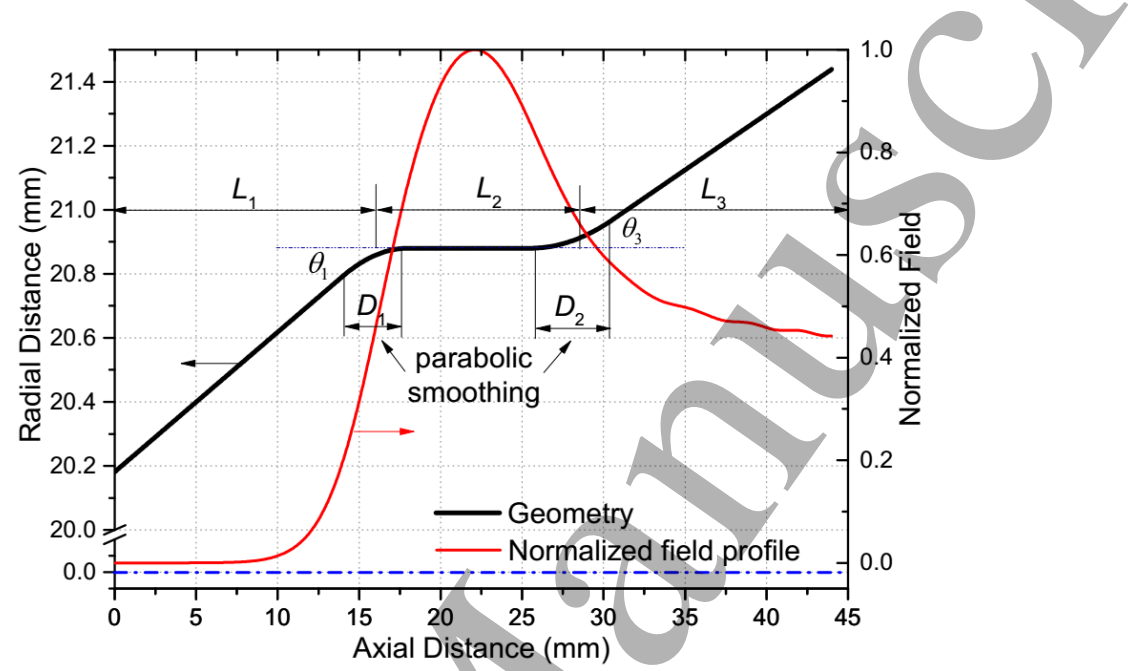

Figure 3. Radius contour of an open-ended circular waveguide gyrotron cavity with normalized profile of the magnitude of the electric field.

(co-rotating). Diffractive quality factors are between 1000 and 1500 [22]. Stable and efficient gyrotron operation in such high-order modes with very dense competing mode spectra became feasible due to the use of high-quality helical electron beams with $\alpha=1.2-1.4$, generated by improved MIGs, and the development of advanced self-consistent, time-dependent multi-mode cavity interaction simulation codes needed for understanding the problems associated with mode competition and start-up scenarios.

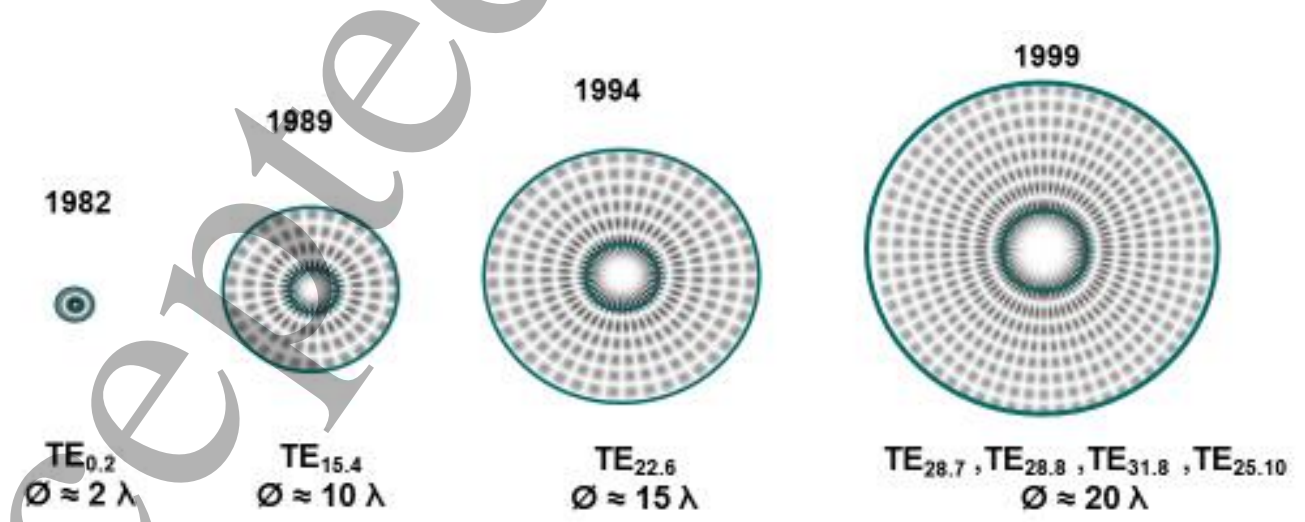

Figure 4. Schematic intensity contours of typical cavity modes and comparison of cavity sizes during the different development steps of gyrotrons for fusion plasma heating. The patterns are plotted for azimuthally standing modes, whereas the actual mode is a rotating one.

Megawatt-class gyrotrons employ electron beams with 70 to $80 \mathrm{keV}$ electron energy and 45 to $40 \mathrm{~A}$ beam current. The annular electron beam is located on the first maximum of the cavity mode electric 
field leading to interaction efficiencies between $35 \%$ and $40 \%$. The cavity material is OFHC copper or dispersion strengthened copper (Glidcop) with improved thermo-mechanical performance. Porous structure or mini-channel cooling is employed resulting in acceptable peak Ohmic wall losses of approximately 2 and $2.5 \mathrm{~kW} / \mathrm{cm}^{2}$, respectively, resulting in cavity expansions (frequency down chirps) of 0.1 to $0.25 \%$.

\subsection{Quasi-optical output coupler}

For $1 \mathrm{MW}$ CW fusion gyrotrons the implementation of an output coupling approach is required that separates the spent electron beam from the outgoing RF beam in order to increase the collector electron beam interception area. It is the short-wavelength, high-output-power and the rotating asymmetric highorder cavity mode of such tubes, which required quasi-optical (q.o.) mode conversion concepts (first in Russia [30]).

The q.o. mode converter is a part of the internal EM system of the gyrotron, which also includes the cavity and the up taper (figure 1). Radial output coupling of the RF power into the linearly polarized fundamental Gaussian $\left(\mathrm{TEM}_{0,0}\right)$ free-space mode has several significant advantages for high-power operation. Q.o. gyrotron mode transducers generating a wave beam consist of an asymmetrical waveguide opening (launcher) with a specific feeding waveguide and several focusing and phase correcting mirrors (figure 1) [31].

At the aperture of conventional cylindrical waveguide launchers, there exists an approximately uniform field distribution in the axial and azimuthal directions, leading to high-diffraction losses of about $20 \%$. Stray radiation in the gyrotron is one of the critical factors affecting pulse-length extension. A prebunching q.o. launcher, which reduces the stray radiation was firstly reported in 1991 [32]. To form a Gaussian field distribution at the launcher output, essentially eight adjacent modes are generated by small periodic helical perturbations on the inner surface of the launcher wall [31-33]. Thereby the diffraction loss was reduced from $20 \%$ to $<5 \%$. In the 2000 's, the diffraction loss was reduced further. In the $140 \mathrm{GHz}$ gyrotron for $\mathrm{W} 7-\mathrm{X}$, in which an analytically-designed mode converter has been installed, a measured internal loss of only $2 \%$ was attained [34], which contributed to long-pulse operation of the tube. Intensity profile measurements of the output beam were performed by inserting a PVC target plate into the RF beam and measuring the temperature profile with an IR-camera. RF beam reconstruction using a phase retrieyal code yielded a Gaussian beam content of around 97.5\% [34].

More recently, numerical methods for launcher optimization were developed [35-38]. In the code developed in [35] the helical surface deformation is optimized such that many modes are excited and combined to form the Gaussian beam at the launcher output. For example, 99.5\% of the radiated power was received by the first mirror in the Japanese $170 \mathrm{GHz}$ gyrotron. In this case, the initial $\mathrm{TE}_{31,8}$ mode is distributed among 15 modes to form the Gaussian intensity distribution.

Reduced launcher length is obtained by an internal line of mirrors with mode-converting and phasecorrection non-quadratic surface contour functions optimized by iteratively solving the scalar diffraction integral equation $[36,37]$. The validation of such improved launchers has been performed using 3D fullwave EM field solvers (e.g. SURF3D [38]). Combination of helical-like and mirror-type wall perturbations (hybrid-type launchers) may even increase the output mode purity [39]. These techniques have been extended to launchers that work for many frequencies. High conversion efficiencies of over $96 \%$ for several modes have been reported, which opens the way for high-efficiency multi-frequency gyrotrons (see Section 5).

\subsection{Synthetic diamond output window}

In order to select the appropriate concept for the development of $1 \mathrm{MW}, \mathrm{CW}$ mm-wave windows one has to compare the thermo-physical, mechanical and dielectric parameters of possible window materials related to the load-failure resistance and the power-transmission capacity at different temperatures. The features of beryllia, boron nitride, silicon nitride, sapphire, Au-doped silicon, silicon carbide and CVD diamond are compared in [40]. 
The evaluation of $\mathrm{BeO}, \mathrm{BN}, \mathrm{Si}_{3} \mathrm{~N}_{4}$, sapphire and $\mathrm{SiC}$ clearly shows that there is no chance to use these dielectrics as an edge-cooled, single-disk $1 \mathrm{MW}, \mathrm{CW}$ window at room temperatures. Experiments at CPI in the USA and at NIFS and JAEA in Japan confirmed, that even a double-disk FC75-face-cooled sapphire window has a CW-power limit around 0.3-0.4 MW [40 and references given there] Nevertheless, these materials are widely used in lower power gyrotrons and pulsed operation. At present, polycrystalline chemical vapour deposition (CVD) diamond is the only material for simple, edge-cooled (water) single-disk MW-class CW gyrotron windows [41-43]. Current CVD capabilities allow samples of up to $140 \mathrm{~mm}$ diameter and $2.5 \mathrm{~mm}$ thickness (570 carat). There are only three suppliers: Element Six in the Netherlands, Diamond Materials in Germany and II-VI Advanced Materials in the USA. CVD diamond is attractive due to its good mechanical properties (bending strength: $\sigma_{B}=400 \mathrm{MPa}$ ), very small thermal expansion $\left(\alpha^{\prime}=10^{-6} / K^{-1}\right)$, modest dielectric constant $\left(\varepsilon_{r}{ }^{\prime}=5.67 \pm 0.01\right)$, low mm-wave attenuation ( $\tan \delta \approx 2.10^{-5}$ ) and very high thermal conductivity ( $k=1900 \mathrm{~W} / \mathrm{mK}$ at room temperature). Nuclear irradiation with $<10^{21}$ neutrons $/ \mathrm{m}^{2}$ and $0.8 \mathrm{~Gy} / \mathrm{s} \gamma / \mathrm{X}$-rays is acceptable and brazing technologies are available. The transmission frequencies of a simple, standard single-disk window are

$$
f=n c / 2 d \sqrt{\varepsilon_{r}}(n=1,2,3 \ldots \ldots),
$$

where $d$ is the thickness. Eq. (9) leads to $d=n \lambda / 2$, where $\lambda$ is the wavelength in the window material. For example, the thickness of a synthetic diamond $170 \mathrm{GHz}(140 \mathrm{GHz})$ gyrotron window disk with approximately $100 \mathrm{~mm}$ diameter is $d=1.852 \mathrm{~mm}(d=1.799 \mathrm{~mm})$, corresponding to $n=5(n=4)$. This thickness can safely handle the vacuum pressure inside the gyrotron. It could also be used as a vacuum window at the plasma device and can withstand up to 2 bar absolute pressure difference, as required by nuclear safety.

$\mathrm{Cu}-\mathrm{Au}-\mathrm{Cu}-\mathrm{Ag}$ - and Al-braze processes are utilized by the different tube companies. When using an Al-braze, the baking temperature of the gyrotron has to be reduced to $450{ }^{\circ} \mathrm{C}$ and the corrosion inhibitor CC15 must be added to the cooling water to prevent corrosion. In the Japanese tubes, the bonding part is coated with a copper plating, and pure water is used as coolant.

\subsection{Single-stage depressed collector}

The electronic interaction efficiency $\eta_{\text {osc }}$ of the annular, helical electron beam in a gyrotron cavity is between 35 and $40 \%$ so that the remaining power of the beam after interaction (spent electron beam) amounts to $65-60 \%$ of the initial beam power. Fortunately, the energy distribution after the electron cyclotron interaction in the cavity has a clear minimum value as discussed in Section 2. By applying a static retarding voltage $V_{\text {dep }}$ between cavity and collector, the spent beam loses its power, which is recovered by the power supply (see figure 5). The total RF generation efficiency is

$$
\eta_{\text {total }}=\eta_{\text {osc }} V_{b} /\left(V_{b}-V_{\text {dep }}\right) .
$$

Here, $V_{b}$ is the beam voltage. The retarding voltage $V_{d e p}$ corresponds to the minimum energy of the spent electron beam. For $\eta_{o s c}=35 \%, V_{\text {dep }}=30 \mathrm{kV}$ and $V_{b}=80 \mathrm{kV}$, this results to $\eta_{\text {total }}=56 \%[44,45]$. The merits of depressed collectors are: The required voltage of the main power supply is significantly reduced (e.g., from $80 \mathrm{kV}$ to $50 \mathrm{kV}$ ) and the energy of the spent electron beam and thus the collector heat load is significantly lowered which allows the reduction of the collector size and/or an increase in the gyrotron reliability as well as a reduction of the required capacities of the cooling and power supply systems. In addition, energy and power of the generated X-rays are less.

There are two gyrotron design modifications used for single-stage depressed collectors (SDCs) differing essentially by the position of the DC break insulator needed to apply the depression voltage (see figure 5) [46]. In the gyrotron design with a ceramic insulator located above the SCM ("top" version), the gyrotron body and outer jacket is held at high positive voltage and has to be electrically insulated from the warm bore of the SCM. In the design with a ceramic insulator located below the SCM (see figure 1), the gyrotron body is at high positive voltage, but the jacket is grounded and does not need any insulation between gyrotron and magnet. In the "bottom" version the ceramic insulator has a smaller diameter facilitating the system for ceramic cooling. On the other hand, this "bottom" version has some disadvantages like lower acceptable depression voltage and correspondingly lower possible rise in the 
total efficiency using a SDC (the difference in efficiency can be about 3\% percentage points). Another disadvantage is that the anode-cavity unit forms a rather long interior cantilever that is sensitive to mechanical shocks and vibrations and needs special care under transportation.

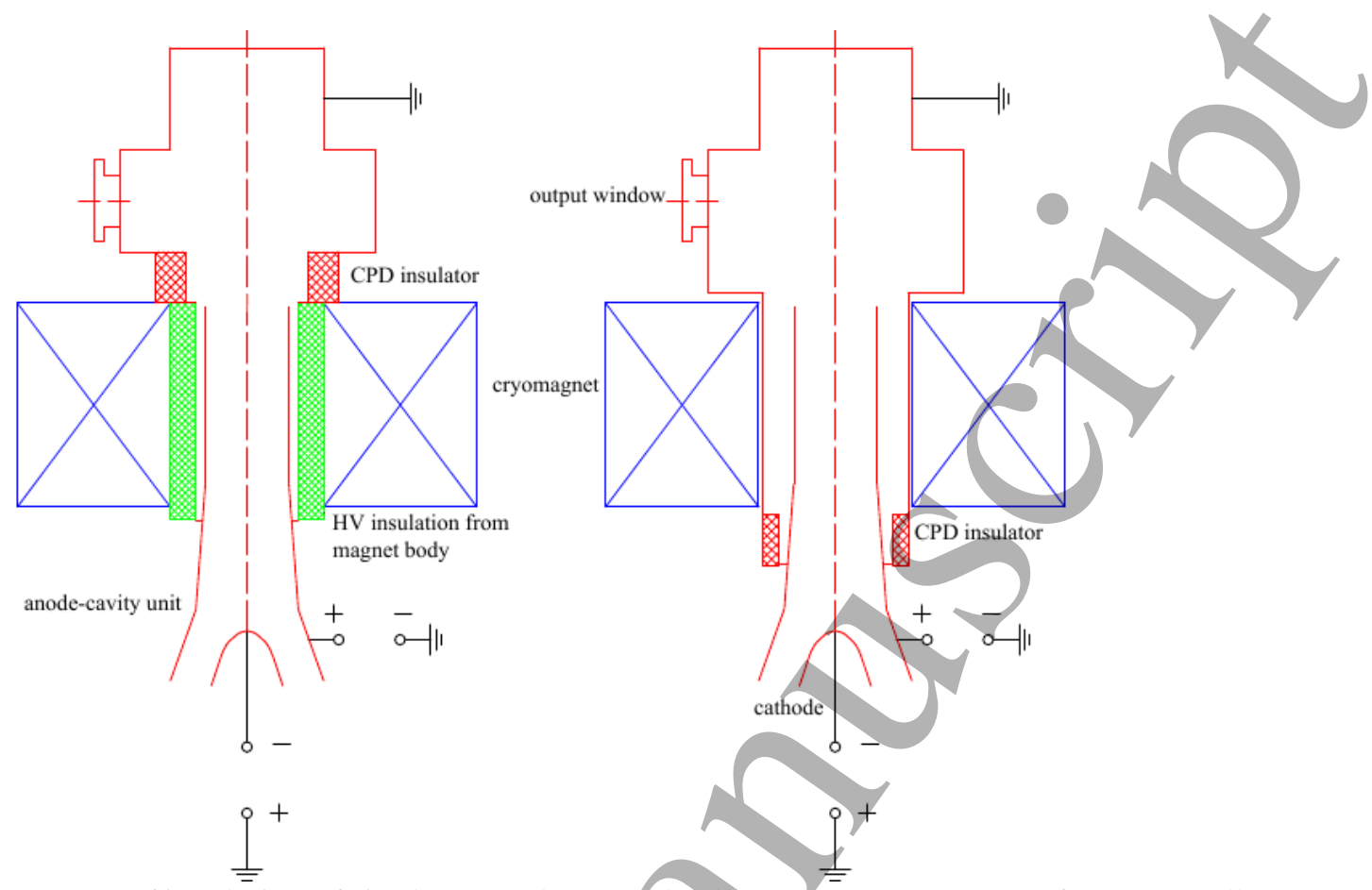

Figure 5. Two types of insulation of single-stage depressed collectors (SDCs) [46]. Left: Upper collector potential depression (CPD) insulator. Right: Lower CPD insulator. In both cases the collector is grounded and the tube body is positively biased. As a result, the voltage of the main power supply can be reduced keeping the initial electron beam energy the same.

\subsection{Auxiliary components}

\subsubsection{Sweeping of spent electron beam in the collector}

Vertical magnetic field sweeping systems (VFSSs) have become a standard technique to keep the timeaveraged heat dissipation from the spent electron beam at the collector within technically acceptable values $\left(<500 \mathrm{~W} / \mathrm{cm}^{2}\right)$. If the collector diameter is constant, such collectors operate close to the technological limit and are a high-risk component with a small safety margin. To address this problem, KIT Karlsruhe in collaboration with IPP Greifswald investigated and optimized a combined $7 \mathrm{~Hz}$ VFSS and a $50 \mathrm{~Hz}$ transverse field sweeping system (TFSS) for the $140 \mathrm{GHz}$ W7-X gyrotrons. The TFSS consists of 3 pairs of TF-coils, which are powered by a conventional 3-phase AC-supply thus generating a transverse field, which rotates at $50 \mathrm{~Hz}$ [47]. At the position of the coils the collector is made of stainless steel in order to reduce the influence of eddy currents. By proper tuning of both systems an almost perfectly flat power deposition profile along the collector area was obtained. The peak loading is reduced by about a factor of 1.6 as compared to VFSS alone [48]. Other possibilities are to employ collectors with an optimized inner radius profile or to utilize an advanced magnet current modulation scheme for the VFSSs or TFSS [47], to lower the maximum surface loading.

\subsubsection{Superconducting gyrotron magnet}

Since the gyrotron is an ECM, it absolutely needs a magnet which according to eq. (1) for mm-wave gyrotrons must be a SCM $(B \approx 6.7 \mathrm{~T}$ for $170 \mathrm{GHz})$. Russian gyrotrons use a magnetic field profile which is symmetric towards both the MIG and collector. Only a weak normal conducting gun coil is employed to slightly correct the magnetic field in the cathode emitter area. In contrast to this, European, Japanese and US tubes operate in a SCM, where a bucking coil in the beam tunnel region lowers the magnetic field in order to reduce the distance between electron emitter and the cavity center. In this case, the gun coil is also superconducting and integrated into the cryostat. The material of the wires is NbTi, which is cooled down only by a refrigerator. These SCMs are maintenance free in principle, and have generally 
been free of operational problems. The Russian and Japanese $170 \mathrm{GHz}$ ITER gyrotrons both operate in cryogen-free JASTEC magnets, whereas the European tube is equipped with a cryogen-free SCM manufactured by CRYOGENIC in UK.

\subsubsection{Dummy load and RF measurement system}

Essential for the development of efficient fusion gyrotrons is a high-power diagnostic system enabling measurement of the output power, frequency- and mode spectra and output mode purity. In a gyrotron test facility, a high-power dummy load is an important apparatus. At present, water-cooled metal vessels, whose inner surfaces are coated by an absorbing dielectric material $[49,50]$, or pure stainless steel vessels are commonly used [46]. Water flow rate and input-output water temperature difference determine the measured power level. The RF beam is injected quasi-optically and absorbed during multireflections in the vessel. By rotating the RF beam with a mirror, the averaged power density is reduced on the surface. $1 \mathrm{MW}$-class operation has proved to be feasible. Sometimes a so-called pre-load absorbs the RF power reflected by the dummy load [29]. Arc detectors at the gyrotron output window, at corrugated surface polarizers and at the input of the dummy load guarantee fast switch-off in case of arcing. For first tube tests at short pulse duration (ms-range) special short-pulse calorimeters (ballistic or with coolant flow) are utilized. Time-dependent frequency spectra are measured by parallel filterbank spectrum analyzers, frequency-time analyzers or pulse spectrum analysis (PSA) systems providing spectrograms [51]. Mode-purity measurements are being performed using thermographic imaging (infrared camera) of the output beam pattern on a target plate at different distances from the window. Beam reconstruction employing phase retrieval codes allows a determination of the fundamental Gaussian mode content [52].

\section{Megawatt-class fusion gyrotrons}

Worldwide, there are four microwave-tube companies, which manufacture megawatt-class gyrotrons for fusion research: Communications \& Power Industries (CPI) in Palo Alto, USA; GYCOM in Nizhny Novgorod, Russia, in collaboration with the Institute of Applied Physics (IAP); Thales - Microwave \& Imaging Subsystems (THALES) in Velizy, France, in collaboration with the European Gyrotron Consortium (EGYC); and Canon Electron Tubes \& Devices Co., Ltd. (CETD, prior to October 2018, Toshiba Electron Tubes \& Devices Co., Ltd. TETD), Otawara, Japan, in collaboration with the National Institutes for Quantum and Radiological Science and Technology (QST). The members of EGYC are: KIT, Germany; SPC, Switzerland; HELLAS, Greece, CNR and ENEA, Italy.

\subsection{ITER Gyrotrons}

\subsubsection{Configuration of ITER gyrotron system for $20 \mathrm{MW} E C H \& C D$}

For ITER a $20 \mathrm{MW}$ (power delivered to the plasma), $170 \mathrm{GHz}$ ECH\&CD system is planned for plasma heating to self-ignition and non-inductive current drive for plasma confinement and control of NTMs $[8,53,54]$. For this purpose, the development of long-pulse $1 \mathrm{MW} 170 \mathrm{GHz}$ gyrotrons has been carried out since the ITER EDA (Engineering Design Activities) phase that started in 1995. 24 MW source RF power is being prepared, taking into account $4 \mathrm{MW}$ transmission losses (16.7\%). $8 \mathrm{MW}$ power generation is allocated for the two parties of Russia and Japan, respectively, $6 \mathrm{MW}$ for the EU and 2 MW for India. CW operation should be considered in the designs. For ITER, a 4-step operation scenario is considered: "First plasma (FP)", "Pre-Fusion Power Operation I (PFPO-I)", "Pre-Fusion Power Operation II (PFPO-II)" and "Fusion Power Operation (DT)". The available heating power will be increased gradually for each step by adding Ion Cyclotron Heating (ICH) and Negative Ion Neutral Beam Injection (NNBI). EC power injection is expected from the first plasma initiation in 2025. In the FP phase, 8 gyrotrons will be used to inject $6.7 \mathrm{MW}$. After the "PFPO-I" phase, full $20 \mathrm{MW}$ EC power injection is expected. In addition, there is a possible strategy to apply dual-frequency gyrotrons $(170 \mathrm{GHz} / 104 \mathrm{GHz})$ in the "PFPO-I" phase for H-mode studies at reduced toroidal magnetic field $(1.8 \mathrm{~T})$. Another role of the ECH\&CD system is MHD mode suppression, in particular Neoclassical Tearing Modes (NTMs). For this purpose, up to $5 \mathrm{kHz}$ power modulation is required (full on/off power modulation is expected). 
In figure 6 the configuration of the ITER and RF building is illustrated. Twenty four $1 \mathrm{MW}$ gyrotrons are placed in the RF building. An evacuated corrugated $\mathrm{HE}_{11}$ waveguide is connected to each gyrotron via a matching optics unit (MOU), from where the power is transmitted to the ITER torus. There are two types of launchers. One is a launcher installed in an equatorial port for plasma ignition and current drive, and the other four launchers are installed in upper vessel ports for plasma initiation and MHD control. The routing of mm-wave power transmission to the different launchers is selected using waveguide switches. In figures 7 and 8, different views of the RF building are shown. The main power supplies are installed on the $1^{\text {st }}$ floor. On the $2^{\text {nd }}$ floor, the body power supplies and anode power supplies (for the eight QST gyrotrons) are placed. The $3^{\text {rd }}$ floor is the location of all the 24 gyrotrons. Gyrotrons are sensitive to stray magnetic fields, since those influence the electron beam trajectories in the tubes. The stray magnetic field of the ITER poloidal field and the plasma current is estimated to be within an acceptable level (2 Gauss in radial direction). If necessary (especially because of the stray magnetic field of the gyrotron SCMs), compensation coils may have to be installed at the gyrotrons.

The specifications for the ITER gyrotrons are as follows:

- Power and $\mathrm{HE}_{11}$-mode purity at the output of the MOU: $\geq 0.96 \mathrm{MW}$ and $>95 \%$, respectively

- RF power generation efficiency: $\geq 50 \%$

- Pulse duration: gyrotron and auxiliaries have to be designed for 3200-s pulses, the acceptance tests are being performed at 1000-s pulse duration

- Reliability: $\geq 95 \%$ defined on 20 full-power pulses with 500-s duration.

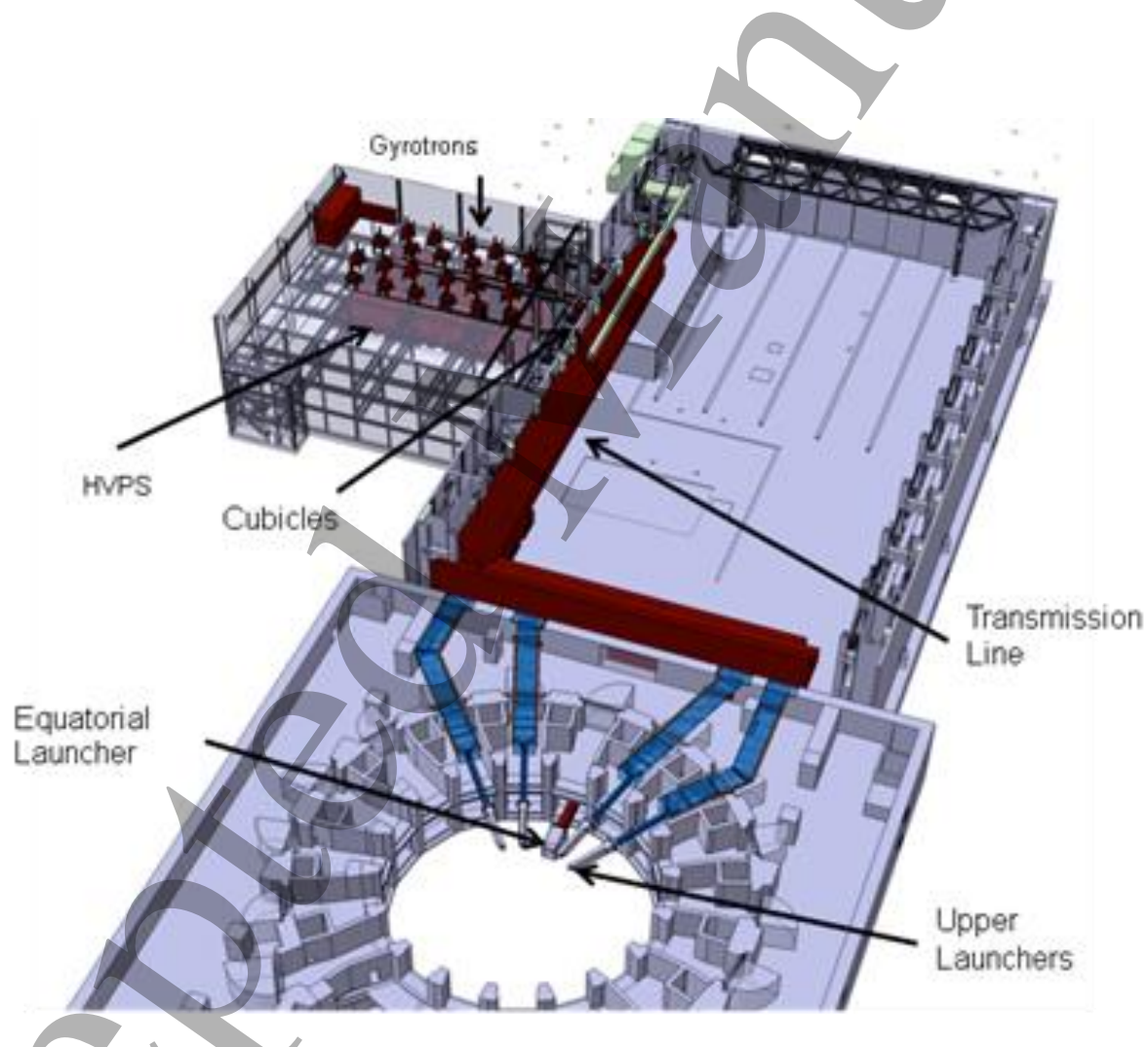

Figure 6. Configuration of ITER building and RF building where the 24 gyrotrons are installed. Long evacuated corrugated waveguides transmit the mm-wave power in the $\mathrm{HE}_{11}$-hybrid mode to the launchers at the torus. The ECH\&CD system has one equatorial launcher, connected with 24 waveguides, and four upper port launchers, each connected with eight waveguides. Power routing is performed by waveguide switches. 


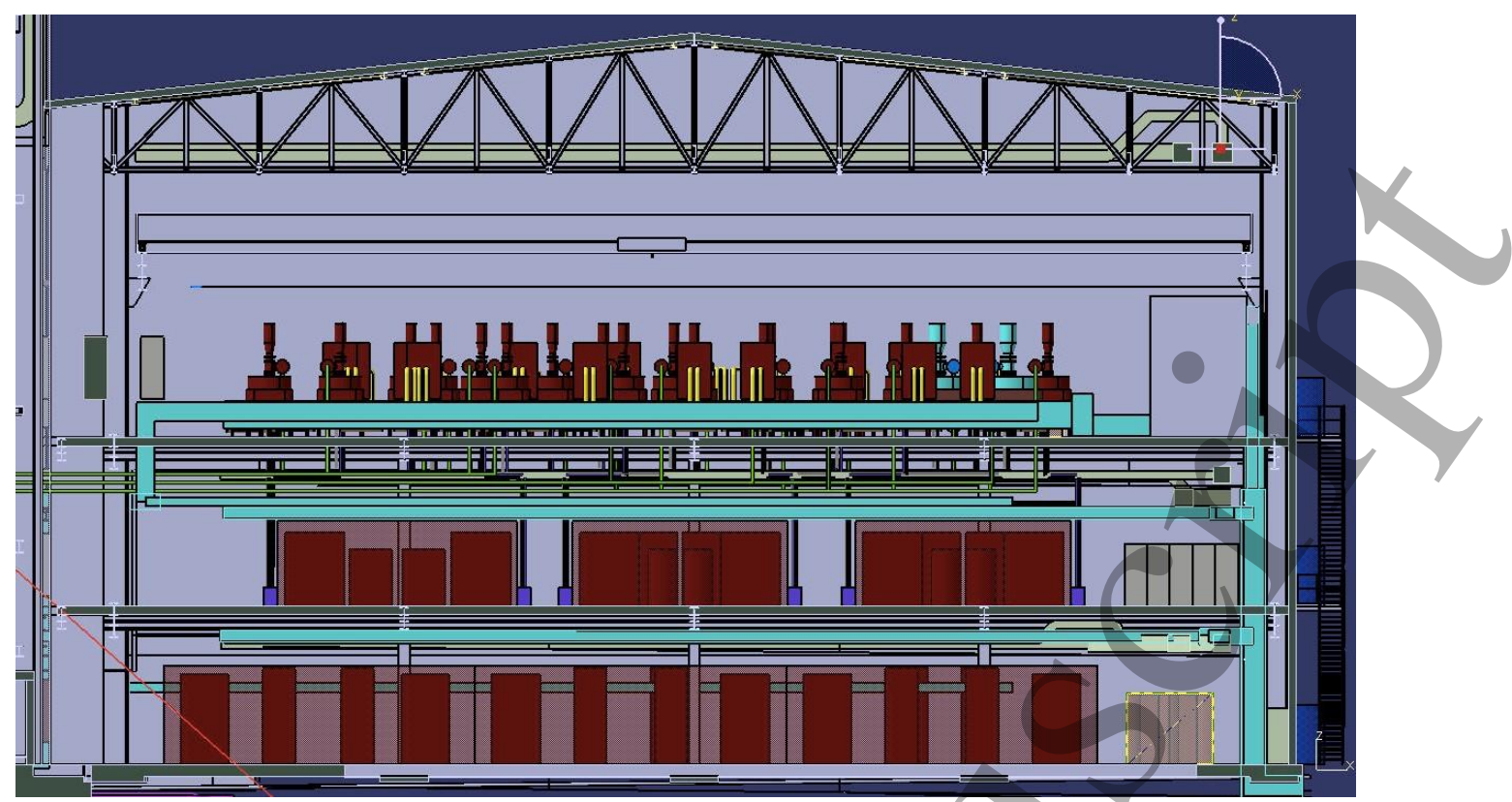

Figure 7. Vertical view of the ITER RF building. The main power supplies are placed on the L1 Ground Level). On level L2, the body and anode (for the JA gyrotrons) power supplies are located. On L3, the gyrotrons and their ancillary facilities, such as superconducting magnets (SCMs), are installed.

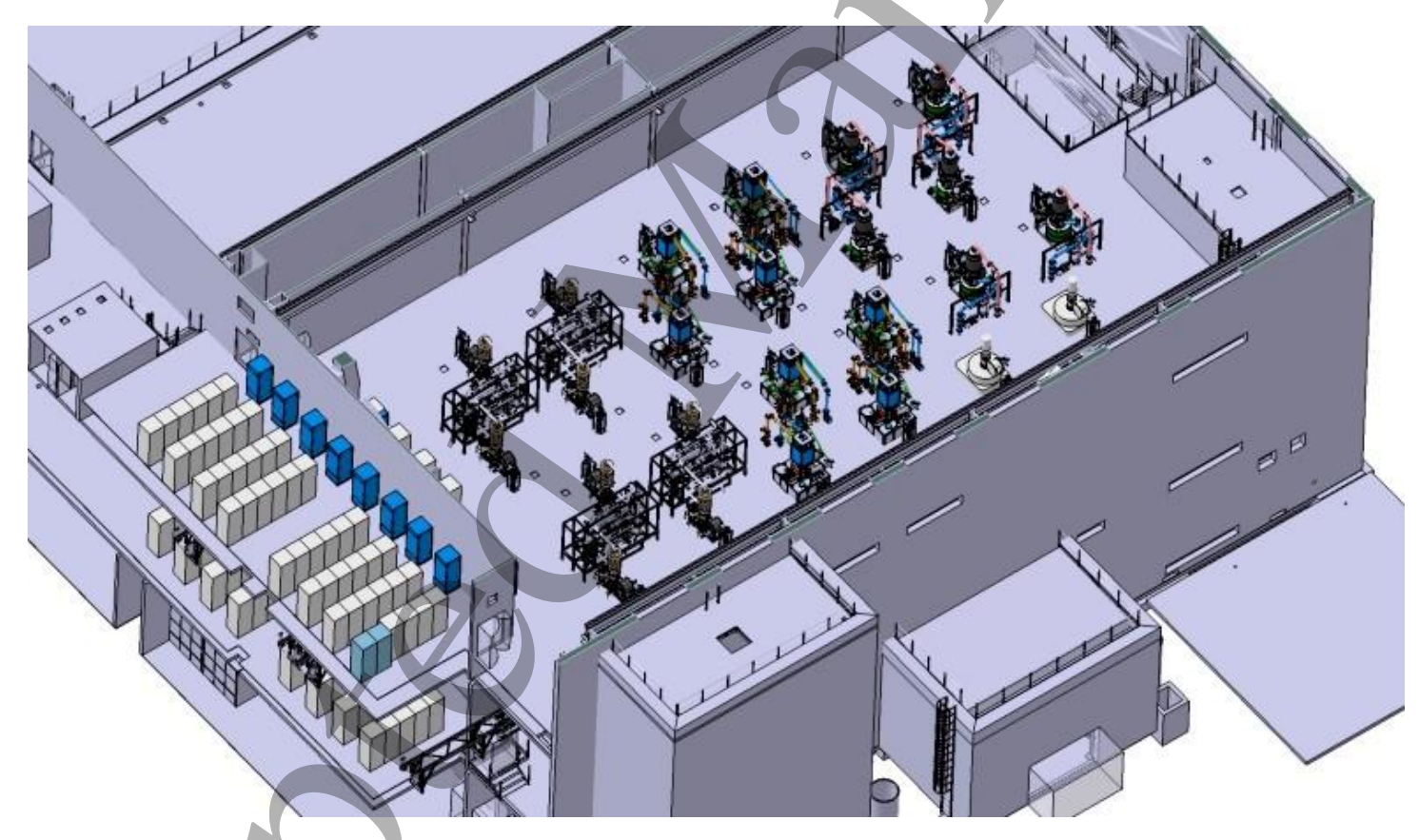

Figure 8. View of level L3 of the ITER RF building where the 24 gyrotrons are placed.

\subsubsection{Japanese ITER gyrotron}

QST is the Japanese Domestic Agency (JADA) of the ITER project. QST has the responsibility for the procurement of eight sets of $1 \mathrm{MW}, 170 \mathrm{GHz}$ gyrotron SCM, gyrotron stand, MOU and anode power supply for triode MIG operation. A photo and a technical drawing of the gyrotron are shown in figure 9. A photo of the gyrotron system composed of the gyrotron, MOU, oil tank, SCM and gyrotron stand is shown in figure 10. The design of the main parts was carried out at QST (formerly JAEA) and fabricated by industry (CETD). All test experiments have been performed by QST at its RF Test Stand (RFTS). The gyrotron MIG is a triode. Initially, the operating cavity mode $\mathrm{TE}_{31,8}$ was selected 
$[29,55,56]$. The mini-channel cooled Glidcop cavity has an inner radius of $17.9 \mathrm{~mm}$. In the beam tunnel (between the MIG and cavity), a silicon carbide cone is installed to suppress parasitic oscillations before the cavity. The material used for the ceramic cylinder between the collector and tube body, where the retarding potential is applied for depressed collector operation (top version insulator, see 3.5), is silicon nitride (Kyocera SN 238), which is used because this ceramic cylinder also acts as "relief window". SN 238 is mechanically tough and has a reasonably low loss tangent $\left(\sim 2.0 \times 10^{-4}\right)$. The collector uses vertical electron beam sweeping (VFSS). After successful demonstration of $1 \mathrm{MW}$ quasi-CW operation, the radial cavity mode number was raised from 8 to 11 obtain a greater margin for the cavity wall heat load caused by Ohmic losses (20.87 mm cavity radius), which enables an increase in power, and maintains the same electron beam radius. In addition, the $\mathrm{TE}_{31,11}$ cavity mode has significant advantages for step-tunable gyrotron operation as discussed in Section 5. The generated power is converted to a Gaussian beam using an in-waveguide mode converter (launcher) followed by four mirrors inside the gyrotron. An edge-cooled synthetic diamond window is used at the tube output. As for the RFTS, the main power supply has a capability of $90 \mathrm{kV} / 50 \mathrm{~A}$ in $\mathrm{CW}$ operation. Switching of the DC power delivery to the gyrotron is done using a chain of IGBTs (Insulated Gate Bipolar Transistors), which has been in operation since 1998 without major trouble. The cryogen-free type SCM (JASTEC), with a 240-mmdiameter room temperature bore hole, is cooled by a refrigerator.

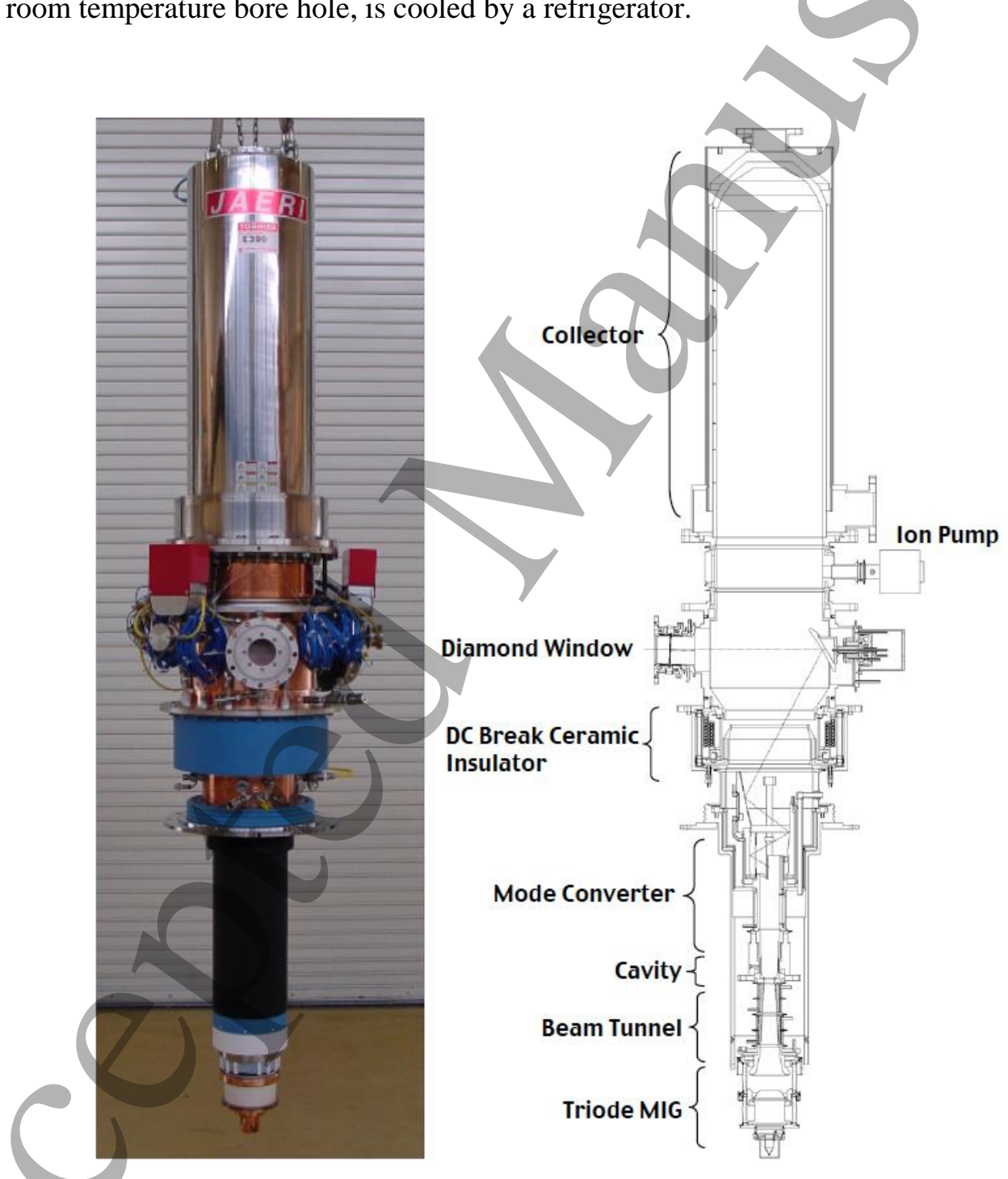

Figure 9. Photo and technical drawing of the Japanese $170 \mathrm{GHz}$ ITER gyrotron. 


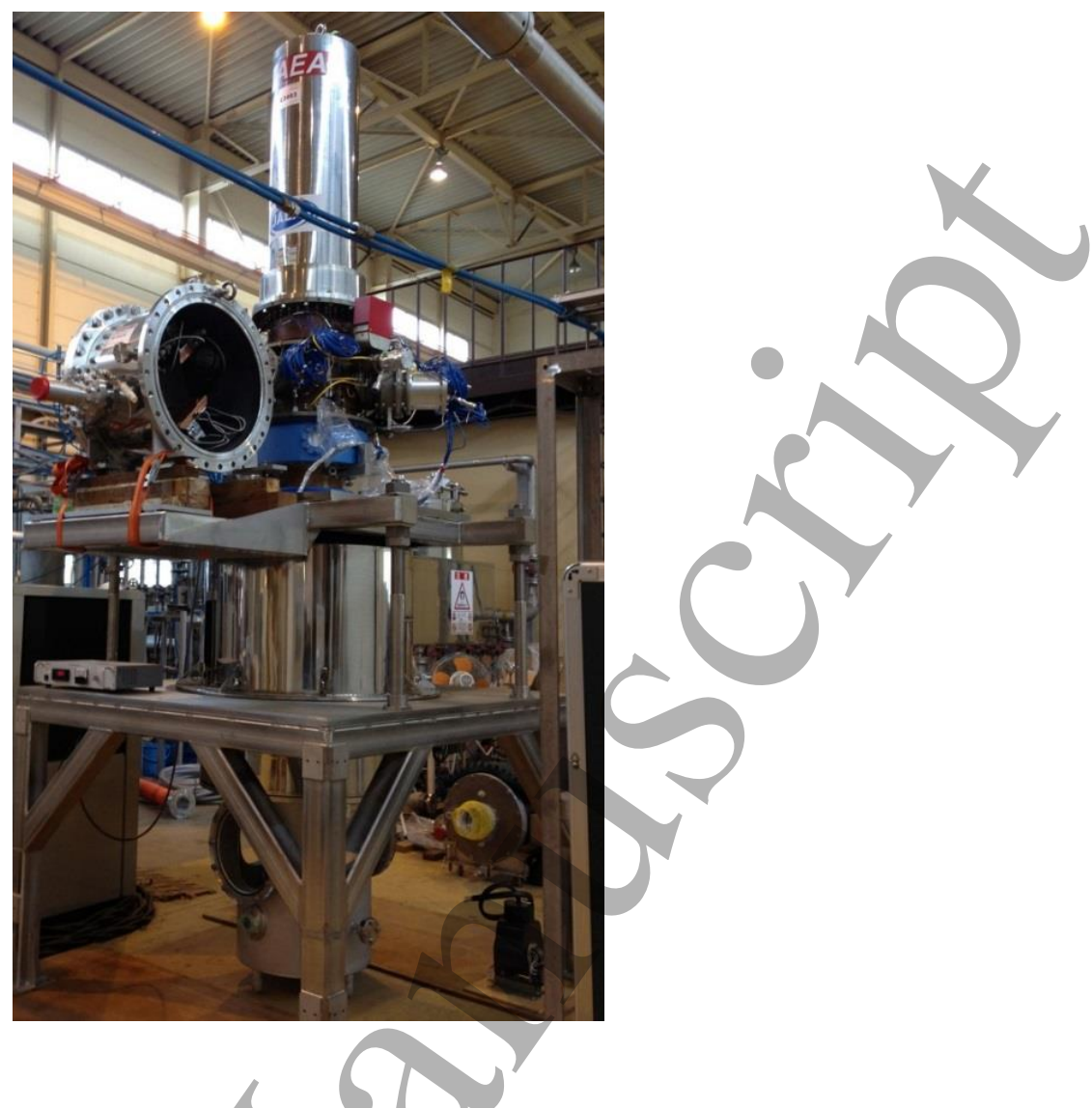

Figure 10. Photo of the Japanese $170 \mathrm{GHz}$ ITER gyrotron system with SCM, MOU and oil tank on the gyrotron stand.

(a) High efficiency long-pulse operation

Using the flexibility offered by the triode MIG, optimized operation parameters can be selected during tube operation by controlling both the magnetic field, $B_{\mathrm{c}}$, in the cavity and the anode voltage, $V_{\mathrm{ak}}$ [5759]. Here, the $B_{\mathrm{c}}$ determines the frequency mismatch parameter $\left(\Delta=\omega-\Omega_{\mathrm{c}}=\omega-e B_{\mathrm{c}} / m \gamma\right)$ and the anode voltage, $V_{\mathrm{ak}}$, determines the pitch factor of the electron beam. For example, $B_{\mathrm{c}}$ was scanned during the operation and a change of output power was monitored keeping the beam voltage $V_{\mathrm{b}}$ (corresponds to $\gamma$ ) constant. Figure 11 shows the $B_{\mathrm{c}}$ dependence of the output power. The arrows indicate the direction of the $B_{\mathrm{c}}$ scanning during the oscillation. As $B_{\mathrm{c}}$ decreases ( $\Delta$ decreases), the power increases. After the plateau, the oscillation mode switches from $\mathrm{TE}_{31,8}$ to $\mathrm{TE}_{30,8}$. Then, $B_{\mathrm{c}}$ is increased again. The oscillation of the $\mathrm{TE}_{30,8}$ mode remains until $B_{\mathrm{c}}=6.7 \mathrm{~T}$, then the operating mode switches to $\mathrm{TE}_{31,8}$ again. The gap between $B_{\mathrm{c}}=6.645 \mathrm{~T} \sim 6.7 \mathrm{~T}$ corresponds to the "hard excitation region". $B_{\mathrm{c}}$ scanning at various $V_{\mathrm{ak}}$ gives the dependence of the output power contour as shown in figure 12. The vertical axis is $V_{\mathrm{ak}}$ and the abscissa is $B_{\mathrm{c}}$. With the control of $B_{\mathrm{c}}$ and $V_{\mathrm{ak}}$, the maximum power operation point can be found taking an arbitrary route in this parameter map. This is the merit of a triode MIG, which is particularly useful if even higher cavity modes are utilized whose mode competition is even more significant. As a result, stable $1 \mathrm{hr}$ oscillation was demonstrated at an output power of $0.8 \mathrm{MW}$ (57\% efficiency), and $1.0 \mathrm{MW}$ (800s) with $55 \%$ efficiency employing a single-stage depressed collector. The maximum efficiency was $60 \%$ at $0.6 \mathrm{MW}$, which is the highest value for high frequency gyrotrons (>100 GHz). The Gaussian output-mode purity was approximately $96 \%$. The optimum operation point was found in the deep hard excitation region, which was attained by active control of the magnetic field and the pitch factor of the electron beam. The vacuum level remained constant during long-pulse operation. 


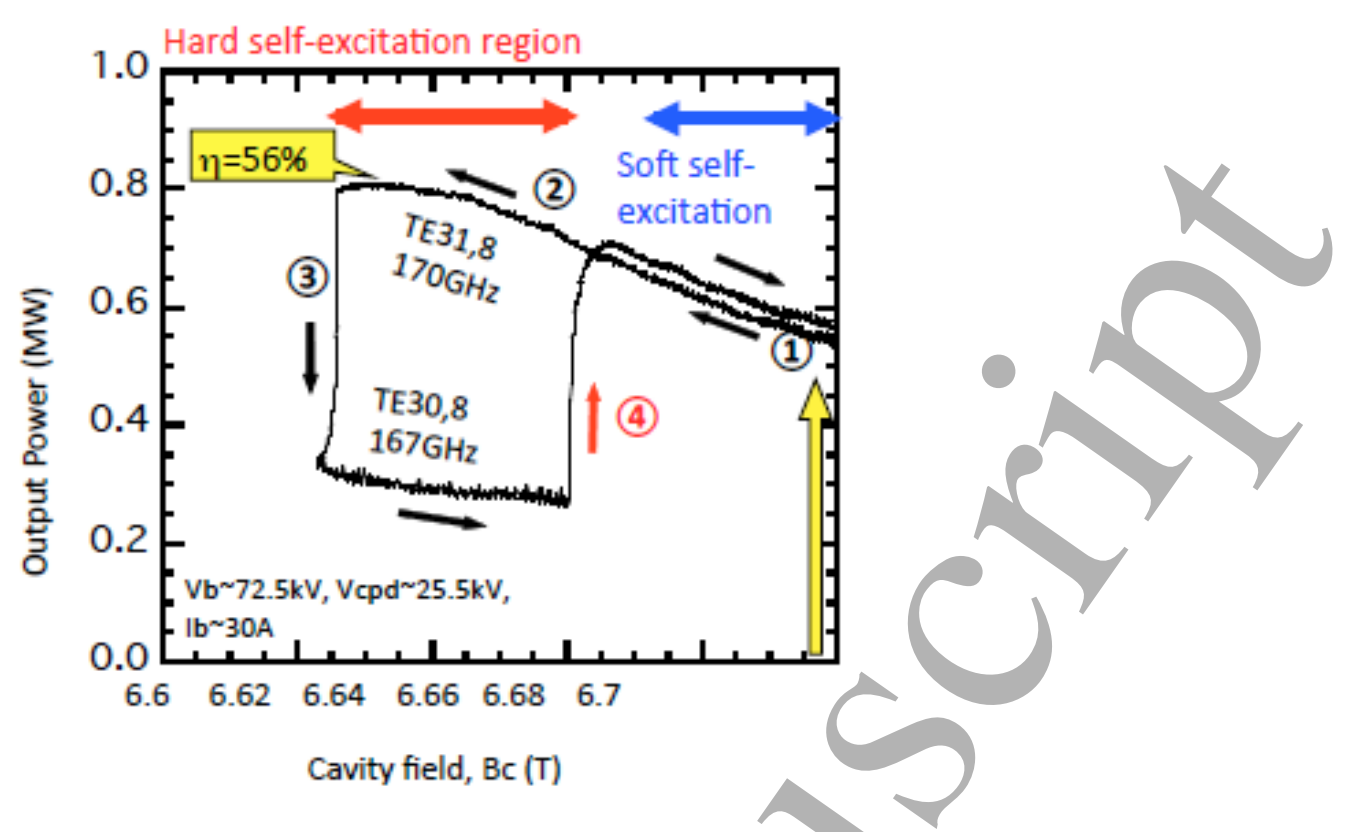

Figure 11. Output power and oscillating cavity mode vs cavity magnetic field [57]. From operating point (1) $B_{\mathrm{c}}$ is decreased while remaining the $\mathrm{TE}_{31,8}$ mode oscillation. At $B_{\mathrm{c}}=6.642 \mathrm{~T}$, the oscillation switches to the $\mathrm{TE}_{30,8}$ mode (3). Then $B_{\mathrm{c}}$ is increased. At $B_{\mathrm{c}}=6.7 \mathrm{~T}$, the $\mathrm{TE}_{30,8}$ mode oscillation switches back to the $\mathrm{TE}_{31,8}$ mode. The region of $B_{\mathrm{c}}=6.642 \mathrm{~T} \sim 6.7 \mathrm{~T}$ corresponds to the "hard selfexcitation region".

\section{(1) Increase of anode voltage ( $\alpha$ ) \\ (2) Decrease of cavity field}

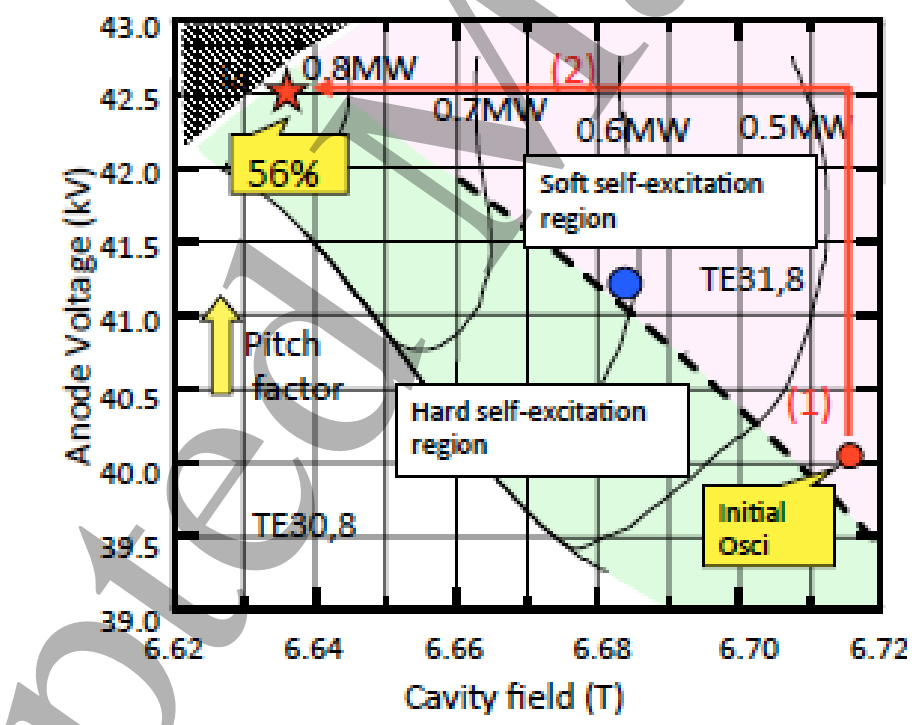

Figure 12. Power contours for $170 \mathrm{GHz} \mathrm{TE}_{31,8}$-mode oscillation versus anode voltage and cavity magnetic field at $V_{\mathrm{b}} \sim-72.5 \mathrm{kV}$ and $I_{\mathrm{b}}=30$ A [57].

(b) Power modulation

Full on/off power modulation with a repetition frequency of up to $5 \mathrm{kHz}$ in continuous operation is required for MHD control of ITER. If the power is modulated using an IGBT switch in the main cathode voltage power supply, the heat load on the switch becomes significant. To realize CW power modulation, a full-current modulation of the electron beam is employed using modulation-anode-voltage switching of the triode MIG. However, if the modulation is done with a finite-current modulation rather large electron beam power flows into the collector. Therefore, it is important to cut the electron current 
to zero in the non-RF-power generation phase by decreasing $V_{\text {ak }}$ to zero. Then the averaged collector heat load can be significantly suppressed. To realize the full-current modulation, the power supply system was newly developed as shown in figure 13. In the case of oscillation phase, voltage is applied between the modulation-anode and cathode by setting switch SW1 closed and SW2 open.

(a)

(b)
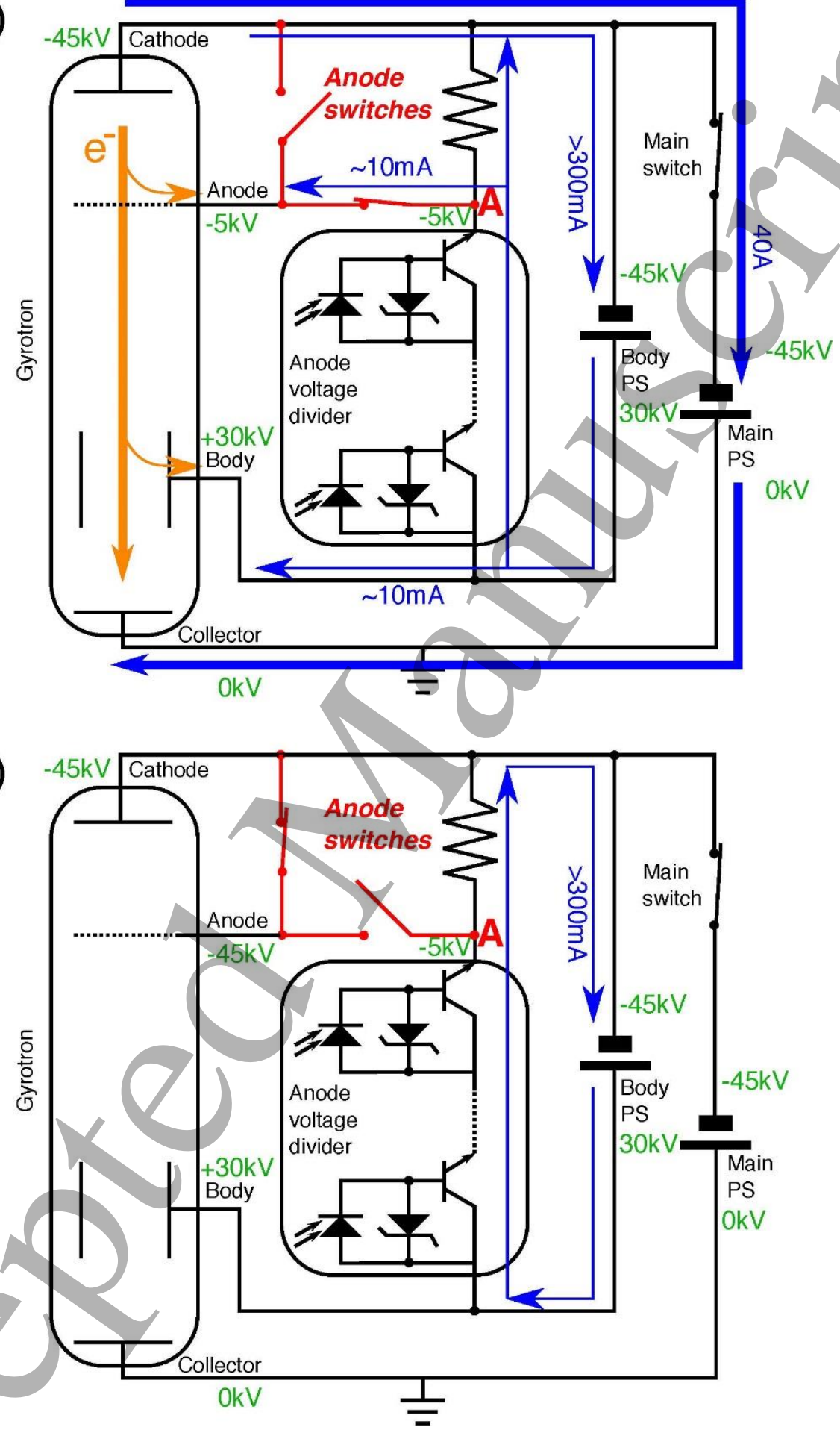

Figure 13. Configuration of power supply with double modulation-anode switches to enable highfrequency power modulation [60]. Rectangular current modulation is achieved by alternative switching. (a) Current flow and voltage for the RF turn-on phase, (b) Same for the RF turn-off phase.

In the non-oscillation phase, SW1 is open and SW2 is closed (then $V_{\mathrm{ak}} \sim 0 \mathrm{~V}$ and $I_{\mathrm{b}} \sim 0 \mathrm{~A}$ ). This alternative double-switch operation is very important to avoid a discharge of the modulation-anode DC power supply and the capacitor. Consequently, a very sharp current rise time is realized ( $3 \mu \mathrm{s})$. As a 
result, the excitation of the competing adjacent $\mathrm{TE}_{30,8}$ mode is suppressed. In addition, the heat loads in the cavity and collector decrease during the modulation. Therefore, operation of more than $1 \mathrm{MW}$ is possible. In figure 14, an example of $60 \mathrm{sec}, 5 \mathrm{kHz}$ power modulation at $1.1 \mathrm{MW}$ is shown [60].

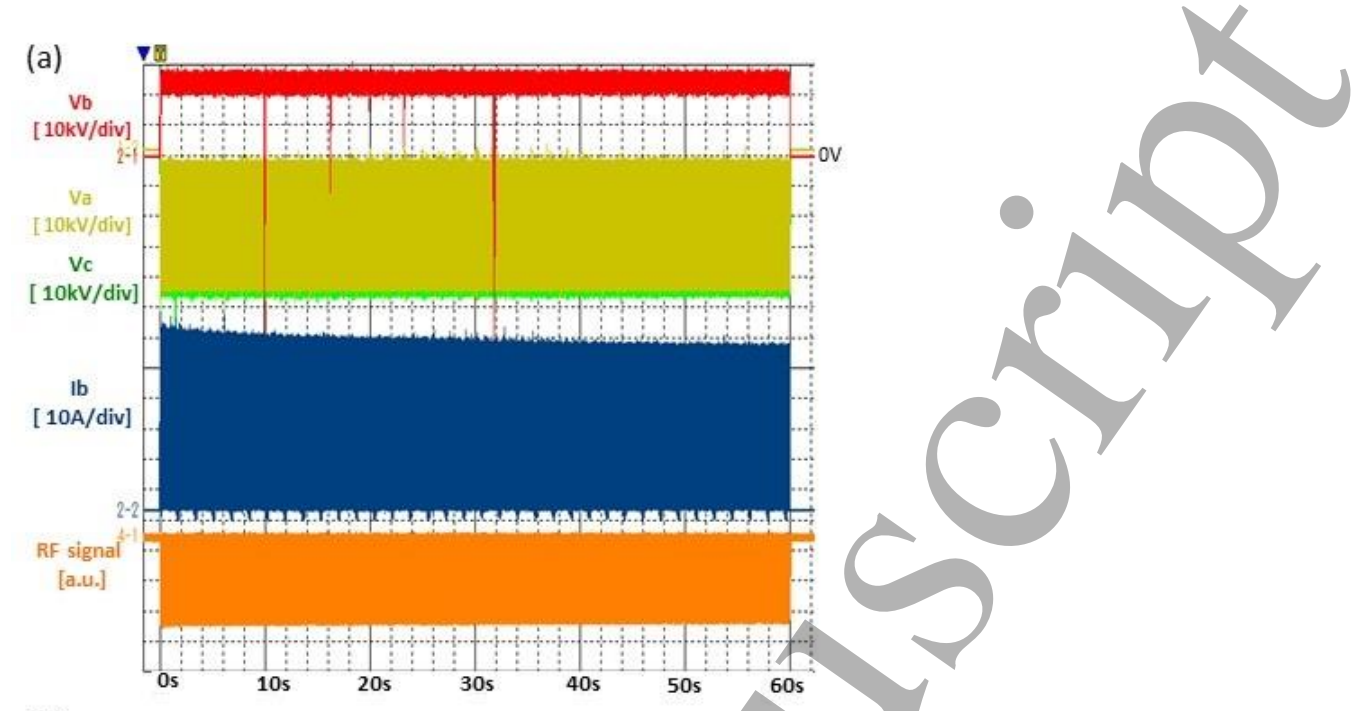

(b)

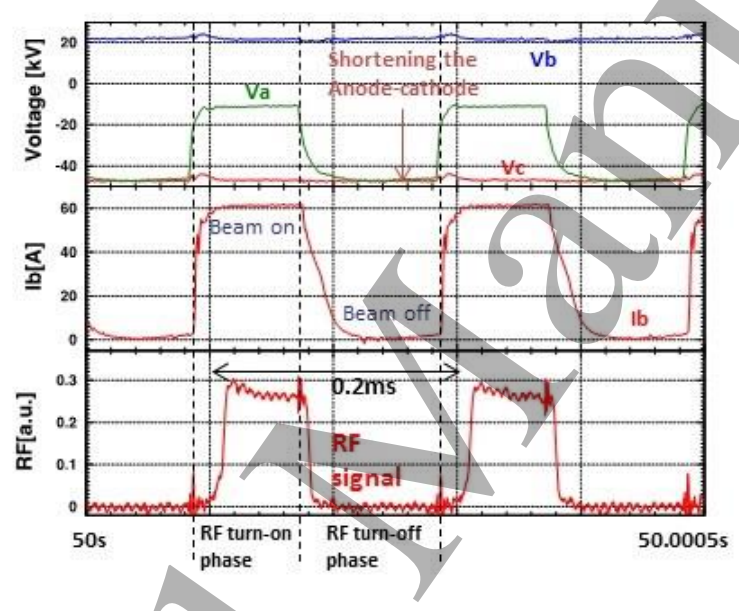

Figure 14. Experimental result of $5 \mathrm{kHz}$ power modulation with full-current modulation using double modulation-anode switching [60]. (a) Signals for $60 \mathrm{~s}$ power modulation. (b) Zoomed signals from 50 to $50.0005 \mathrm{~s}$. The pulse power is $1.1 \mathrm{MW}$.

(c) Reliability

For simulation of ITER operation, $600 \mathrm{~s}$ pulses of $0.8 \mathrm{MW}$ were repeated with an interval of $20 \sim 30 \mathrm{~min}$. 72 shots of 88 trials were very stable over the full pulse duration. The other pulses were interrupted by internal arcing, etc. The operational reliability will increase by employing a fast re-start system during the pulse (Section 5.7.2). This gyrotron generated a total of 250 GJ of output energy without trouble $[61,62]$.

(d) $\mathrm{TE}_{31,11}$-mode gyrotron

To increase the output power to more than $1 \mathrm{MW}$, a TE 31,11 -mode gyrotron was fabricated and tested. Its outside appearance and geometrical size are identical to the $\mathrm{TE}_{31,8}$-mode tube. The radius of the larger $\mathrm{TE}_{31,11}$-mode cavity is $20.87 \mathrm{~mm}$, so that the heat load on its wall is $\sim 1.4$ times lower than that for the $\mathrm{TE}_{31,8}$ mode. Therefore, more than $1 \mathrm{MW}$ output power is available, or a larger safety margin is maintained for $1 \mathrm{MW}$ operation. In addition, the $\mathrm{TE}_{31,11}$ mode is very attractive for multi-frequency operation as described in Section 5. A concern of this higher-mode operation was the stronger mode competition. In fact, the $\mathrm{TE}_{31,11}$-mode oscillation is often limited by adjacent counter-rotating modes such as the $\mathrm{TE}_{28,12}$ mode. However, reliable performance of this $\mathrm{TE}_{31,11}$-mode gyrotron for ITER 
ECH\&CD has been obtained by introducing active modulation-anode voltage and beam radius control and optimizing the electron beam position in the cavity to suppress excitation of the counter-rotating modes. Long-pulse operation of 1.0 MW with $46 \%$ efficiency for $300 \mathrm{~s}$ has been achieved. 1.2 MW output power operation was achieved for up to $5 \mathrm{~s}$ [63]. In 2018, the first of these $\mathrm{TE}_{31,11}$-mode gyrotrons satisfied the ITER criteria [64].

\subsubsection{Russian ITER gyrotron}

The ITER gyrotron from Russia was developed by IAP, GYCOM, and the Kurchatov Institute Moscow [19,65-69]. The tube uses a diode-type MIG, a non-axisymmetric conical all-metal beam tunnel, an advanced four mirror quasi-optical output coupler and a single-stage depressed collector (top version/ insulator) with tapered inner diameter keeping the impact area of the spent electron beam approximately constant. Vertical electron beam sweeping (VFSS) is employed. The oscillation mode in the cavity is $\mathrm{TE}_{25,10}$. The mini-channel cooled copper cavity has an inner radius of $17.77 \mathrm{~mm}$

(a) High efficiency long-pulse operation

Four Russian gyrotron prototypes (figure 15) were tested with CRYOMAGNETICS (USA) and JASTEC (Japan) cryogen-free SCMs. It is important to note that all gyrotrons demonstrated very similar output parameters. $1 \mathrm{MW}$ output power at $1000 \mathrm{~s}$ pulse duration and 53-56\% overall efficiency has been achieved in single-stage depressed collector operation. For $100 \mathrm{~s}$ pulses, even $1.2 \mathrm{MW}$ power at the same efficiency was obtained. The Gaussian output mode purity was around $97 \%$.

(b) Power modulation

The Factory Acceptance Test (FAT) requirements for full on/off power modulation are:

- 3 pulses $1 \mathrm{MW} / 200 \mathrm{~s}$ ON/OFF modulated at $100 \mathrm{~Hz}$

- 3 pulses $1 \mathrm{MW} / 200 \mathrm{~s}$ ON/OFF modulated at $500 \mathrm{~Hz}$

- 3 pulses $1 \mathrm{MW} / 200 \mathrm{~s}$ ON/OFF modulated at $1000 \mathrm{~Hz}$,

All tested tubes fulfilled these specifications.

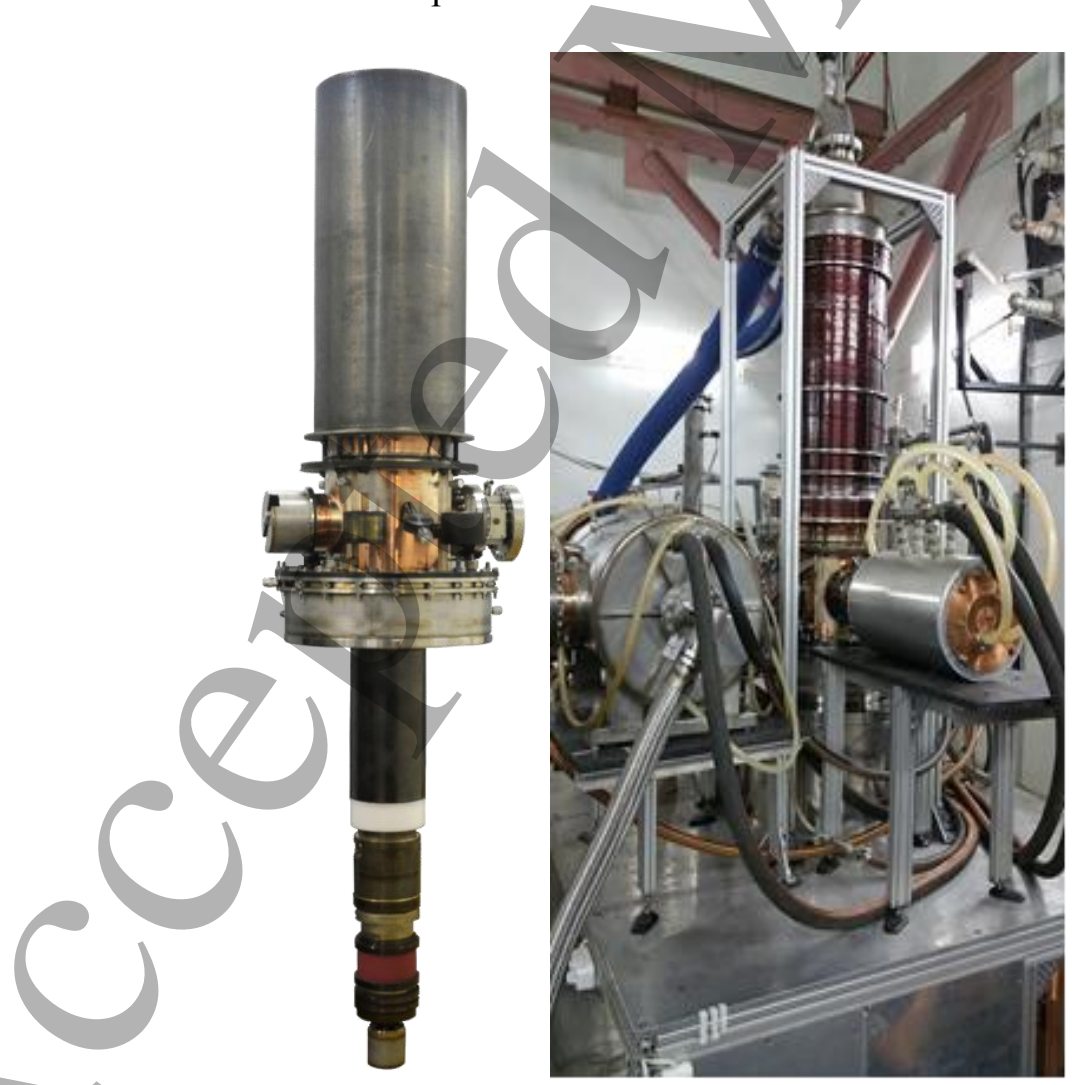

Figure 15. Left: Russian $170 \mathrm{GHz}$ ITER gyrotron. Right: Gyrotron together with SCM, MOU and relief load in the support structure (X-ray shielding is removed). 
(c) Reliability

In 2014 gyrotron run tests at $1 \mathrm{MW}$ output power with pulse durations of $500 \mathrm{~s}$ and $1000 \mathrm{~s}$ were performed. After conditioning the reliability of gyrotron operation was higher than $95 \%$ (figure 16 ).

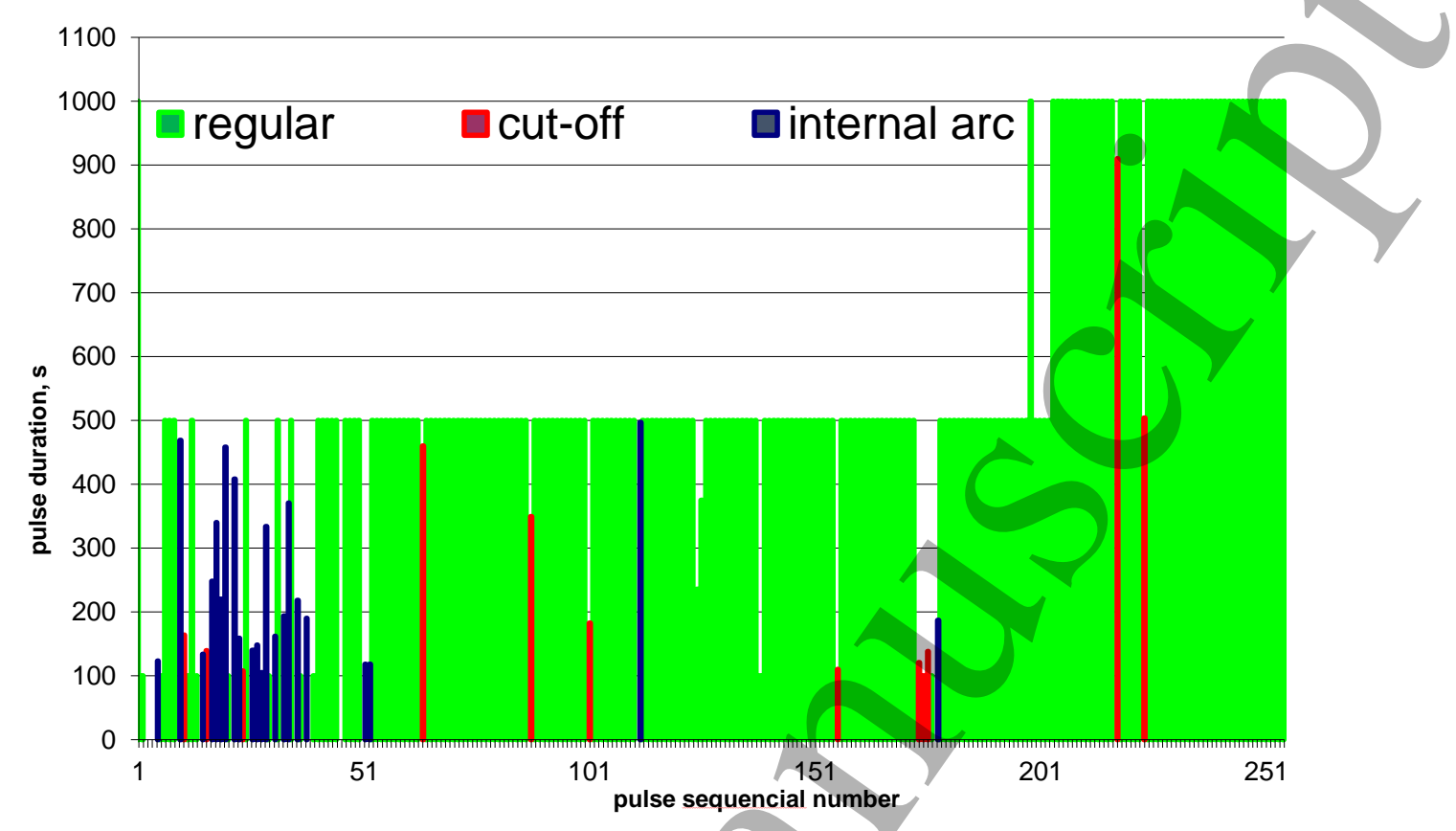

Figure 16. Gyrotron run test at $1 \mathrm{MW}$ output power with pulse durations of $500 \mathrm{~s}$ (160 pulses) and $1000 \mathrm{~s}$ ( 55 pulses). The first 50 pulses are used as conditioning pulses.

The development of the gyrotron system for ITER is based on the solution of many very difficult scientific and engineering problems. At present, the main purpose of system modifications is to enhance system reliability and the implementation of all gyrotron systems into the ITER machine and its control and safety system. In May 2015 a prototype of the Russian ITER gyrotron system was completed and its operation was demonstrated. The system includes the gyrotron tube, cryogen-free SCM, supplementary magnets, several electric power supplies, cooling systems, control and protection systems, and other auxiliary units (figure 17).

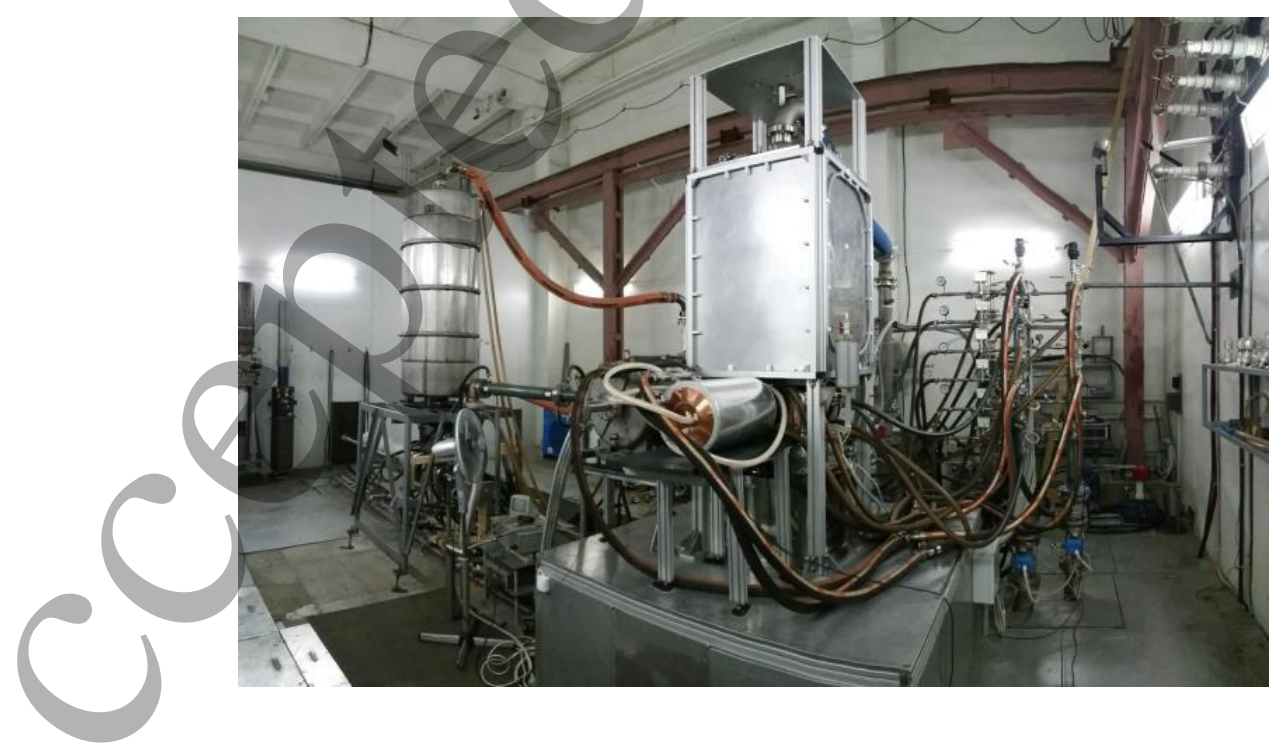

Figure 17. Shielded gyrotron system with $\mathrm{HE}_{11}$-mode waveguide, calorimetric millimeter-wave load and copling water manifolds (gyrotron collector and load flow rates are $201 / \mathrm{s}$ and $10 \mathrm{l} / \mathrm{s}$, respectively). 
The gyrotron system exhibited reliable operation with the required parameters: $170 \mathrm{GHz}$ frequency, $1 \mathrm{MW}$ output power and 55\% efficiency. The tests were performed in the presence of ITER IO and ITER RF DA representatives. In October 2015, the Final Design Procedure for the gyrotron system was successfully passed [70,71]. The procedure included preparation of several documents such as descriptions, drawings, diagrams, protocols, etc, and 20 presentations with related discussions. The presented materials received a positive evaluation. In 2016, fabrication of the first serial gyrotron system was completed. In 2017 the second serial gyrotron system was fabricated and tested. All three ITER gyrotron systems showed reliable operation in 1000-s pulses at megawatt power levels with efficiency higher than $50 \%$. The gyrotron microwave beam was fed with low losses into a 50-mm-diameter corrugated $\mathrm{HE}_{11}$ waveguide. The measured $\mathrm{X}$-ray radiation and stray microwave radiation did not exceed safety levels. In 2018 the third serial system was in fabrication.

\subsubsection{European ITER gyrotron}

The European $1 \mathrm{MW} \mathrm{CW}, 170 \mathrm{GHz}$ industrial prototype ITER gyrotron is also a conventional (hollowcavity) tube, which has been developed by the European GYrotron Consortium (EGYC) in cooperation with the industrial partner THALES, under the coordination of the European Joint Undertaking for ITER and the Development of Fusion Energy (F4E). The development started in 2008, as a risk mitigation action during the development of the $2 \mathrm{MW}, 170 \mathrm{GHz}$ coaxial-cavity gyrotron for ITER and was completed at the end of 2015 [72]. According to the strategy, the design of the CW gyrotron is completely based on a corresponding modular short-pulse (SP) prototype and the $1 \mathrm{MW}, 140 \mathrm{GHz}$ gyrotron development for the stellarator W7-X (see 4.2.3). The SP prototype was built in order to validate the scientific design in terms of output RF power, total efficiency and quality of the output RF beam. As with the Russian ITER gyrotron, the tube uses a diode-type MIG. The beam tunnel between the MIG and cavity is a conical alternating stack of $\mathrm{BeO} / \mathrm{SiC}(60 / 40)$ ceramic damping rings and indented copper rings. The cavity mode is $\mathrm{TE}_{32,9}$. The porous-structure cooled Glidcop cavity has an inner radius of $19.24 \mathrm{~mm}$. In contrast to the Japanese and Russian tubes, the body insulation is located in the lower part of the tube, close to the MIG (bottom type insulator, see figure 5), and the advanced three-mirror q.o. output coupler has no adjustable last mirror. The collector uses $7 \mathrm{~Hz}$ vertical electron beam sweeping combined with $50 \mathrm{~Hz}$ transversal sweeping with 6 coils located around a stainless steel collector section. The SP prototype was successfully tested at the KIT test facility with its OXFORD INSTRUMENTS superconducting magnet equipped with an additional normal-conducting coil to reach the required magnetic field of $6.78 \mathrm{~T}$. The scientific design of the individual tube components were verified, with the gyrotron delivering an output power of $1.0 \mathrm{MW}$ at $170.1 \mathrm{GHz}$ with $30 \%$ efficiency (in non-depressed collector operation) and with an output RF beam Gaussian mode content of about $\sim 97 \%$ [73].

(a) Long-pulse operation

The industrial CW prototype was delivered to the KIT test facility (figure 18) in early 2016 and the experiments started immediately in the short-pulse regime (with pulse lengths less than $10 \mathrm{~ms}$ ) [74]. The optimal operational parameters that were determined with short-pulses were then used as a starting point for conditioning the tube with RF and slowly extending the pulse length. After approximately seven weeks of conditioning, it was possible to operate the gyrotron with more than $0.8 \mathrm{MW}$ output power at pulse lengths up to $180 \mathrm{~s}$, which is the limit at the High-Voltage (HV) power supply that is currently available at KIT. Up to that point, the maximum efficiency was $38 \%$ (in depressed collector operation) with a Gaussian mode content of the output RF beam of at least $97 \%$ [75,76]. The reason for the reduced power performance of the industrial $\mathrm{CW}$ prototype is not known up to now. For further investigation and pulse duration extension up to one hour, the CW prototype was delivered to the Swiss Plasma Center (SPC), Lausanne, where the tube will be operated with the designated SCM manufactured by CRYOGENICS (figure 19). Power modulation and reliability of the tube will also be investigated. 


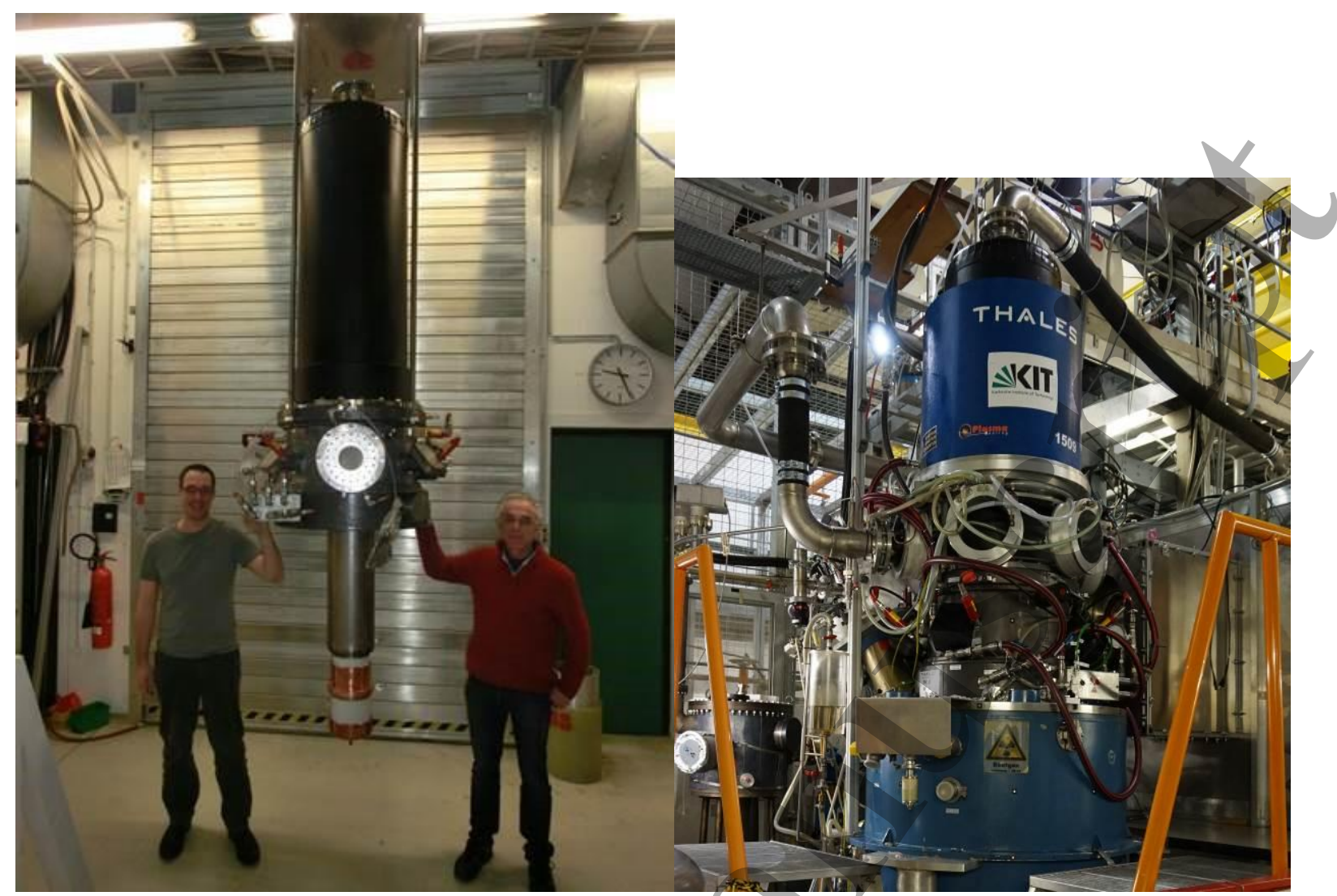

Figure 18. The EU 1MW, $170 \mathrm{GHz} \mathrm{CW}$ industrial prototype gyrotron (left) installed in the KIT OXFORD INSTRUMENTS superconducting magnet (right) (@ 2017 IEEE. Reprinted, with permission from [76] Ioannidis ZC et al 2017, IEEE Trans. on Electron Devices 64, 9, 3885).

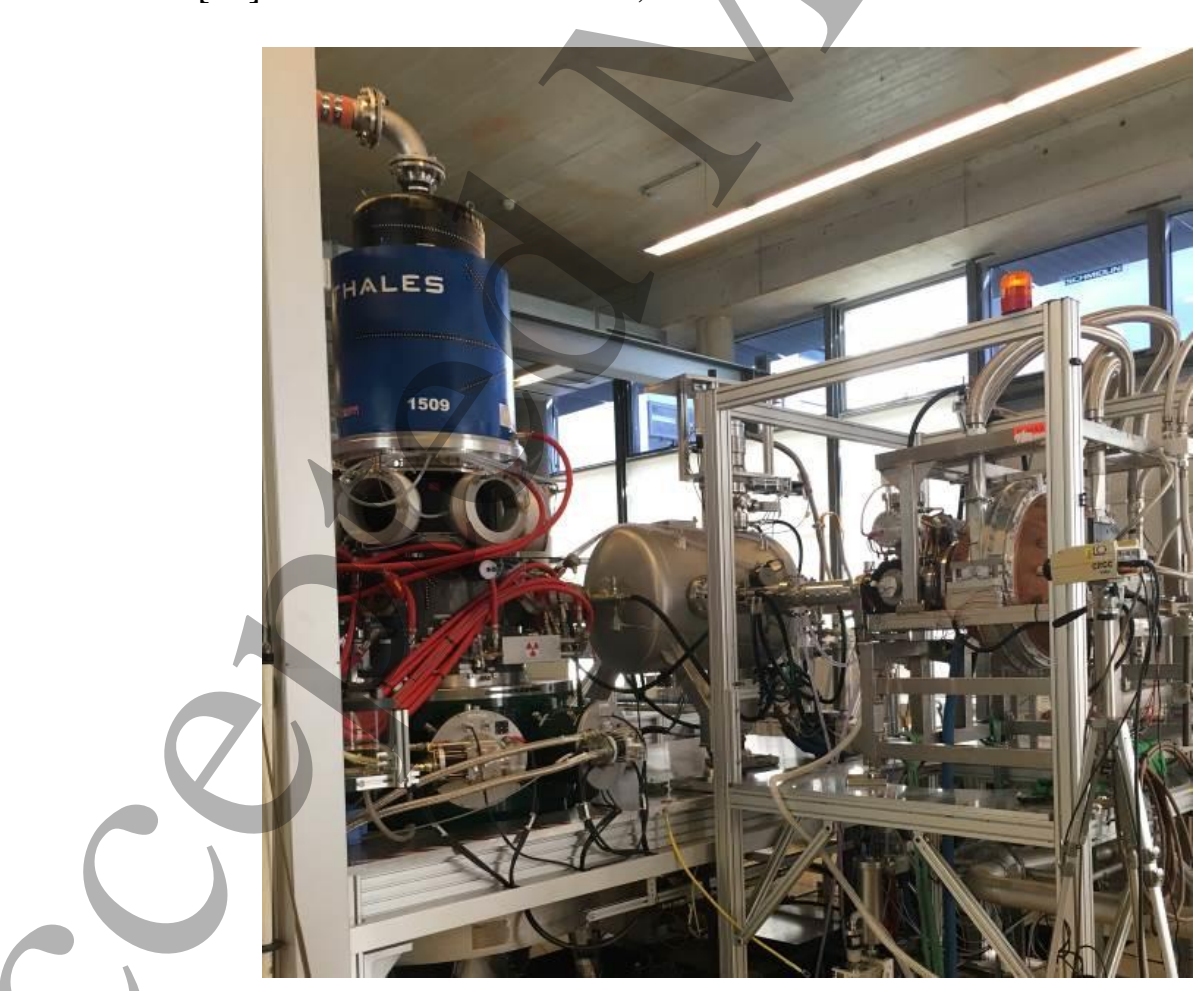

Figure 19. The EU $1 \mathrm{MW}, 170 \mathrm{GHz} \mathrm{CW}$ industrial prototype gyrotron installed at SPC with the CRYOGENICS superconducting magnet. The gyrotron is connected to the calorimetric RF load [50] using an $\mathrm{MOU}$ and an $\mathrm{HE}_{11}$-mode waveguide under vacuum. 


\subsubsection{Comparison of the different ITER gyrotrons}

The design parameters, specifications and typical results of the different $170 \mathrm{GHz}$ ITER gyrotrons are summarized in table 1.

Table 1. Parameters and typical results (up to the end of 2018) of the Japanese and Russian $170 \mathrm{GHz}$ ITER gyrotrons and of the first European prototype tube developed for ITER.

\begin{tabular}{|l|l|l|l|}
\hline & JA & RF & EU \\
\hline Operating Cavity Mode & TE31,8/ TE31,11 & TE25,10 & TE32,9 \\
\hline Radial Mode Eigenvalue & $63.76750 / 74.32574$ & 63.31966 & 68.56314 \\
\hline Cavity Radius & $17.9 \mathrm{~mm} / 20.87 \mathrm{~mm}$ & $17.77 \mathrm{~mm}$ & $19.24 \mathrm{~mm}$ \\
\hline Electron Beam Radius & $9.13 \mathrm{~mm}$ & $7.4 \mathrm{~mm}$ & $9.5 \mathrm{~mm}$ \\
\hline Launcher Angle & $0.2 \mathrm{deg}$. & $0.2 \mathrm{deg}$. & $0.23 \mathrm{deg}$. \\
\hline Output Mode Purity & $96 \%$ & $97 \%$ & $97 \%$ \\
\hline Output Power & $1 \mathrm{MW}(0.8 \mathrm{MW}) / 1 \mathrm{MW}(1.2 \mathrm{MW})$ & $1 \mathrm{MW}(1.2 \mathrm{MW})$ & $0.8 \mathrm{MW}$ \\
\hline Pulse Duration & $800 \mathrm{~s}(3600 \mathrm{~s}) / 300 \mathrm{~s}(2 \mathrm{~s})$ & $1000 \mathrm{~s}(100 \mathrm{~s})$ & $180 \mathrm{~s}$ \\
\hline Overall Efficiency & $55 \%(57 \%) / 46 \%(47 \%)$ & $54 \%(53 \%)$ & $38 \%$ \\
\hline Magnetron Injection Gun & Triode & Diode & Diode \\
\hline Electron Beam Energy & $72 \mathrm{keV}$ & $70 \mathrm{keV}$ & $72 \mathrm{keV}$ \\
\hline Depression Voltage & $30 \mathrm{kV}$ & $27.5 \mathrm{kV}$ & $25 \mathrm{kV}$ \\
\hline Beam Current & $43 \mathrm{~A}$ & $42 \mathrm{~A}$ & $45 \mathrm{~A}$ \\
\hline Mean Emitter Radius & $46.5 \mathrm{~mm}$ & $41.5 \mathrm{~mm}$ & $53.5 \mathrm{~mm}$ \\
\hline Magnet Bore Hole & $240 \mathrm{~mm}$ & $160 \mathrm{~mm}$ & $220 \mathrm{~mm}$ \\
\hline
\end{tabular}

4.2 Gyrotrons for the long-pulse plasma experiments LHD, QUEST, JT-60SA, EAST, KSTAR, W7-X, and Tore Supra

\subsubsection{Japanese gyrotrons for LHD, QUEST, and JT-60SA}

The ECH system of JT-60U using $110 \mathrm{GHz}$ gyrotons stopped its operation in 2008. Its performance has been summarized in [81]. Now JT-60U is being upgraded to JT-60SA, which is a joint international R\&D project involving Japan and Europe using the existing infrastructure of JT-60U. A gyrotron enabling high-power, long-pulse operation at both $110 \mathrm{GHz}$ and $138 \mathrm{GHz}$ has been developed for ECH\&CD in JT-60SA. The configuration of the JT-60 SA EC system is shown in figure 20. Operation at $1 \mathrm{MW}$ for $100 \mathrm{~s}$ has been demonstrated at both frequencies in 2014 [82]. After this, high-power gyrotron development toward 1.5-2 MW output power for several seconds was carried out. In 2015, stable oscillation of 1.5 MW for 5-s pulses was demonstrated as a first step to confirm the high-power capability in comparison with previous gyrotron version. Operation at even higher power has been carried out toward a goal of $2 \mathrm{MW}$, which is the maximum acceptable power for the cavity in design. An oscillation of 1.9 MW for 1-s pulses has been obtained. However, mode competition with the adjacent modes or counter-rotating modes at pulse lengths from $0.1 \mathrm{~s}$ to $0.5 \mathrm{~s}$ limits the pulse length at power levels higher than $1.9 \mathrm{MW}$, so far. The rise time of the power supply is approximately $0.1 \mathrm{~s}$. Thus a 


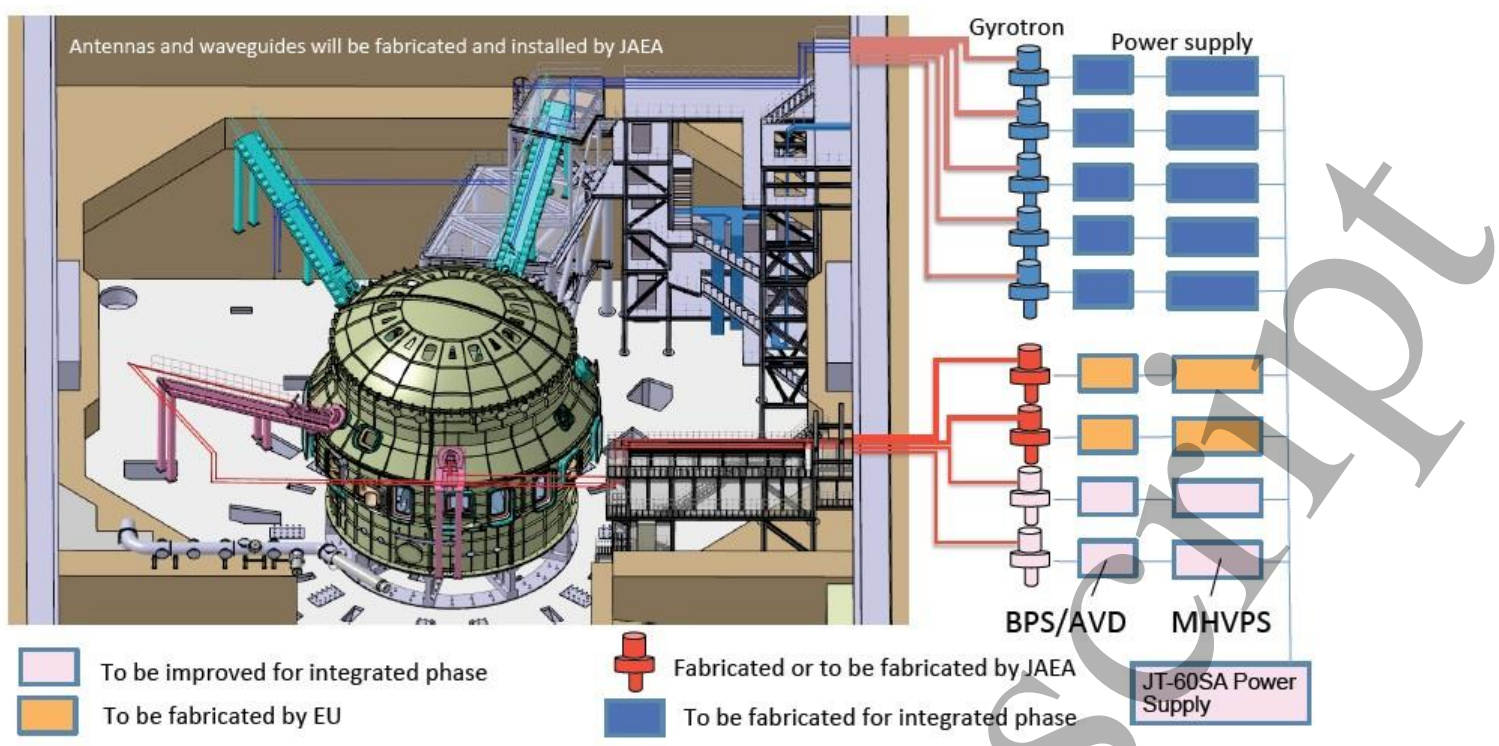

Figure 20. Conceptual view of the JT-60SA and its ECH\&CD system. A power injection of $3 \mathrm{MW}$ with 4 gyrotrons is planned in the initial stage, and will be upgraded to $7 \mathrm{MW}$ power using 9 gyrotrons in the final stage (integrated phase). JAEA was renamed as QST.

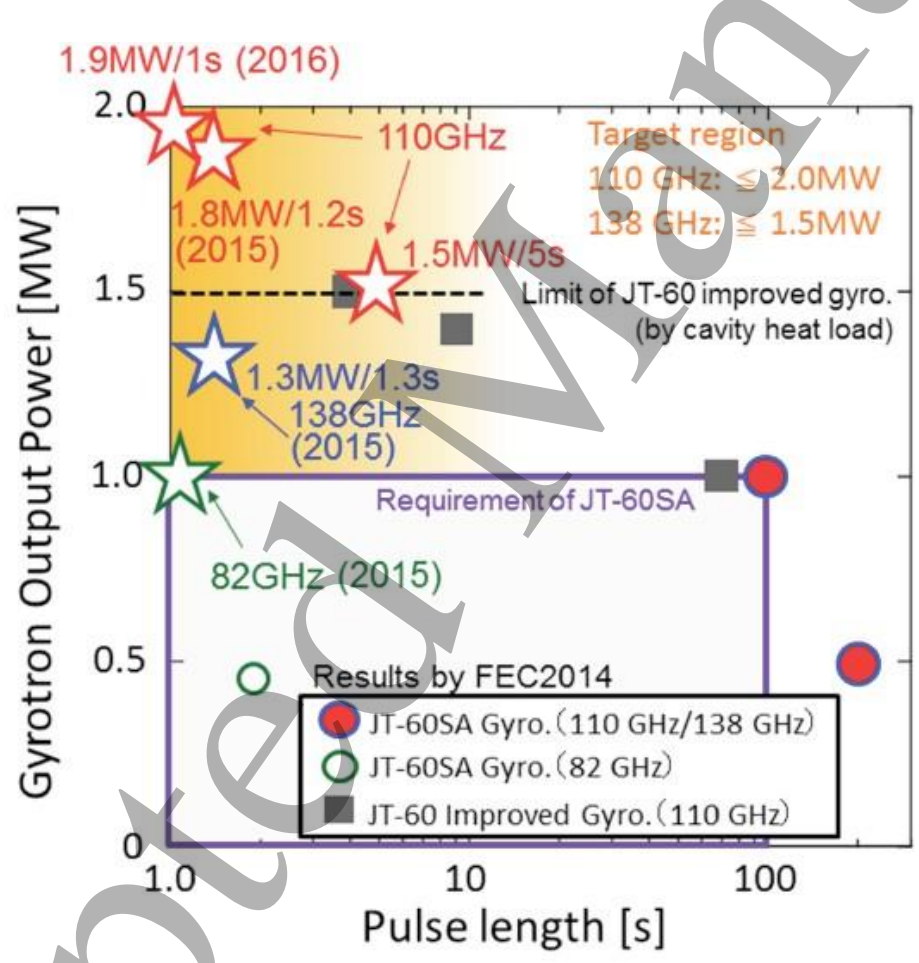

Figure 21. Status of gyrotron performance for JT-60SA.

change in the oscillation condition, which results in mode competition, appeared after the applied voltages reached flat top values. In addition to the above result at $110 \mathrm{GHz}$ ( $\mathrm{TE}_{22,8}$-cavity mode), oscillations of $1.3 \mathrm{MW}$ for 1.3-s pulse duration at $138 \mathrm{GHz}$ ( $\mathrm{TE}_{27,10}$ mode) and $1 \mathrm{MW}$ for1-s pulses at $82 \mathrm{GHz}\left(\mathrm{TE}_{17,6}\right.$ mode) have been demonstrated. The achieved power and pulse length at each frequency is summarized in figure 21 (see also Section 5.3.2).

\subsubsection{Russian gyrotrons for EAST and KSTAR}

GYCOM in collaboration with IAP designed, manufactured and tested a series of long-pulse gyrotrons in the $105-140 \mathrm{GHz}$ frequency range with parameters similar to the ITER tubes $[19,46,67,68,83]$. Two- 
(b)

frequency $140 / 105 \mathrm{GHz} 1 \mathrm{MW} \mathrm{TE} 22,8 / \mathrm{TE}_{17,6}$-mode gyrotrons with $1.8 \mathrm{~mm}$ thick plane CVD-diamond window disks operating with a pulse duration of $300 \mathrm{~s}$ were successfully tested at the customer site at NFRI in Korea. The overall gyrotron efficiency calculated by taking into account the TEM00-mode content in the output power, reached 50-55\%. At present time this gyrotron operates at the plasma machine KSTAR in Korea. The second tube of this type has been delivered to NFRI. Development of these two-frequency gyrotrons required solving several key tasks, as effective excitation of the two operating cavity modes, design of the q.o. mode converter that transforms the different cavity modes at different frequencies into a Gaussian output wave beam, and the design of a gyrotron collector that is consistent with the various guiding magnetic fields. Since the $\mathrm{TE}_{22,8}$-cavity mode at $140 \mathrm{GHz}$ is corotating and the $\mathrm{TE}_{17,6}$ mode at $105 \mathrm{GHz}$ is counter-rotating, the magnetic field has to be reversed for proper performance of the q.o. output coupler.

(a)
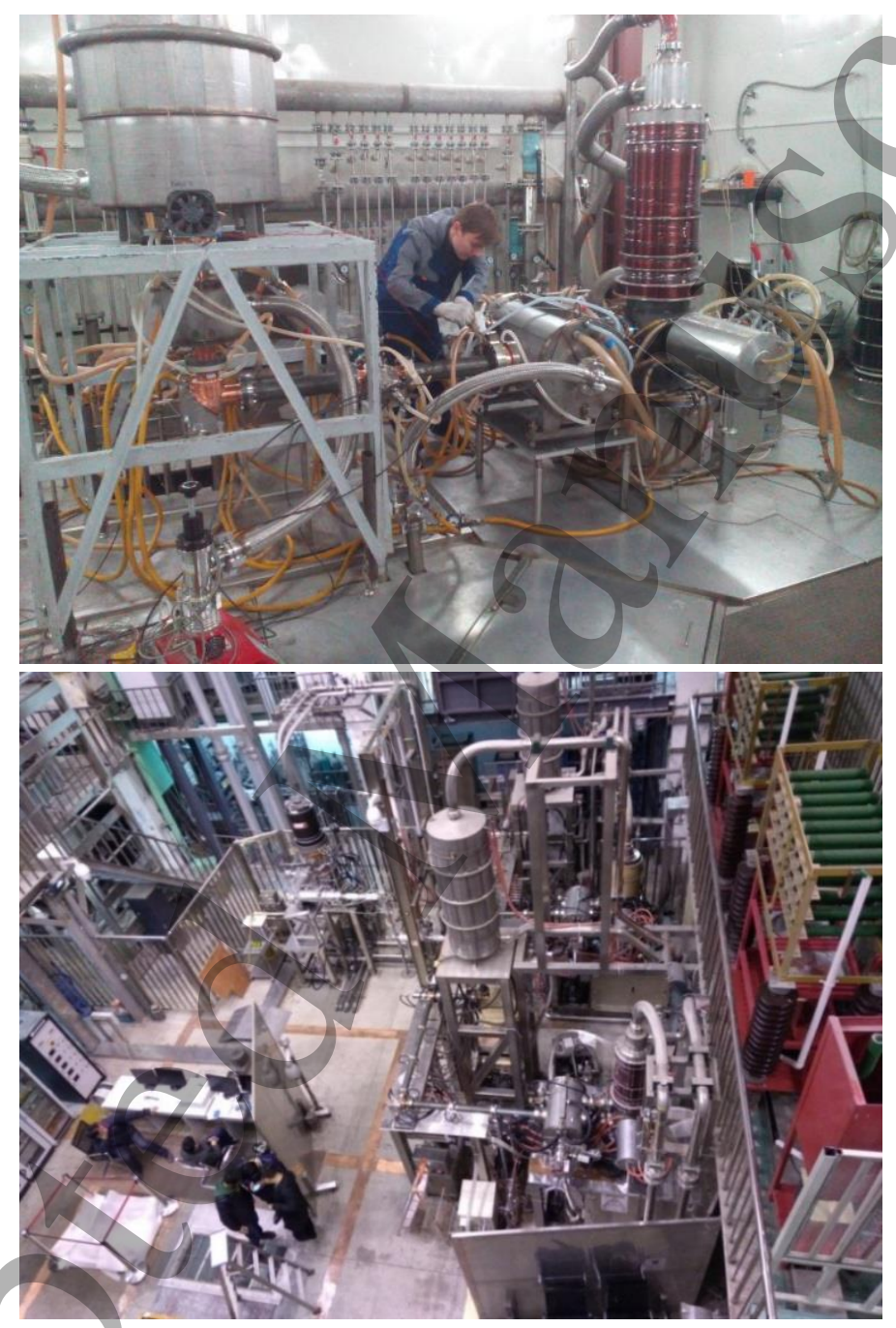

Figure 22. $140 \mathrm{GHz}$ gyrotron setup for EAST tokamak during factory test (a), two GYCOM gyrotrons with MOU, waveguides and terminal loads installed at EAST site (b) (photo in April, 2018). Upper photo shows the system installed in 2015, lower photo corresponds to the system accepted in 2018.

A GYCOM/IAP $140 \mathrm{GHz}, 1 \mathrm{MW}, 1000$-s gyrotron has operated at the EAST tokamak at ASIPP in China since the middle of 2015. The second tube of this gyrotron type passed the factory tests in July 2016, and the acceptance tests at the beginning of 2018. Figure 22 shows one of the tubes at the factory tests and the same tube installed at the ASIPP site. Beside the gyrotrons, all of the deliveries to KSTAR and EAST include other components of the gyrotron complex, including superconducting magnets (produced by JASTEC, Japan), MOUs, elements for the evacuated $\mathrm{HE}_{11}$ transmission lines and fullpower evacuated dummy loads. 


\subsubsection{European and US gyrotrons for W7-X and EU Tore Supra gyrotron}

Megawatt-class $140 \mathrm{GHz}$ long-pulse gyrotrons with $1.80 \mathrm{~mm}$ thick CVD diamond output window and single-stage depressed collector were developed by CPI and the EU team (KIT, SPC, THALES, Max Planck Institute for Plasma Physics in Greifswald (IPP Greifswald), IPF University of Stuttgart), independently, for the $10 \mathrm{MW}$ ECH\&CD system of the W7-X stellarator at IPP Greifswald. The specifications are listed in table 2. Both gyrotrons have been successfully tested for $\mathrm{CW}$ operation using the power supply of IPP [84]. The ECH\&CD system of W7-X is routinely operated employing nine THALES gyrotrons and one CPI tube.

-CPI gyrotron $[84,85]$

A photo of the CPI gyrotron is shown in figure 23 (a). The tube has a diode-type MIG. The body voltage is supplied from a second terminal from the bottom (bottom version insulator). The collector is grounded and the $-55 \mathrm{kV}$ cathode voltage is supplied from the bottom terminal. After the test at CPI, where $500 \mathrm{~kW}$ with $600 \mathrm{~s}$ was obtained for numerous shots, the tube was sent to IPP Greifswald. 0.9 MW power output was demonstrated for $30 \mathrm{~min}$ for the first time in 2005 . The efficiency was $\sim 36 \%$ with $+25 \mathrm{kV}$ body voltage. The measured internal diffraction loss is $4 \%$ of the generated power. Two of these megawatt-class $140 \mathrm{GHz}, \mathrm{CW}$ CPI gyrotrons are being used at EAST at ASIPP in Hefei, China [86].

Table 2. Specification and typical results of 140-GHz gyrotrons of EU and United States (CPI) developed for W7-X.

\begin{tabular}{|l|l|l|}
\hline & EU & US \\
\hline Frequency & $140 \mathrm{GHz}$ & $140 \mathrm{GHz}$ \\
\hline Cavity Radius & $20.48 \mathrm{~mm}$ & $19.26 \mathrm{~mm}$ \\
\hline Cavity Length & $14.5 \mathrm{~mm}$ (straight) & $16.46 \mathrm{~mm}$ (straight) \\
\hline Electron Beam Radius & $10.1 \mathrm{~mm}$ & $10.1 \mathrm{~mm}$ \\
\hline Diffractive Q-Factor & 1100 & 1200 \\
\hline Cavity Mode & TE28,8 & TE28,7 \\
\hline Output Mode Purity & $98.0 \%$ & $97.5 \%$ \\
\hline Launcher Angle & $0.229 \mathrm{deg}$. & $0.14 \mathrm{deg}$. \\
\hline Output Power & $1.0 \mathrm{MW}$ & $1.0 \mathrm{MW}$ \\
\hline Pulse Duration & $1800 \mathrm{~s}(\mathrm{CW})$ & $1800 \mathrm{~s}(\mathrm{CW})$ \\
\hline Overall Efficiency & $48 \%$ & $42 \%$ \\
\hline Magnetron Injection Gun & Diode & Diode \\
\hline Electron Beam Energy & $81 \mathrm{keV}$ & $80 \mathrm{keV}$ \\
\hline Beam Current & $40 \mathrm{~A}$ & $40 \mathrm{~A}$ \\
\hline Depression Voltage & $27-30 \mathrm{kV}$ & $20 \mathrm{kV}$ \\
\hline \hline Experimental Results & $0.92 \mathrm{MW} / 1800 \mathrm{~s} / 44 \%$ & $0.9 \mathrm{MW} / 1800 \mathrm{~s} / 36 \%$ \\
\hline & $1.02 \mathrm{MW} / 360 \mathrm{~s} / 43 \%$ & \\
\hline
\end{tabular}

-EU gyrotron $[19,34,84,87-90]$

A photo of the EU gyrotron is shown in figure 23 (b). The tube also has a diode-type MIG and bottom version insulation of the depression voltage. The collector uses $7 \mathrm{~Hz}$ vertical electron beam sweeping combined with $50 \mathrm{~Hz}$ transversal sweeping. The measured inner stray radiation loss only amounts to $\sim 2 \%$ due to the high efficiency internal mode converter [91]. At IPP an output power of $0.92 \mathrm{MW}$ in 30 min. operation was obtained. The efficiency was $44 \%$ using an SDC. Very high efficiency q.o. mmwave transmission of approximately $90 \%$ was measured for a $25 \mathrm{~m}$ long line with 17 mirrors [30]. The series production of seven tubes was done at THALES. Together with the corresponding two THALES prototype gyrotrons, nine THALES tubes are in operation at W7-X, as already mentioned above [7]. The power-modulation capabilities of the THALES tube have also been experimentally investigated. Modulation depths higher than $80 \%$ have been obtained either by modulating the cathode voltage or the depression voltage. Modulation frequencies as high as $50 \mathrm{kHz}$ have been obtained with cathode voltage modulation and $1.5 \mathrm{kHz}$ with depression voltage modulation [92]. 


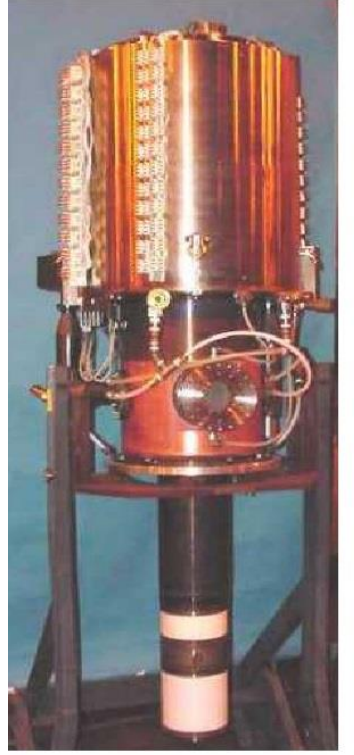

US

(a)

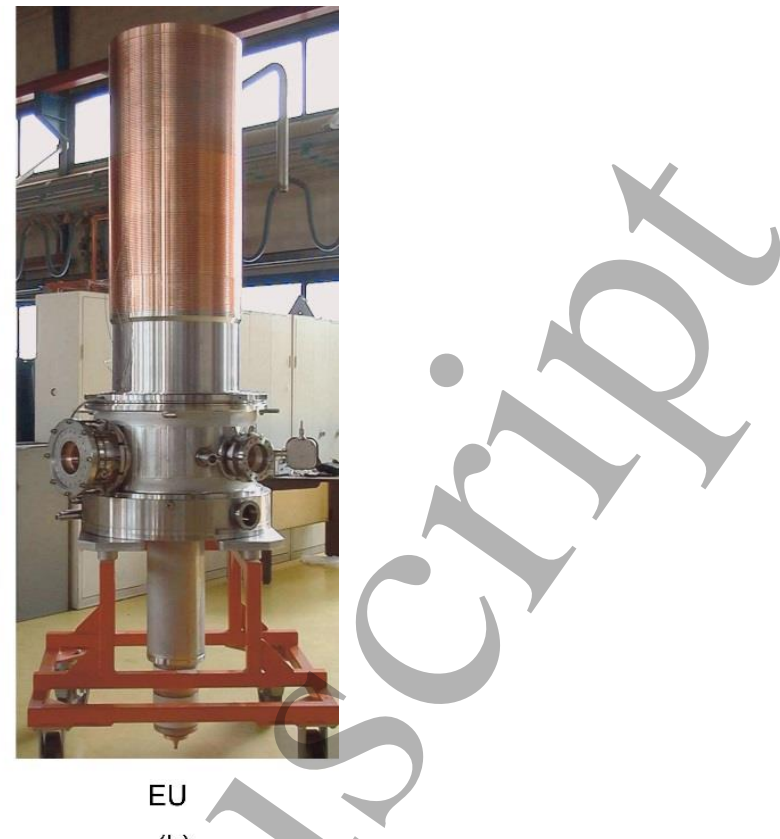

(b)

Figure 23. The 140-GHz gyrotrons for W7-X [19] developed by (a) the US (CPI) and (b) the EU team.

A $0.5 \mathrm{MW}, 118 \mathrm{GHz}$ long-pulse gyrotron (without SDC) with a q.o. output coupler and a cryogenically cooled single-disk sapphire output window was developed by the EU team in collaboration with THALES for Tore Supra and TCV [87,93]. It operates in the TE22,6-cavity mode and delivers $0.53 \mathrm{MW}$ in 5-s pulses and $0.35 \mathrm{MW}$ in pulses with 111-s duration.

\subsection{Gyrotrons for moderate pulse-length plasma devices (GAMMA 10, DIII-D, AUG, TCV, HL-2A)}

\subsubsection{Japanese gyrotrons for GAMMA 10}

As already mentioned in Section 4.2.1, megawatt-class $28 \mathrm{GHz}$ fusion gyrotrons with a q.o. output coupler and SDC for the mirror machine GAMMA 10 are under development in Japan in collaboration with Tsukuba University, QST, NIFS and CETD. The operating cavity mode is $\mathrm{TE}_{8,3}$. The maximum output power obtained is $1.38 \mathrm{MW}$, which is a new record at this frequency. In long-pulse operation, $0.6 \mathrm{MW}$ for $2 \mathrm{~s}$ at $28 \mathrm{GHz}$ has been achieved [79]. For the next step of the $28 \mathrm{GHz}$ gyrotron development, the test of a gyrotron with greater than 1.5 MW output power has begun to study multi-MW oscillation. The possibility of $0.4 \mathrm{MW} \mathrm{CW}$ and $2 \mathrm{MW}$ output power for pulse durations of a few seconds, after improvements to the output window and mode converter, is being investigated. This gyrotron can oscillate at two frequencies, 28 and $35 \mathrm{GHz}$, which shows the versatility of such multi-purpose gyrotrons. In short pulses, maximum powers of $1.65 \mathrm{MW}$ at $28.04 \mathrm{GHz}$ and $1.21 \mathrm{MW}$ at $34.83 \mathrm{GHz}$ were achieved [82].

\subsubsection{Russian gyrotrons for $A U G$ and $H L-2 A$}

A 10-s pulse duration, two-frequency gyrotron was developed by IAP/GYCOM in Russia for use in the ECH\&CD system on ASDEX Upgrade at IPP Garching (see 4.2.2) [94]. Currently, eight tubes are running there. By changing the magnitude and direction of the magnetic field in the cavity, the operating mode is controlled. The generated powers and frequencies are $0.85 \mathrm{MW}$ and $0.95 \mathrm{MW}$ for $105 \mathrm{GHz}$ and $140 \mathrm{GHz}$, respectively. The operating modes are $\mathrm{TE}_{17,6}$ and $\mathrm{TE}_{22,8}$ at $105 \mathrm{GHz}$ and $140 \mathrm{GHz}$, respectively. The results show that the q.o. mode converter works well for both frequencies/modes. This is the first two-frequency gyrotron that has ever been used in an ECH\&CD experiment. The transmission loss in the corrugated $\mathrm{HE}_{11}$ mode transmission line to the tokamak is low, i.e., $12 \%$ and $10 \%$ at $105 \mathrm{GHz}$ and $140 \mathrm{GHz}$, respectively. Two corresponding megawatt-class $140 \mathrm{GHz}$ gyrotrons with 3 s pulse duration are in operation at the HL-2A tokamak in Chengdu, P.R. China. 


\subsubsection{European gyrotrons for TCV}

Three $2 \mathrm{~s}$ pulse duration versions of the $0.5 \mathrm{MW}, 118 \mathrm{GHz}$ gyrotron developed by the EU team in collaboration with THALES for Tore Supra (see 4.2.3) are in operation at TCV [87,93]. In one of these tubes the cryogenically-cooled sapphire window was replaced by a water cooled 1.6-mm-thick CVDdiamond window. Currently, an upgrade of the EC-system for the TCV tokamak has begun and is part of a broader upgrade of TCV [95].

Table 3. Dual-Frequency Gyrotron Design Parameters.

\begin{tabular}{|l|l|l|}
\hline Operating Cavity Mode & TE17,5 & TE26,7 \\
\hline Frequency & $83.91 \mathrm{GHz}$ & $126.16 \mathrm{GHz}$ \\
\hline Output Power & $1.05 \mathrm{MW}$ & $1.2 \mathrm{MW}$ \\
\hline Cavity Wall-Loading & $1.1 \mathrm{~kW} / \mathrm{cm}^{2}$ & $2.1 \mathrm{~kW} / \mathrm{cm}^{2}$ \\
\hline Electron Beam Current & $40 \mathrm{~A}$ & $40 \mathrm{~A}$ \\
\hline Electron Beam Energy & $78 \mathrm{keV}$ & $78 \mathrm{keV}$ \\
\hline Modulation-Anode Voltage & $-38 \mathrm{kV}$ & $-26 \mathrm{kV}$ \\
\hline Electron Pitch Factor & 1.3 & 1.3 \\
\hline Cavity Magnetic Field & $3.31 \mathrm{~T}$ & $4.98 \mathrm{~T}$ \\
\hline Electronic Efficiency & $35 \%$ & $41 \%$ \\
\hline Gaussian Mode Content & $97.7 \%$ & $97.6 \%$ \\
\hline
\end{tabular}

A MW-class dual-frequency gyrotron ( 84 or $126 \mathrm{GHz}, 2$-s pulse duration, $1 \mathrm{MW}$ power level) has been developed by the EU gyrotron team [95]. The design parameters are listed in table 3. Two tubes are being manufactured by THALES. The first gyrotron was already installed at the TCV site and successfully tested at short pulses $(10 \mathrm{~ms})$. It delivers $0.9 \mathrm{MW}$ and 1.0 $\mathrm{MW}$ at the lower and higher frequencies, respectively, in a high-purity Gaussian output beam [96].

\subsubsection{US gyrotrons for DIII-D}

For higher performance of the CPI $110 \mathrm{GHz}$ gyrotrons [97-100], a project for $1.5 \mathrm{MW}$ gyrotron output power is underway in the USA. As a physics research project, a $110 \mathrm{GHz}$, high efficiency $1.5 \mathrm{MW}$ gyrotron with $48 \%$ overall efficiency was operated at MIT in short pulses $(3 \mu \mathrm{s})$. The cavity was carefully designed taking into account the probable competing modes [101]. The operating cavity mode is $\mathrm{TE}_{22,6}$. The tube contains a built-in q.o. output coupler and a depressed collector. Parallel to this development a corresponding long pulse $110 \mathrm{GHz}$ gyrotron and a $117.5 \mathrm{GHz}$ tube $\left(\mathrm{TE}_{20,9}\right)$ is on-going at CPI. Up to now, short pulse operation at $1.28 \mathrm{MW}$ output power with $42.3 \%$ efficiency and $1.7 \mathrm{MW}$ at $37 \%$ efficiency was obtained at $110 \mathrm{GHz}$ and $117.5 \mathrm{GHz}$, respectively [102,103]. Long-pulse operation aiming at $1.3 \mathrm{MW}$ is being carried out at General Atomics. Up to now the $117.5 \mathrm{GHz}$ gyrotron has achieved $1 \mathrm{MW}$ for $5 \mathrm{~s}$.

\section{Development of future advanced fusion gyrotrons}

\subsection{Higher gyrotron frequencies for DEMO}

The ECH\&CD system of a future, commercially attractive tokamak DEMOnstration fusion reactor operating under stationary conditions must be optimized to provide maximum possible CD efficiency. The achievable ECCD efficiency in two DEMO scenarios has been investigated in [6], one for pulsedand one for steady-state operation. Millimeter $(\mathrm{mm})$-wave beam propagation, absorption and current drive have been simulated employing beam-tracing techniques and including momentum conservation in electron-electron collisions. For mid-plane wave launching the achievable CD efficiency has been found to be limited by $2^{\text {nd }}$-harmonic absorption. Higher efficiencies can be obtained by injecting the millimeter $(\mathrm{mm})$-wave beams from the top of the tokamak, using wave absorption by more energetic, less collisional electrons and due to the reduced number of trapped electrons that absorb the waves. $C D$ efficiencies competitive with those usually achieved by neutral beam CD have been calculated. 
Assuming the EUROfusion 2012 baseline for DEMO with an aspect ratio $A=R / a$ (major/minor plasma radius) of 4.0 and $B>7 \mathrm{~T}$ the operation frequencies for optimum ECCD are significantly above $200 \mathrm{GHz}$, while lower frequencies around $170 \mathrm{GHz}$ and $200 \mathrm{GHz}$ appear useful for plasma start-up and bulk heating. However, in the meantime DEMO machines with smaller aspect ratio are being discussed [13]. Table 4 summarizes the gyrotron frequencies, $\mathrm{f}$, required for ECH and ECCD as a function of aspect ratio and magnetic field. Even for $A=3.1$ frequencies of up to approximately $200 \mathrm{GHz}$ are needed.

Table 4. Gyrotron frequencies $f$ needed for plasma heating and current drive for different values of the aspect ratio $A$ and toroidal magnetic field $B_{\mathrm{t}}$ ( $\gamma$ is a measure of the current drive efficiency).

\begin{tabular}{|c|c|c|c|c|}
\hline$A=R / a$ & 2.60 & 3.1 & 3.6 & 0 \\
\hline $\boldsymbol{B}_{t}$ & $4.2 \mathrm{~T}$ & $5.7 \mathrm{~T}$ & $7.0 \mathrm{~T}$ & $7.6 \mathrm{~T}$ \\
\hline$f$ for Heating & $118 \mathrm{GHz}$ & $160 \mathrm{GHz}$ & $197 \mathrm{GHz}$ & $213 \mathrm{GHz}$ \\
\hline$f$ for Current Drive & $144 \mathrm{GHz}$ & $196 \mathrm{GHz}$ & $240 \mathrm{GHz}$ & $280 \mathrm{GHz}$ \\
\hline$\gamma($ Top Launch) & $0.16 \mathrm{~A} / \mathrm{m}^{2} \mathrm{MW}$ & $0.32 \mathrm{~A} / \mathrm{m}^{2} \mathrm{MW}$ & $0.36 \mathrm{~A} / \mathrm{m}^{2} \mathrm{MW}$ & $0.45 \mathrm{~A} / \mathrm{m}^{2} \mathrm{MW}$ \\
\hline
\end{tabular}

The requirements for DEMO gyrotrons are as follows: 2 MW unit power, > $95 \%$ Gaussian output beam purity, $>60 \%$ overall efficiency, $>99 \%$ reliability, multi-frequency capability for different functions of the ECH\&CD system, and if possible, fast (within a few seconds) step-wise frequency tunability in $2-3 \mathrm{GHz}$ steps within the maximum frequency span of $+1-10 \mathrm{GHz}$ for plasma stabilization employing simple fixed antenna systems [104]. Such tubes need broadband or tunable CVD-diamond output windows [19,40-42,67,105-107]. The development of electron guns with high beam quality and of multi-stage depressed collectors (MSDC) for energy recovery is necessary, to achieve such a high efficiency.

\subsubsection{Japanese developments for future DEMO gyrotrons}

Two activities relevant to DEMO/gyrotrons have been carried out in Japan. First, the Japanese multifrequency gyrotron was operated at $203 \mathrm{GHz}$ and $7.98 \mathrm{~T}$ cavity magnetic field. This successful result is discussed in Section 5.3.2. The second activity is basic research using a short pulse test, sub-THz gyrotron, which was developed by QST (JAEA) and shown in figure 24. The gyrotron employs a 13-T SCM with a 110-mm warm-bore diameter, also designed at QST (JAEA) [79]. The cavity is designed to generate a maximum frequency of $300 \mathrm{GHz}$ in the $\mathrm{TE}_{32,18}$ mode. The power is extracted via an axial output/collector waveguide without a q.o. mode converter. The experiment was carried out at University of Tsukuba, in collaboration with QST. More than 0.6 MW output power was measured in 2-ms pulses at $20 \%$ efficiency, as shown in figure 25 [108]. The highest output power was achieved by inclining the output window disk by 1.15 deg. (black circles) to avoid mode trapping inside the tube. By decreasing the magnetic field, oscillation of lower frequencies around $240 \mathrm{GHz}$ was demonstrated by scanning the cavity magnetic field. Up to now, $345 \mathrm{~kW}$ was obtained at $243.9 \mathrm{GHz}\left(\mathrm{TE}_{28,14}\right)$ [79]. 


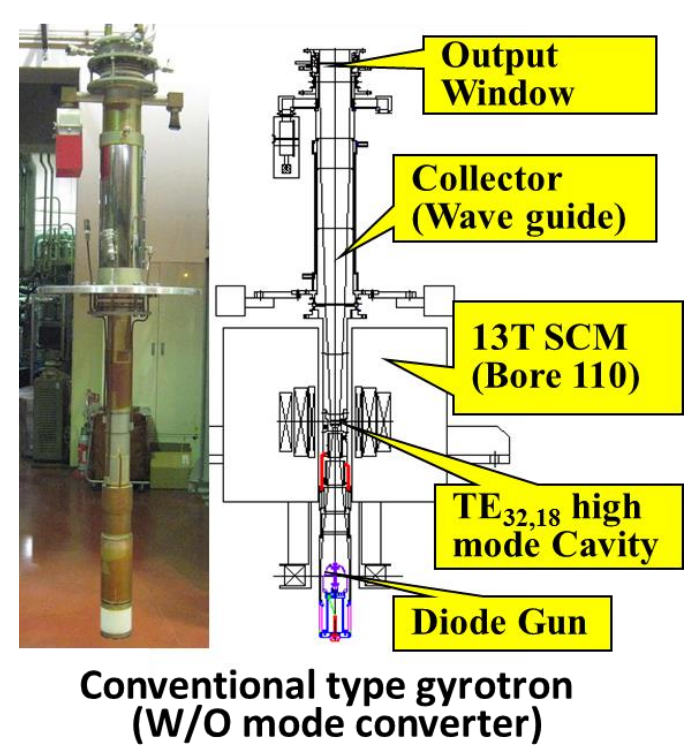

Figure 24. QST $300 \mathrm{GHz}$ gyrotron

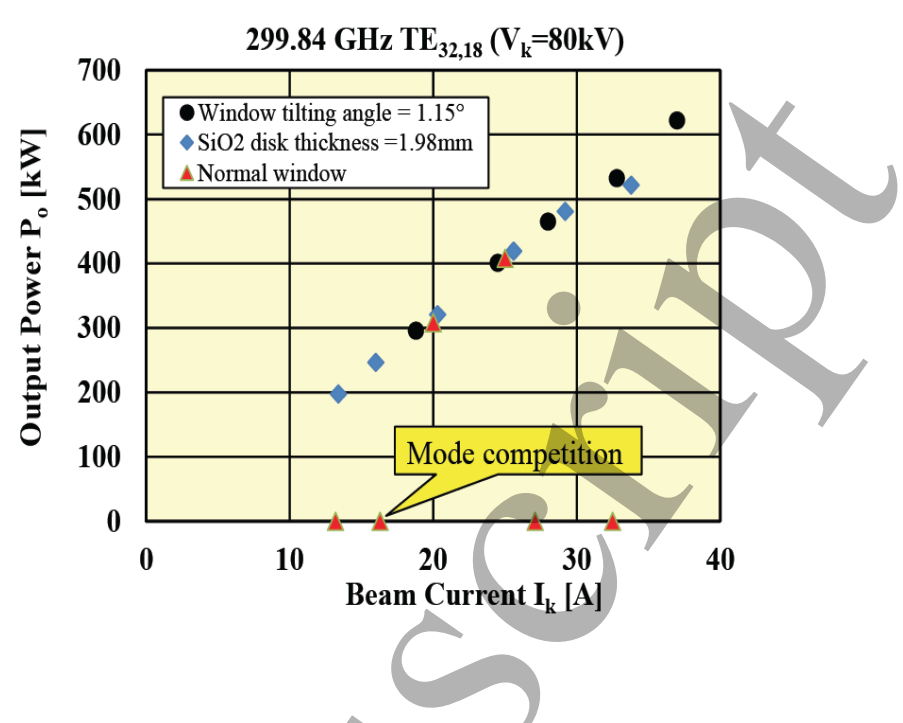

Figure 25. Output power vs. electron beam current for the QST $300 \mathrm{GHz}$ gyrotron.

\subsubsection{Russian developments for future DEMO gyrotrons}

At the IAP, in collaboration with GYCOM, a prototype fundamental frequency $250 \mathrm{GHz}$ gyrotron for $200 \mathrm{~kW}$ CW operation was designed and tested (see figure 26) [109,110]. For this tube a magnetic field of more than $9.5 \mathrm{~T}$ is required, which is available in the cryogen-free JASTEC SCM (JMTD10T100) at the IAP, with a 100-mm warm-bore diameter. This warm-bore diameter determined the dimensions of the electron optics and cavity, taking into account the technical requirements for cooling systems. As a result, to ensure stable RF generation at the selected frequency, the $\mathrm{TE}_{19,8}$ mode was selected as the working mode with a cavity radius of $9.34 \mathrm{~mm}$. Due to the close coupling factors of this operating cavity mode and the parasitic modes $\mathrm{TE}_{18,8}$ and $\mathrm{TE}_{20,8}$, the optimal radius of the electron beam in the interaction cavity is $R_{\text {beam }}=3.93 \mathrm{~mm}$, which differs slightly from the radius of maximum coupling coefficient for the working mode $R_{\mathrm{opt}}=3.85 \mathrm{~mm}$. The length of the homogeneous cavity section was chosen to be $L=10 \mathrm{~mm}$. The calculated operational parameters of the gyrotron are summarized in table 5 .

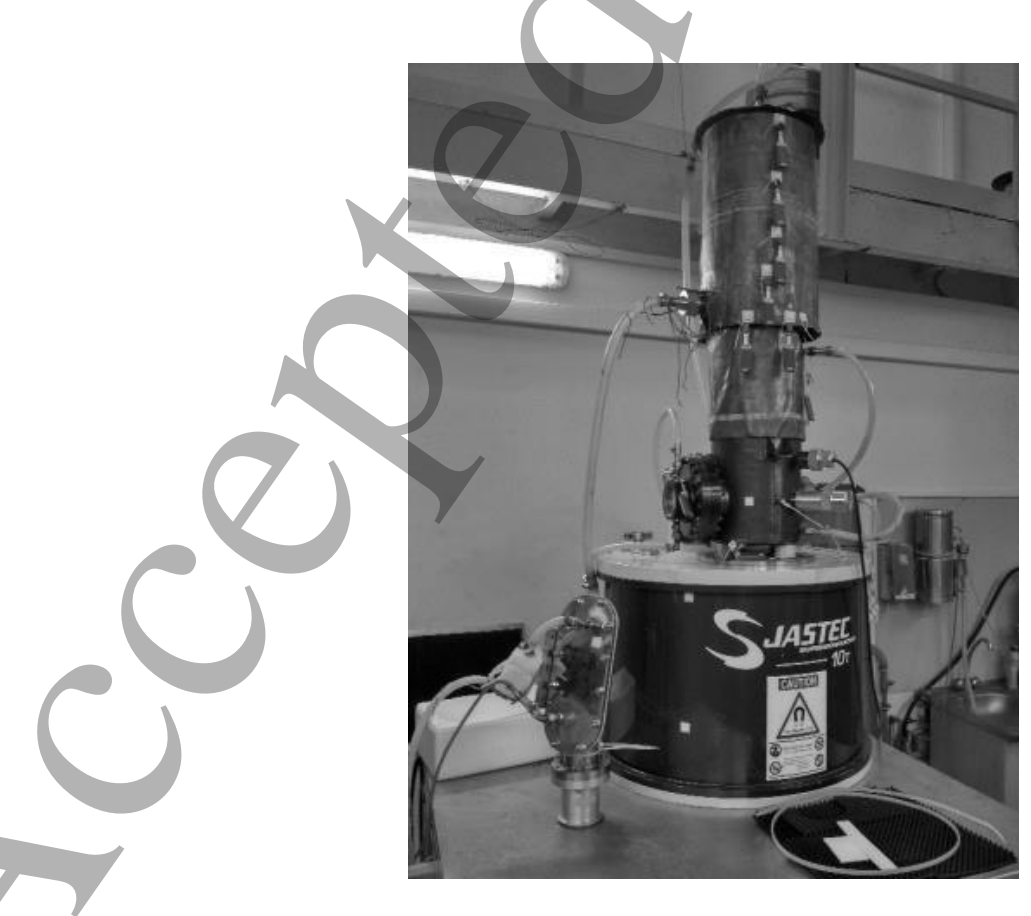

Figure 26. Photo of the IAP/GYCOM $250 \mathrm{GHz}, 200 \mathrm{~kW}$, CW gyrotron in the 10 T JASTEC SCM. 
Table 5. Design parameters of the IAP/GYCOM $250 \mathrm{GHz}, 200 \mathrm{~kW}$, CW gyrotron.

\begin{tabular}{|c|c|}
\hline Operating Frequency & $250 \mathrm{GHz}$ \\
\hline Operating Mode & $\mathrm{TE} 19,8$ \\
\hline Cyclotron Harmonic & 1 \\
\hline Accelerating Voltage & $55 \mathrm{kV}$ \\
\hline Depressed Collector Potential & $30 \mathrm{kV}$ \\
\hline Cavity Magnetic Field & $9.6-9.7 \mathrm{~T}$ \\
\hline Beam Current (nominal in CW mode) & $12 \mathrm{~A}$ \\
\hline Beam Current (pulsed mode) & $20 \mathrm{~A}$ \\
\hline Cavity Radius & $9.34 \mathrm{~mm}$ \\
\hline Cavity Length (homogeneous part) & $10 \mathrm{~mm}$ \\
\hline Beam Radius inside Cavity & $3.93 \mathrm{~mm}$ \\
\hline Pitch Factor & $\geq 1.1$ \\
\hline
\end{tabular}

The tube is equipped with an internal q.o. wave beam converter, which transforms the cavity mode into a Gaussian TEM To $_{00}$ beam and couples it radially to the output vacuum window. The converter consists of a shaped waveguide, a curved mirror, four flat mirrors, and a synthesized mirror with a non-quadratic curvature function.

The first experimental tests were carried out at the IAP RAS. Due to the limitations of the HV power supply, the first experiments were carried out in short pulses. For these tests a removable BN output window with $66 \mathrm{~mm}$ aperture diameter was manufactured and installed. The thickness of the window was chosen to be about $3.1 \mathrm{~mm}$ in order to minimize reflections at the operating frequency of $250 \mathrm{GHz}$. The pulse duration in the experiment was $20-40 \mu$ s with a repetition frequency of $10 \mathrm{~Hz}$. The frequency of the output radiation was measured using a resonant-cavity wavemeter. $249.74 \mathrm{GHz}$ operation at $200 \mathrm{~kW}$ was obtained at the following parameters: $55 \mathrm{kV}$ accelerating (cathode) voltage, 12.5 A electron beam current, and $9.625 \mathrm{~T}$ magnetic field. These results agree with the simulation data. A reduction of the thermal load in the cavity during pulsed operation made it possible to test the gyrotron with parameters exceeding the nominal design values. Thus, with an increase of the beam current to $20 \mathrm{~A}$, it was possible to reach a power of $330 \mathrm{~kW}$ at an accelerating voltage of $55 \mathrm{kV}$. The obtained experimental results are shown in figures 27 and 28 . Measurements of the transverse intensity distribution of the mmwave beam formed by the built-in q.o. mode converter were made, and the content of the TEM ${ }_{00}$ Gaussian beam wave was estimated. The measurement was performed using the thermal imaging technique [36] in several cross sections along the propagation of the wave beam. The analysis showed a Gaussian mode content in the reconstructed wave beam of $98.6 \%$.

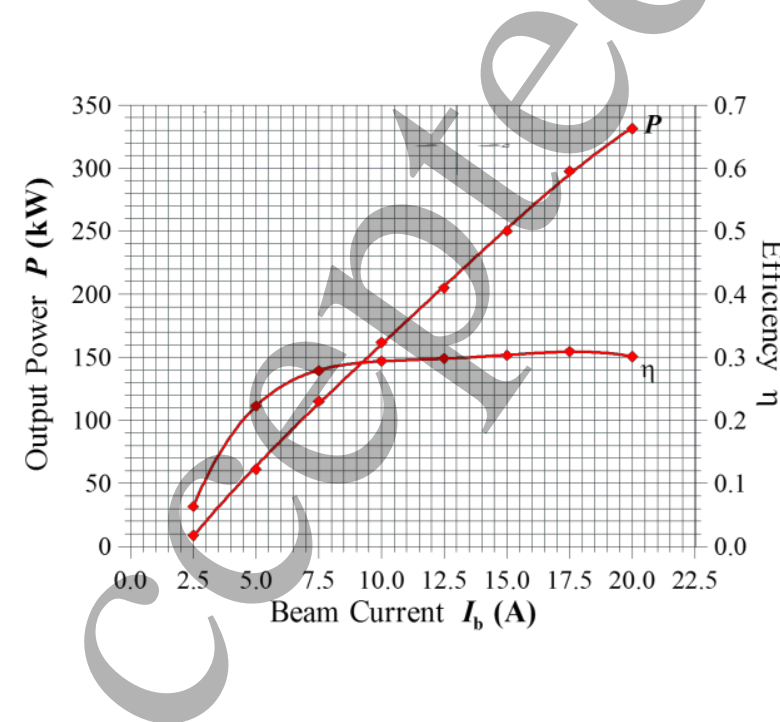

Figure 27. Output power and efficiency vs. electron beam current at $V_{\mathrm{b}}=55 \mathrm{kV}$ for the IAP $250 \mathrm{GHz}$ gyrotron.

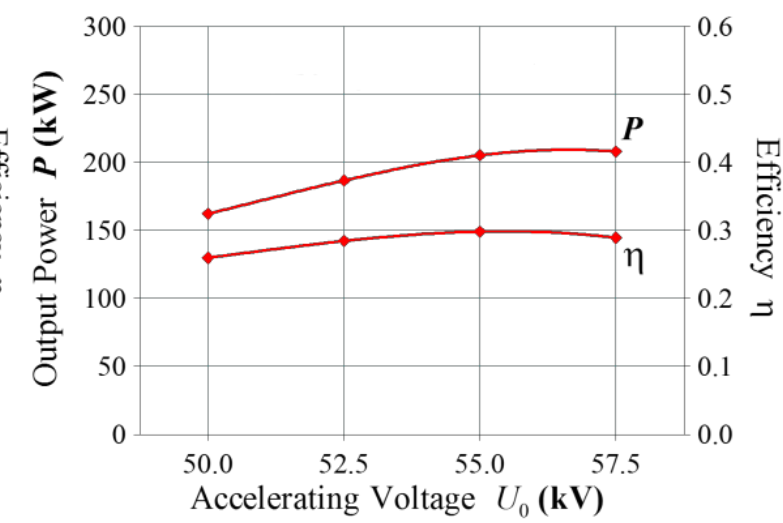

Figure 28. Output power and efficiency vs. acceleration voltage at $I_{b}=12.5 \mathrm{~A}$ for the IAP $250 \mathrm{GHz}$ gyrotron. 


\subsubsection{EU developments for future DEMO gyrotrons}

Within the Work Package Heating and Current Drive (WPHCD), coordinated by the Power Plant Physics and Technology Department of EUROfusion, detailed studies are ongoing, which cover three different systems for plasma heating and current drive. These are, namely, systems using electron cyclotron waves, ion cyclotron waves, and neutral beam injection. The studies are in line with the European Fusion Roadmap towards a DEMO [13,111]. Following the development of $1 \mathrm{MW}, \mathrm{CW}$ $140 \mathrm{GHz}$ and $170 \mathrm{GHz}$ gyrotrons for the W7-X stellarator and the ITER tokamak, respectively, the conceptual designs of tubes with frequencies up to approximately $240 \mathrm{GHz}$ were perfomed at KIT-IHM [112-117]. Along with a $237.5 \mathrm{GHz}, 2 \mathrm{MW}$ coaxial-cavity gyrotron design, a $236 \mathrm{GHz}, 1 \mathrm{MW}$ hollowcavity approach was under investigation, as backup solution. In both cases, operating modes have been selected considering multi-frequency operation at around $170 \mathrm{GHz} / 204 \mathrm{GHz} / 237 \mathrm{GHz}$ and $270 \mathrm{GHz}$ for multi-purpose applications and fast-frequency tunability in steps of $2-3 \mathrm{GHz}$ within the frequency range of $\pm 10 \mathrm{GHz}$ around the operating center frequency for plasma stability control.

At $237.5 \mathrm{GHz}$, a coaxial-cavity design for the $\mathrm{TE}_{49,29}$-mode (eigenvalue $\chi_{m, n} \sim 158$ ) has been found and optimized using realistic electron beam parameters with quite promising $1.9 \mathrm{MW}$ output power and $33 \%$ interaction efficiency at a maximum cavity wall loading of $2 \mathrm{~kW} / \mathrm{cm}^{2}$. At $203.8 \mathrm{GHz}$, oscillating in the $\mathrm{TE}_{42,25}$-mode $\left(\chi_{m, n} \sim 136\right)$, the same cavity could deliver $1.9 \mathrm{MW}$ output power with $32 \%$ interaction efficiency at reduced maximum cavity wall loading of $1.7 \mathrm{~kW} / \mathrm{cm}^{2}$. For $170.0 \mathrm{GHz}$ operation in the $\mathrm{TE}_{35,21}$-mode $\left(\chi_{m, n} \sim 113\right)$, the corresponding parameters would be $1.8 \mathrm{MW}, 31 \%$ and $1.3 \mathrm{~kW} / \mathrm{cm}^{2}$.

In the case of a $\mathrm{TE}_{43,15}$-mode $\left(\chi_{m, n} \sim 103\right)$ hollow-cavity gyrotron operating at $236.1 \mathrm{GHz}$ (see Section 5.3.2), again considering realistic electron beam parameters in the cavity (rms velocity spread: $6 \%$, radial beam width: $\lambda / 4$ ) and a realistic conductivity of the anticipated cavity material Glidcop, the results suggest stable output power of $0.92 \mathrm{MW}$ with an interaction efficiency of $36 \%$ at a maximum cavity wall loading of $2 \mathrm{~kW} / \mathrm{cm}^{2}$. For the $\mathrm{TE}_{37,13}$-mode $\left(\chi_{m, n} \sim 89\right)$ at $203.0 \mathrm{GHz}$ and the $\mathrm{TE}_{31,11}$-mode $\left(\chi_{m, n} \sim 74\right)$ at $170.0 \mathrm{GHz}$ the corresponding parameters are $1.15 \mathrm{MW}$ and $1.55 \mathrm{MW}$ and $35 \%$ and $33 \%$, respectively.

Currently, the existing $170 \mathrm{GHz}, 2 \mathrm{MW}$ coaxial-cavity design is studied regarding multi-frequency operation. Possible operation at $170 \mathrm{GHz}, 204 \mathrm{GHz}$ and $238 \mathrm{GHz}$ (window resonances) is targeted [118]. The aim of the study is to check if the actual working gyrotron can operate at the above mentioned frequencies without huge efforts in redesigning new components. The condition for mode selection is given by a maximal deviation of $<3.6 \%$ in caustic radius compared to the one for the $\mathrm{TE}_{34,19}$ mode. This is the condition that determines whether the quasi-optical system can perform equally well at the different frequencies. The chosen operating modes, based on using the nominal $\mathrm{TE}_{34,19}$-mode at $170 \mathrm{GHz}$, are $\mathrm{TE}_{40,23}$ at $204 \mathrm{GHz}, \mathrm{TE}_{48,26}$ at $237 \mathrm{GHz}$, and $\mathrm{TE}_{46,27}$ at $238 \mathrm{GHz}$. Instrumental to the gyrotron R\&D is the new Fusion Long Pulse Gyrotron Lab (FULGOR) at KIT-IHM, a test stand that is able to support the development of $\mathrm{CW}$ gyrotrons with a power of up to $4 \mathrm{MW}$ at frequencies up to $240 \mathrm{GHz}[119]$.

\subsection{Sub-THz gyrotrons for Collective Thomson Scattering}

Collective Thomson Scattering (CTS) diagnostics enables measurement of the ion velocity distribution function in fusion plasmas. Up to now, only gyrotrons developed for plasma heating have been used. However, high-density plasmas require very-high-frequency gyrotrons in order to avoid refraction and/or absorption. Such gyrotrons are being developed at the Research Center for Development of FarInfrared Region of the University of Fukui (FIR-FU) in Japan. Recently, they have succeeded in achieving $83 \mathrm{~kW}$ at $389 \mathrm{GHz}$ and 3-ms pulse duration [120]. Second harmonic oscillation was used to relax the requirements for the superconducting magnet. However, mode competition with fundamental harmonic modes has prevented operation at higher power [121]. Currently, the FIR-FU team is investigating a fundamental frequency $\mathrm{mm}$-wave gyrotron for CTS, which is mounted in a cryogen-free $12 \mathrm{~T}$ magnet. In a first stage, the cavity mode was the co-rotating $\mathrm{TE}_{14,2}$ mode oscillating at $295 \mathrm{GHz}$. The maximum power was $220 \mathrm{~kW}$ at $60 \mathrm{kV}$ beam voltage, $14 \mathrm{~A}$ beam current and 5 - $\mu$ s pulse length. The efficiency was about 25\%, nearly independent of the beam current [121]. In a second stage, the 
tube is now operated in the $\mathrm{TE}_{22,2}$ mode at $303 \mathrm{GHz}$ and delivers $320 \mathrm{~kW}$ Gaussian-mode output power at $32.8 \%$ efficiency and $100-\mu$ s pulse length. The experimental results are shown in figure 29 [122].
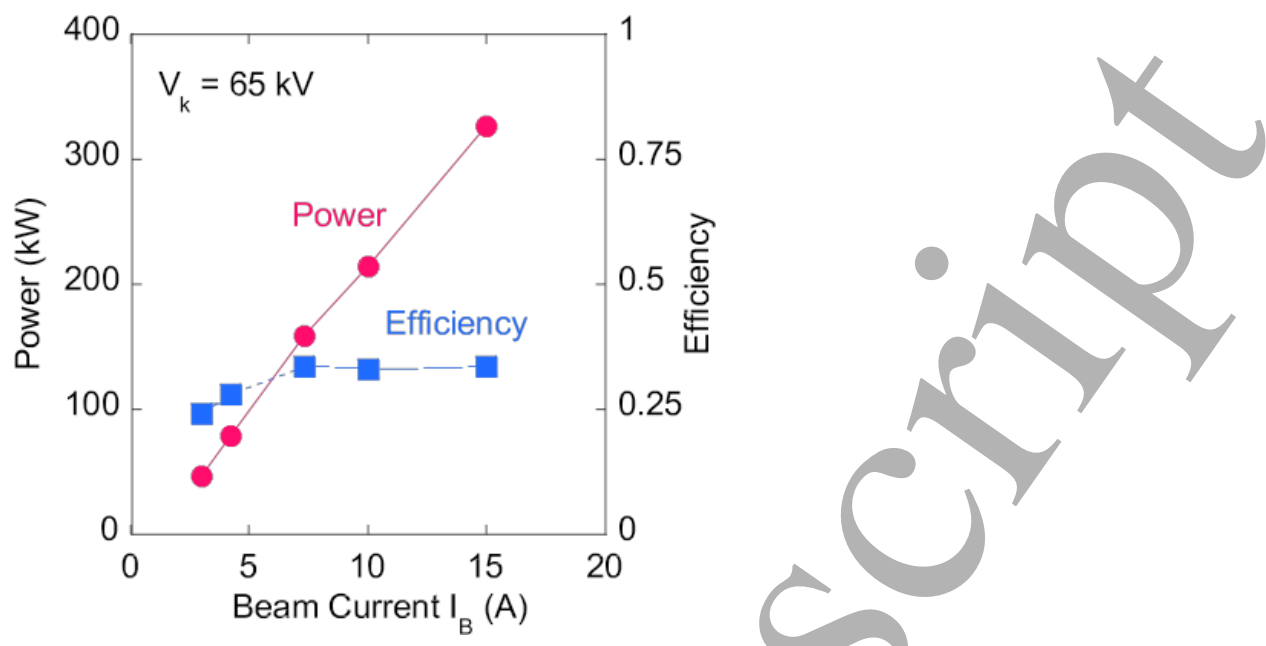

Figure 29. Measured output power (closed circles) and efficiency (closed squares) of a $303 \mathrm{GHz}$ CTS gyrotron vs. electron beam current (Reprint from [122] Saito T et al 2017, Plasma and Fusion Res. Rapid Communications 12, 1206013, with permission from JSPF).

A fundamental frequency $670 \mathrm{GHz}$ gyrotron with record power $(210 \mathrm{~kW})$ and efficiency (20\%) has been developed in joint experiments of the IAP Nizhny Novgorod, Russia, and the University of Maryland in the USA [123]. The required magnetic field of $27-28 \mathrm{~T}$ is produced by a pulsed solenoid with several ms pulse duration. The gyrotron operates in the $\mathrm{TE}_{31,8}$ cavity mode and is equipped with an external q.o. mode converter. The RF-pulse duration was $20-30 \mu$ s.

A record frequency stability was demonstrated using a $263 \mathrm{GHz}, 100 \mathrm{~W}$ sub-THz gyrotron employing a phase-locked loop in the modulation-anode voltage control. The relative width of the frequency spectrum and the frequency stability were $4 \times 10^{-12}$ and $10^{-10}$, respectively [124]. Of course, in a longpulse megawatt-class CTS gyrotron, sufficient frequency stabilization only may be achieved after the cavity deformation is in equilibrium.

\subsection{Multi-frequency gyrotrons}

The transmission frequencies of a simple, standard single-disk window are given by eq. (9). For example, the thickness of a synthetic diamond $170 \mathrm{GHz}$ gyrotron window disk is $d=1.852 \mathrm{~mm}$, corresponding to $n=5$ half-wavelengths in CVD diamond (see Section 4). Other transparent frequencies are $102,136,204$ and $238 \mathrm{GHz}$. If one finds for a cavity with radius $R_{\text {cav }}$ a series of modes with the same sense of rotation, oscillating very close to these window transmission frequencies and having very similar caustic radii $R_{\mathrm{c}}=\left(m / \chi_{m, n}\right) R_{\mathrm{cav}}$, the gyrotron can be operated as a multi-frequency (multi-purpose) gyrotron just by selecting the correct electron beam position and setting the proper external magnetic field in the cavity as discussed in Section 2 . Since the Brillouin angles $\theta_{\mathrm{B}}=\arccos \left[1-\left(R_{\text {cav }} / R_{\mathrm{L}}\right)^{2}\right]^{1 / 2}$ in the launcher of the q.o. output coupler with radius $R_{\mathrm{L}}$, the azimuthal radiation spread angles at the launcher aperture $2 \phi=2 \arccos \left(m / \chi_{m, n}\right)$ and the required launcher cut length $L=2 \pi R_{\mathrm{L}} \sin \phi /\left(\phi \tan \theta_{\mathrm{B}}\right)$ for the various modes are also almost the same, the q.o. output coupler can provide a Gaussian output beam for this series of modes at different frequencies [113]. Of course, the wave beams have to be matched to the transmission line by specific correction mirrors in a matching optics unit (MOU).

\subsubsection{Two-frequency gyrotrons in Russia and EU}

A two-frequency gyrotron is technically the simplest variant of a multi-frequency gyrotron. Twofrequency $140 / 105 \mathrm{GHz} 1 \mathrm{MW} \mathrm{TE} 22,8 / \mathrm{TE}_{17,6}$-mode GYCOM gyrotrons with $1.8 \mathrm{~mm}$ thick CVDdiamond window disks operating with pulse duration of up to $300 \mathrm{~s}$ are successfully operated at ASDEX Upgrade in Germany, KSTAR in Korea and HL-2A tokamak in Chengdu, P.R. China (see Section 4). 
The ASDEX Upgrade tubes with 10-s pulse duration were the first two-frequency gyrotrons to be used in an ECH\&CD experiment [94]. The generated powers and frequencies are $0.85 \mathrm{MW}$ and $0.95 \mathrm{MW}$ at $105 \mathrm{GHz}$ and $140 \mathrm{GHz}$, respectively. To obtain the maximum transmission line efficiency for both frequencies, the two MOU mirror sets are mounted on a revolving support for exchange when the frequency is changed. The measured transmission loss in the corrugated $\mathrm{HE}_{11}$-mode transmission line to the tokamak is low, i.e., $12 \%$ and $10 \%$ at $105 \mathrm{GHz}$ and $140 \mathrm{GHz}$, respectively.

For future multi-purpose applications, the Russian $170 \mathrm{GHz}, 1 \mathrm{MW}, 1000 \mathrm{~s}$ ITER gyrotron was operated at a second frequency of $135 \mathrm{GHz}$ for $0.1 \mathrm{~s}$ pulses and generated $0.8 \mathrm{MW}$ power. This preliminary test has encouraged the IAP/GYCOM team to develop an optimized two frequency gyrotron employing a triode gun.

Operation of one of the $140 \mathrm{GHz}, 1 \mathrm{MW}$ gyrotrons of W7-X at IPP Greifswald (see Section 4.2.3) as a two-frequency gyrotron with a standard CVD-diamond window $(d=1.799 \mathrm{~mm})$ delivered $0.41 \mathrm{MW}$ in 10 -s pulses at $103.8 \mathrm{GHz}[34]$.

A MW-class two-frequency gyrotron ( 84 or $126 \mathrm{GHz}, 2$-s pulse duration, $1 \mathrm{MW}$ power level) has been developed by the EU gyrotron team (see Section 4.3.3) [95]. Two tubes will be manufactured by THALES. The first gyrotron was already installed at the TCV site and successfully tested at short pulses (10 ms). It delivers 0.9 MW and 1.0 MW at the lower and higherfrequencies, respectively, in a highpurity Gaussian wave beam [96].

\subsubsection{Three- and Four-frequency gyrotrons in Japan}

The QST gyrotron team found that the mode series of $\mathrm{TE}_{37,13}(203 \mathrm{GHz}), \mathrm{TE}_{31,11}(170 \mathrm{GHz})$, $\mathrm{TE}_{25,9}(137 \mathrm{GHz}), \mathrm{TE}_{19,7}(104 \mathrm{GHz})$ has very similar caustic radii as shown in table 6 . In addition, these frequencies are located near the transparent frequencies of a single-disk diamond window with $1.853 \mathrm{~mm}$ thickness. In the mode converter design, conversion efficiencies of more than $97 \%$ were obtained from all the excited modes to a Gaussian output beam. The first gyrotron which employs this mode series was developed in 2009. Its outward appearance and dimensions are unchanged from the previous QST (JAEA) gyrotrons including the former $\mathrm{TE}_{31,8}$ mode ITER gyrotron. The corresponding design parameters are summarized in table 6 . Basically, the beam radius in the cavity to excite the target mode is optimized using the gun field. The electron gun is a triode MIG type, which enables selection of the pitch factor of the electron beam for each operating frequency separately.

Table 6. Design parameters of QST multi-frequency gyrotron.

\begin{tabular}{|l|l|l|l|l|}
\hline Frequency & $203 \mathrm{GHz}$ & $170 \mathrm{GHz}$ & $137 \mathrm{GHz}$ & $104 \mathrm{GHz}$ \\
\hline Cavity Mode & TE37,13 & TE31,11 & TE25,9 & TE19,7 \\
\hline \begin{tabular}{l|l|l|l|} 
Cavity Magnetic Field \\
Gun Field
\end{tabular} & $7.98 \mathrm{~T}$ & $.63 \mathrm{~T}$ & $5.32 \mathrm{~T}$ & $4.08 \mathrm{~T}$ \\
\hline Beam Radius in/Cavity & $9.10 \mathrm{~mm}$ & $9.13 \mathrm{~mm}$ & $9.19 \mathrm{~mm}$ & $9.25 \mathrm{~mm}$ \\
\hline $\begin{array}{l}\text { Beam Voltage } \\
\text { Anode Voltage }\end{array}$ & $72 \mathrm{kV}$ & $72 \mathrm{kV}$ & $72 \mathrm{kV}$ & $72 \mathrm{kV}$ \\
\hline Beam Current & $40 \mathrm{kV}$ & $42 \mathrm{kV}$ & $36 \mathrm{kV}$ & $28 \mathrm{kV}$ \\
\hline Pitch Factor & 1.35 & 1.35 & 1.35 & 1.32 \\
\hline Oscillation Power & $1.3 \mathrm{MW}$ & $1.3 \mathrm{MW}$ & $1.26 \mathrm{MW}$ & $1.12 \mathrm{MW}$ \\
\hline
\end{tabular}


The $110 \mathrm{GHz}$ QST gyrotron for JT-60SA obtained 1.9 MW for 1-s pulse operation utilizing the $\mathrm{TE}_{22,8-}$ cavity mode (see Section 4.2.1). In addition, oscillations of $1.3 \mathrm{MW}$ for 1.3-s pulses at $138 \mathrm{GHz}\left(\mathrm{TE}_{27,10}\right.$ mode) and $1 \mathrm{MW}$ for 1-s pulses at $82 \mathrm{GHz}$ ( $\mathrm{TE}_{17,6}$ mode) have been demonstrated with this tube.

\subsection{Stepwise frequency tunable gyrotrons}

One of the major roles of local ECH\&CD in ITER and other tokamaks is the suppression of Neoclassical Tearing Modes (NTMs) [5,104]. In order to compensate for the lack of current in the center (O-point) of a magnetic island, external current drive is required inside the island. The use of frequency steptunable gyrotrons could greatly enhance the flexibility and performance of the ITER ECH\&CD system. A system based on frequency step-tunable sources with frequency steps of 2-3 GHz could be used together with simple, fixed launcher structures without loss of performance. Because the magnetic field strength decreases toward the major radius direction in the case of tokamak, the power deposition point can be controlled by frequency control. As a reference, the power deposition point roughly moves $\sim 10 \mathrm{~cm}$ with a frequency shift of $3 \mathrm{GHz}$ in the plasma for ITER class tokamaks. Gyrotrons with broadband CVD-diamond windows and fast-tunable superconducting gyrotron magnets (sweeping speed $0.2 \mathrm{~T} / 5 \mathrm{~s}$ corresponding to $1 \mathrm{GHz} / \mathrm{s}$ ) would allow stepwise frequency tuning in a time scale of seconds over the full D-band $(110-170 \mathrm{GHz})$.

One idea for a broadband high-power window is a double CVD-diamond disk window. By changing the width of the gap between the two diamond disks mechanically, the transmission efficiency can be optimized for each frequency. However, RF arcing due to standing waves between the two disks could be a problem. In addition, if used as a gyrotron output window, reflections could influence the search for optimum gyrotron operating parameters. A second idea is a Brewster window. When the RF beam, linearly polarized in the reflection plane, is injected with the Brewster angle defined by

$$
\theta_{\mathrm{B}}=\arctan \left(\sqrt{\frac{\varepsilon_{1}}{\varepsilon_{2}}}\right)=67.2^{\circ} \text { (for CVD diamond), }
$$

no reflection occurs over a wide range of frequencies. Here, $\varepsilon_{1}$ and $\varepsilon_{2}$ are the dielectric constant of the material and the atmosphere/vacuum, respectively. This type of window was first demonstrated on multi-frequency gyrotrons using an elongated silicon nitride disk $[129,130]$. A third possibility is a travelling wave window (see Section 5.4.2).

\subsubsection{Fast frequency-tunable gyrotron in Japan}

A cryogen-free SCM for fast frequency tuning has already been developed in Japan [59,131]. In this SCM, an additional superconducting sweeping coil is installed inside the main coil. The diameter of the room temperature bore is $240 \mathrm{~mm}$, and the center magnetic field is $7 \mathrm{~T}$. Using commercially available DC power supplies, cavity field sweeping is realized at $7 \mathrm{~T}$ over a range of $0.4 \mathrm{~T}$, which corresponds to $\sim 10 \mathrm{GHz}$ shift, within $10 \mathrm{~s}$. For example, around $0.125 \mathrm{~T}$ is required to switch between the modes $\mathrm{TE}_{31,8}(170 \mathrm{GHz})$ and $\mathrm{TE}_{30,8}(166.8 \mathrm{GHz})$ at optimum efficiency. In figure 32, the preliminary experimental results for the fast frequency control experiment are shown. Here, the beam voltage, $V_{\mathrm{b}}$, is fixed at $71.0 \mathrm{kV}$, and the beam current is $I_{\mathrm{b}}=27.4 \mathrm{~A}$. The frequency shift between $170 \mathrm{GHz}$ and $166.8 \mathrm{GHz}$ was performed within $3.5 \mathrm{~s}$. The oscillation modes are $\mathrm{TE}_{31,8}$ and $\mathrm{TE}_{30,8}$, respectively. Power and efficiency without a depressed collector are $615 \mathrm{~kW} \mathrm{(32 \% )} \mathrm{and} 538 \mathrm{~kW}(27 \%)$, respectively. This could be beneficial to plasma stabilization experiments [126]. In addition, by adding electron beam voltage control, fast frequency change can be realized. 


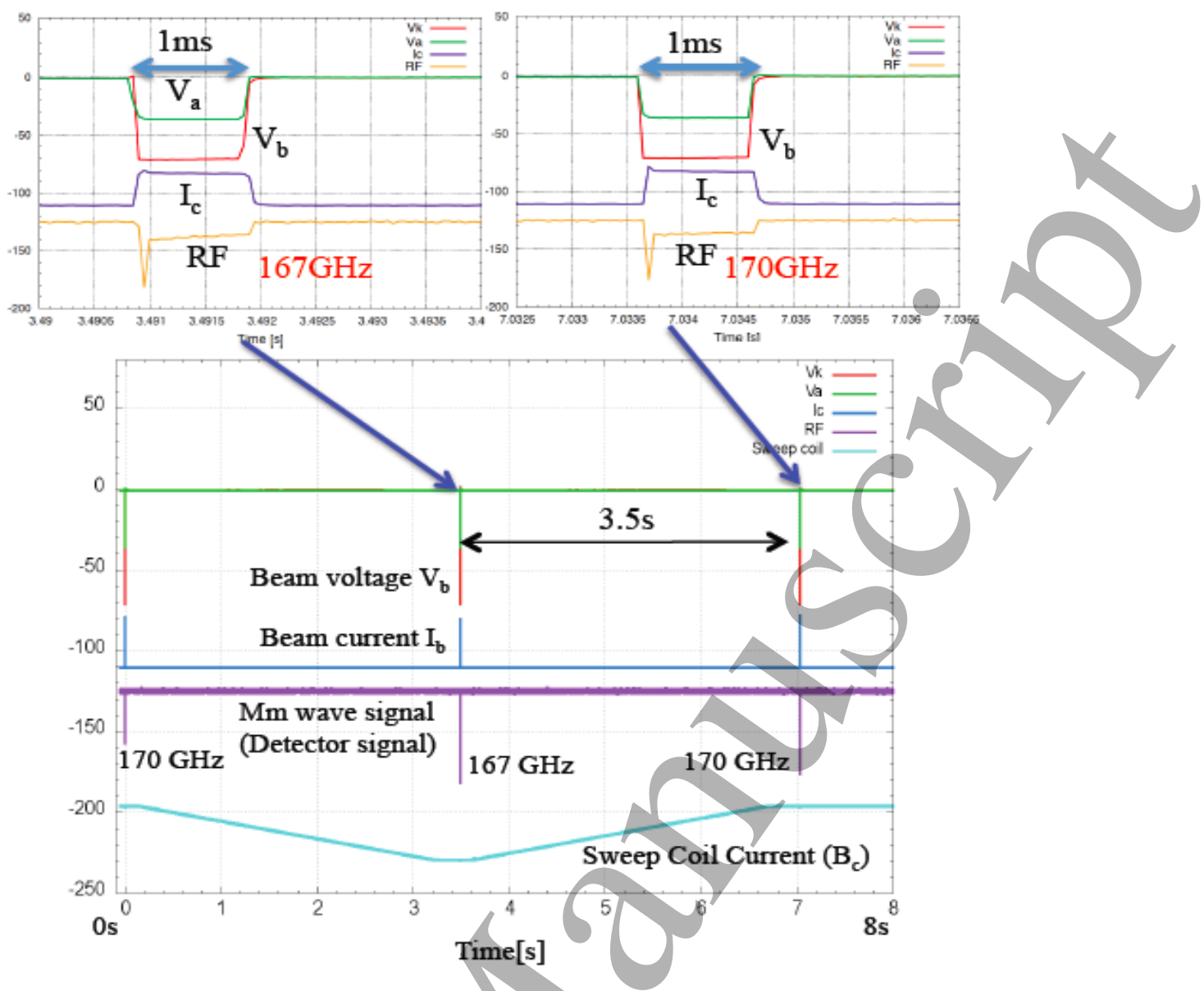

Figure 32. Time traces of beam voltage $V_{\mathrm{b}}$, beam current $I_{\mathrm{c}}, \mathrm{mm}$-wave diode signal and sweeping coil current (which corresponds to a change in the cavity magnetic field) of the $\mathrm{TE}_{31,8}$-mode QST gyrotron. At the bottom of the sweeping current, the $\mathrm{TE}_{30,8}$ mode $(166.8 \mathrm{GHz})$ is excited. The duration of the pulses is $1 \mathrm{~ms}$ as indicated in the upper figures.

\subsubsection{Frequency-tunable gyrotrons in Russia}

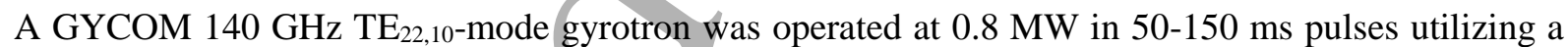
BN Brewster window at 11 frequencies (modes) between 104 and $143 \mathrm{GHz}$ [107].

At present, GYCOM/IAP is deyeloping in collaboration with IPP Garching and KIT, an industrial, frequency-tunable $1 \mathrm{MW}$ gyrotron with almost 50\% efficiency (SDC) for the new ASDEX Upgrade ECH system [94]. A four-frequency tube $(105,117,127$ and $140 \mathrm{GHz})$ with the $\mathrm{TE}_{22,8}$ cavity mode at $140 \mathrm{GHz}$, delivered $0.8 \mathrm{MW}$ at $105 \mathrm{GHz}$ and $0.9 \mathrm{MW}$ at $140 \mathrm{GHz}$ in 10-s pulses (two-frequency gyrotron) (see 5.3.1). The single-disk CVD-diamond window has maximum transmission for these two frequencies. After the installation of a circularly-brazed CVD-diamond Brewster window with specific internal and external mirrors mounted close to the window disk, the GYCOM/IAP group operated this gyrotron also at the two intermediate frequencies. However, the CVD-diamond disk broke due to successive RF arcing in front of the disk. Therefore, GYCOM is now developing a tunable travellingwave window consisting of two CVD-diamond disks and two mirrors (see figure 33) [132]. The principle of the travelling wave window can be explained by figure 33. The two windows (shown by green cuffs) and two adjustable mirrors form a ring resonator with a travelling wave. The system has zero reflections at the resonant frequency. At non-resonant frequencies some reflection from the resonator occurs, but the reflected wave does not propagate back into the cavity and does not disturb the gyrotron operation. It is directed via a relief window into a relief load. In addition, this window unit is transparent for the frequencies where the disks are transparent. This ring resonator mock-up with typical gyrotron-wave-beam window sizes was tested at low power and found to be an appropriate solution [132]. 


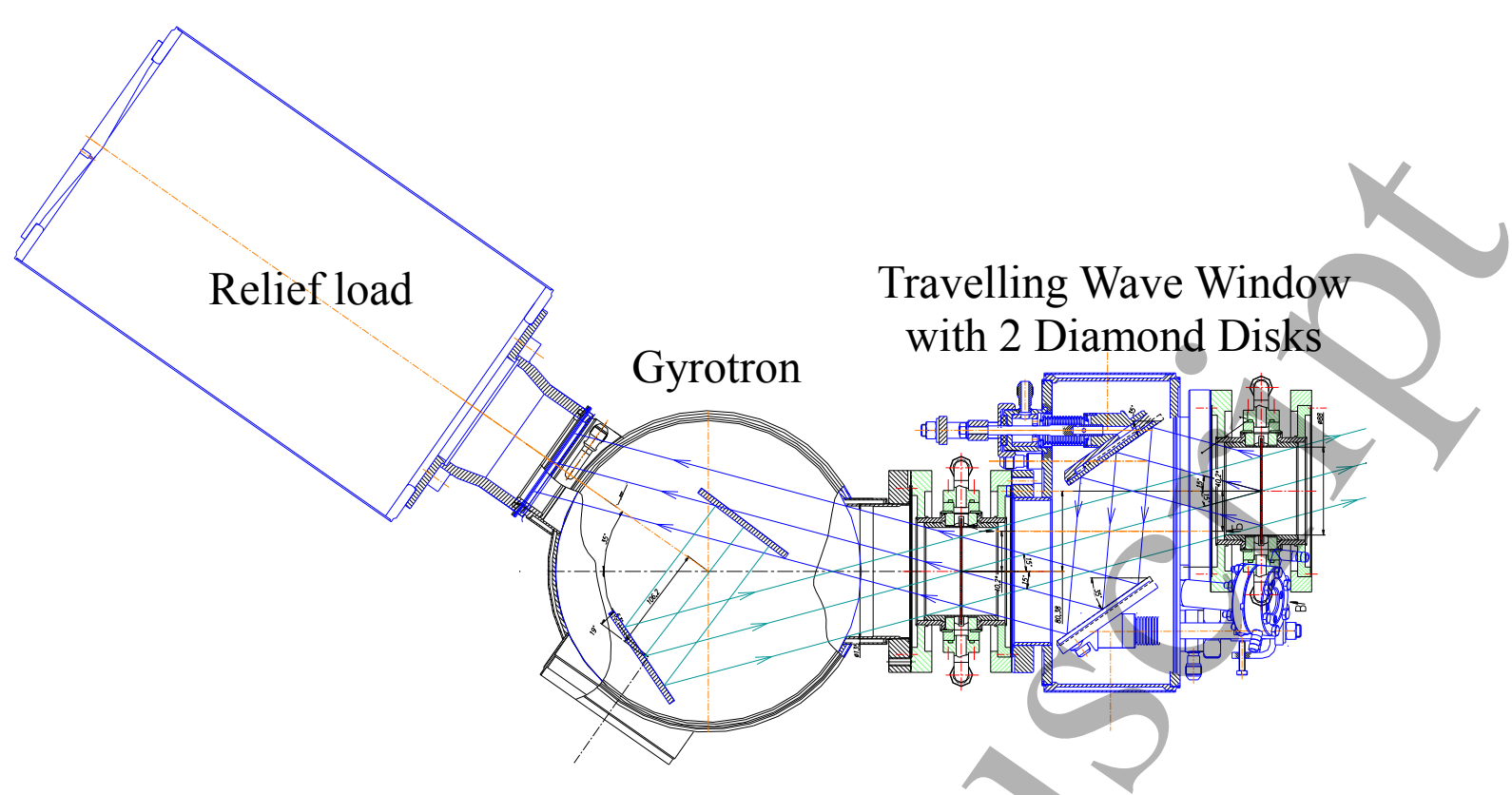

Figure 33. GYCOM tunable travelling-wave window employing two standard 106-mm-diameter CVD-diamond disks, two tunable mirrors and a calorimetric load at the relief window.

\subsubsection{Frequency-tunable gyrotrons in EU}

Already in the 1990's, D-band short-pulse (1 ms) frequency tunable megawatt-class gyrotrons with broadband SiN Brewster-angle windows were tested at KIT (FZK) $[129,130]$. In the conventional cylindrical -cavity tube $\left(114-166 \mathrm{GHz}, \mathrm{TE}_{22,6}\right.$ cavity mode at $\left.140 \mathrm{GHz}\right)$, in which such frequency tuning was realized, the frequency spacing was $3.7 \mathrm{GHz}$ [41], whereas the different modes of the coaxialcavity tube $\left(133-148 \mathrm{GHz}, \mathrm{TE}_{28,16}\right.$ cavity mode at $\left.140 \mathrm{GHz}\right)$ had a frequency separation of $2.2 \mathrm{GHz}$ [105]. In addition, the $1 \mathrm{MW} \mathrm{TE} 22,6$-mode gyrotron was investigated with respect to fast-frequency tunability between 5 modes in the $15 \mathrm{GHz}$-bandwidth range from 132.6 to $147.4 \mathrm{GHz}$ [133]. For that purpose, the gyrotron was equipped with a special hybrid-magnet system consisting of the SCM in the cryostat and additional normal-condueting (NC) copper magnets with a fast time constant at the cavity and cathode locations. Special problems due to the magnetic coupling between the different magnets were investigated by calculation and experiment. Making use of these investigations different current regulation schemes for the NC magnets were implemented and tested experimentally. Finally, megawatt-level step-tuning operation between the modes from $\mathrm{TE}_{20,6}$ to $\mathrm{TE}_{24,6}$, in time steps of $1 \mathrm{~s}$, was achieved.

Currently, KIT is developing a step-frequency tunable D-band MW gyrotron using an elliptically brazed CVD-diamond window. As in the Russian tube, the cavity mode at $140 \mathrm{GHz}$ is the $\mathrm{TE}_{22,8}$ mode. The dimensions of the diamond disk are $139 \times 95 \times 1.7 \mathrm{~mm}$ (figure 34) [134]. The elliptically shaped disk was brazed at the Brewster angle $\left(67.2^{\circ}\right)$ together with two OFHC copper cuffs with 49 -mm inner diameter and $0.5-\mathrm{mm}$ wall thickness. The total length of the window system is $206 \mathrm{~mm}$. A proper braze design is the key to success. It must withstand the significantly different thermal expansion coefficients for diamond and copper (1:17). The diamond disk and the copper cuffs were brazed at a temperature of about $800^{\circ} \mathrm{C}$, while the system is used at room temperature. Extensive 3D-FEM thermo-mechanical calculations (ANSYS) indicated that the stress in the disk and the copper cuffs did not exceed critical values. The distribution of the stress on the top side of the disk showed a maximum value of less than $150 \mathrm{MPa}$, which is considered as a conservative permissible stress (ultimate strength of diamond is 450$500 \mathrm{MPa}$ ). This value is higher by a factor of 1.4 compared to a circular disk. The equivalent von Mises stress on the copper cuffs at $20^{\circ} \mathrm{C}$ is $45 \mathrm{MPa}$, whereas the ultimate strength is $250 \mathrm{MPa}$. Low-power measurements confirm a transmission efficiency of more than $99 \%$. 

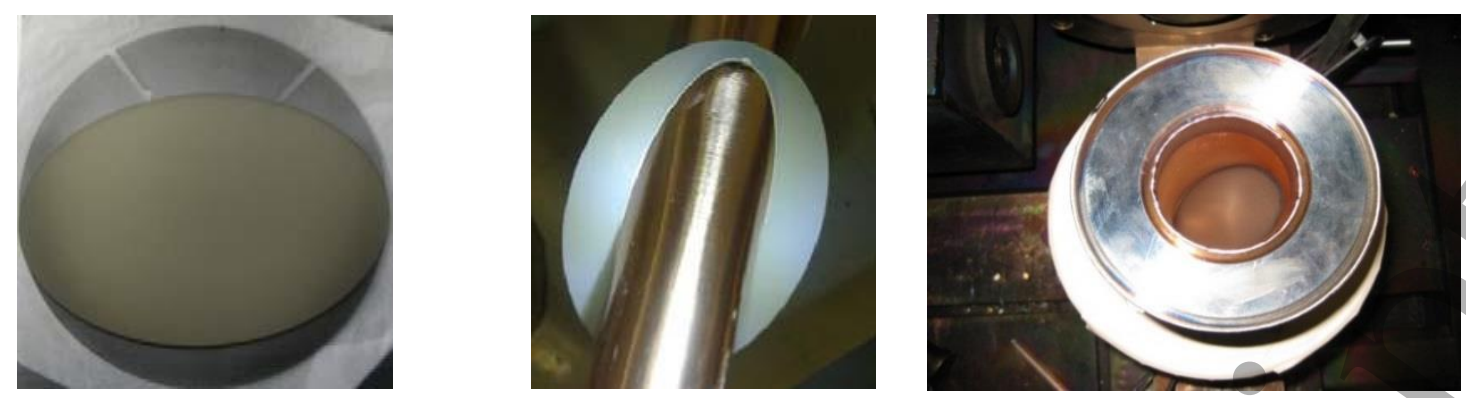

Figure 34. CVD-diamond disk and elliptically brazed Brewster window at KIT [132] (@ 2014 IEEE. Reprinted, with permission from [134] Gantenbein G et al 2014, IEEE Trans. on Electron Devices 61, $6,1806)$.

Table 7. Cavity modes, electron beam energy, beam current, output power and efficiency of KIT steptunable megawatt-class D-band gyrotron with CVD-diamond Brewster window (pulse length $=3 \mathrm{~ms}$ ).

\begin{tabular}{|c|c|c|c|c|c|}
\hline Mode & $\begin{array}{l}\text { Frequency } \\
\text { [GHz] }\end{array}$ & $\mathbf{E}_{\text {beam }}[\mathrm{keV}]$ & $\begin{array}{l}\mathbf{I}_{\text {beam }} \\
{[\mathrm{A}]}\end{array}$ & $\begin{array}{l}\text { Power } \\
{[\mathrm{kW}]}\end{array}$ & $\begin{array}{l}\text { Efficiency [\%] } \\
\text { (without SDC) }\end{array}$ \\
\hline $\mathrm{TE}_{19,6}$ & 111.6 & 84.1, short cavity & 41 & 830 & 24.1 \\
\hline $\mathbf{T E}_{20,7}$ & 124.2 & 71.6 & 42 & 1004 & 33.0 \\
\hline $\mathbf{T E}_{21,7}$ & 127.5 & 68.8 & 43 & 1035 & 35.0 \\
\hline $\mathrm{TE}_{22,8}$ & 140.1 & 69.1 & & 1150 & 37.0 \\
\hline $\mathbf{T E}_{23,8}$ & 143.4 & 67 & 44 & 1210 & 40.5 \\
\hline $\mathbf{T E}_{24,8}$ & 146.7 & 68.2 & 42.5 & 1200 & 41.4 \\
\hline $\mathrm{TE}_{24,9}$ & 155.9 & 85.2 , short cavity & 43 & 1000 & 27.3 \\
\hline $\mathrm{TE}_{25,9}$ & 159.2 & & 44 & 1093 & 32.9 \\
\hline $\mathrm{TE}_{26,9}$ & 162.6 & & 42 & 1200 & 36.9 \\
\hline $\mathrm{TE}_{27,9}$ & 16 & 78.3 & 44 & 1100 & 31.9 \\
\hline $\mathrm{TE}_{28,9}$ & 169.2 & 74.9 & 43 & 1150 & 35.7 \\
\hline
\end{tabular}

The step-frequency tunable KIT gyrotron has been operated in 3-ms-pulses with 11 modes in the frequency range starting from 111.6 to $169.2 \mathrm{GHz}$. The corresponding cavity modes, electron beam parameters, output powers and efficiencies (without depressed collector) are summarized in table 7 [135]. The results at 111.6 and $155.9 \mathrm{GHz}$ were obtained using a shorter cavity with lower diffractive $Q$ (850 compared to 1200).

\subsection{Coaxial-cavity gyrotrons}

To keep the number of required gyrotrons and magnets as low as possible, to reduce the costs of future fusion reactor ECH\&CD systems and to allow compact poloidal launchers for plasma stabilization, $2 \mathrm{MW}$ power per tube is desirable. Conventional, cylindrical gyrotron cavities are not suitable for very high-frequency (e.g. $204 \mathrm{GHz}$ for DEMO), high-power applications because of high Ohmic wall losses 
and/or mode competition problems. However, in coaxial cavities the existence of the longitudinallycorrugated inner conductor reduces the problems of mode competition and limiting current, thus allowing one to use even higher order modes with lower Ohmic attenuation than in cylindrical cavities [136]. In addition, the inner rod enables a specific voltage depression scheme for energy recovery and ultra-fast frequency step tuning just by applying an appropriate voltage to this coaxial insert. CVDdiamond windows with a transmission capability of $2 \mathrm{MW}, \mathrm{CW}$ are feasible (see Section 3.4).

Successful activities on the development of $1.5-2 \mathrm{MW}$ short-pulse gyrotrons with coaxial cavities were conducted at IAP Nizhny Novgorod (TE 28,16 at $140 \mathrm{GHz}$ [137]) and KIT (FZK) Karlsruhe ( $\mathrm{TE}_{28,16}$ at $140 \mathrm{GHz}$ and $\mathrm{TE}_{31,17}$ at $165 \mathrm{GHz}$ ) [136,138]. In single-pulse operation of the $165 \mathrm{GHz}$ tube, the pulse length was extended up to $17 \mathrm{~ms}$. At $V_{b}=93 \mathrm{kV}$ and $I_{b}=84 \mathrm{~A}$ a maximum RF output power as high as 2.2 MW was achieved with an efficiency of $28 \%$. Operation with a single-stage depressed collector was performed at an efficiency of $49 \%$ and an output power of $1.5 \mathrm{MW}$.

A $2 \mathrm{MW}, \mathrm{CW}, 170 \mathrm{GHz}$ coaxial-cavity gyrotron operating in the $\mathrm{TE}_{34,19}$ mode for ECH\&CD in ITER was under development in the EU by EGYC [72]. The design of critical components like the electron gun, beam tunnel, cavity and quasi-optical mm-wave output system was studied in a short-pulse coaxial gyrotron (pre-prototype) at KIT. At a magnetic field of $B=6.87 \mathrm{~T}$ a maximum mm-wave output power $P_{\text {out }}=2.2 \mathrm{MW}$ was obtained at $V_{b}=93 \mathrm{kV}$ and $I_{b}=80 \mathrm{~A}$ with an efficiency of around $30 \%$ at $1 \mathrm{~ms}$ pulse duration in non-depressed collector operation [139]. If a CVD-diamond window had been installed instead of the fused silica window, the output power would have been $2.3 \mathrm{MW}$ with an efficiency of $31 \%$, due to lower mm-wave absorption in diamond. The Gaussian output mode purity was almost $96 \%$.

$\mathrm{RF}$ tests with an industrial prototype gyrotron (THALES) were done at the EU test facility at SPC (CRPP) Lausanne in December 2011 [72]. This tube did show excellent voltage stand-off. It was possible to excite the nominal operating $\mathrm{TE}_{34,19}$ mode. The output $\mathrm{RF}$ beam profile was in good agreement with the expected profile. The output power reached a level of almost $2.1 \mathrm{MW}$ in short-pulse (1 ms) operation with SDC operation corresponding to $46 \%$ efficiency. The results were achieved after only 4 days of operation without any further optimization. However, the next day when an internal water-cooled, alumina-pipe-stray-radiation load broke, the tube was lost and the EU ITER gyrotron development strategy changed to the back-up solution of a $1 \mathrm{MW}$ conventional cylindrical cavity gyrotron operating in the $\mathrm{TE}_{32,9}$ mode.

Nevertheless, the development of multi-megawatt coaxial-cavity gyrotrons will continue in the EU, because very-high frequency gyrotrons (e.g. 204 or $238 \mathrm{GHz}$ ) for ECH and efficient non-inductive ECCD in future nuclear fusion reactors like DEMO will likely require coaxial cavities to generate unit powers of more than $1.5 \mathrm{MW}$. Currently, a longer-pulse $(100 \mathrm{~ms})$ version of this $170 \mathrm{GHz}, 2 \mathrm{MW}$ coaxial-cavity gyrotron is under test at KIT (see figure 35) [140,141]. The measured mm-wave output power (ms pulses) versus the cathode voltage at $I_{b}=81 \mathrm{~A}$ is shown in figure 36 [141]. The figure also contains the results of numerical simulations performed with the KIT self-consistent multi-mode code including $6 \% \mathrm{rms}$ transverse electron velocity spread. The agreement between experiment and simulations is very good if approximately $5 \%$ of the generated output power in the nominal mode is assumed to be lost inside the tube due to stray radiation, Ohmic losses and absorption in the output window. After further parameter optimization, the RF power was increased to $2.2 \mathrm{MW}$ at an efficiency of approximately $33 \%$ (without SDC).

In order to extend the range of stable single-mode operation at very high frequencies and multi-megawatt power level, the outer cavity wall could be equipped with mode-converting corrugations, which transform the azimuthal satellites of the operating cavity mode to low-Q modes, that are strongly disturbed by the inner conductor. Such an experiment was conducted at IAP in 2002 [142], employing the co-rotating $\mathrm{TE}_{+28,16}$-cavity mode at $140 \mathrm{GHz}$ in a $1 \mathrm{MW}$ short-pulse gyrotron. In this case, 44 longitudinal, rounded vanes $(0.2 \mathrm{~mm}$ deep $)$ in the outer cavity wall converted the co-rotating $\mathrm{TE}_{+29,16}$ and $\mathrm{TE}_{+27,16}$ satellite modes to the degenerate counter-rotating modes $\mathrm{TE}_{-15,20}$ and $\mathrm{TE}_{-17,19}$, respectively. Conversion to counter-rotating modes is utilized to guarantee only negligible unwanted conversion of the operating mode. In [143], a numerical code based on the spatial harmonics method is used to study this method in detail. However, if step-wise frequency tuning is required, such cavities would provide a mode spectrum with two times larger frequency separation compared to cavities with smooth outer wall. 

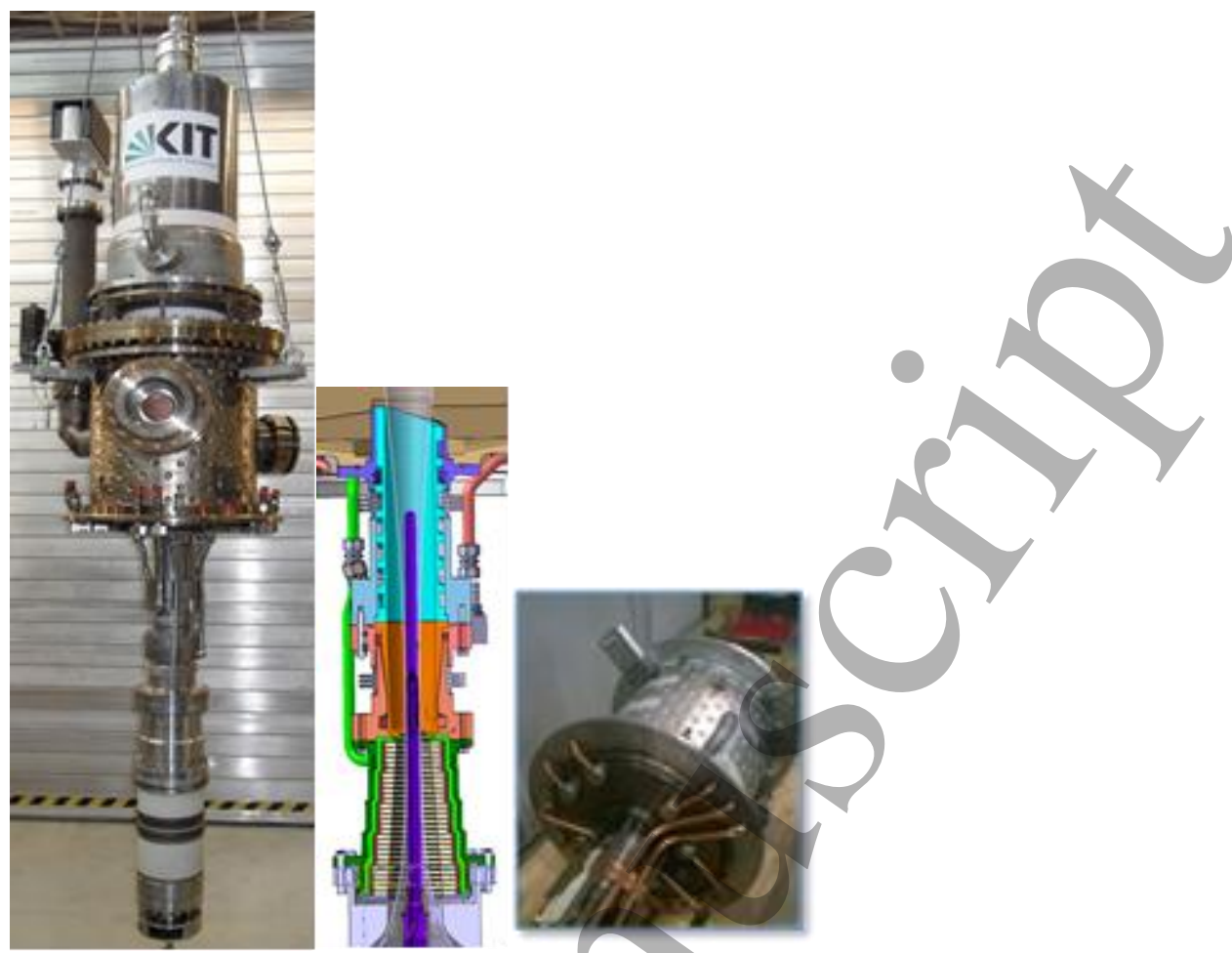

Figure 35. Photo of the upgraded KIT $170 \mathrm{GHz}, 2 \mathrm{MW}$ coaxial-cavity pre-prototype to operate at pulse lengths up to $100 \mathrm{~ms}$ (left). Sketch of the key components which have been upgraded with advanced cooling systems (middle). Upgrade of the mirror box showing the cooling system (right).

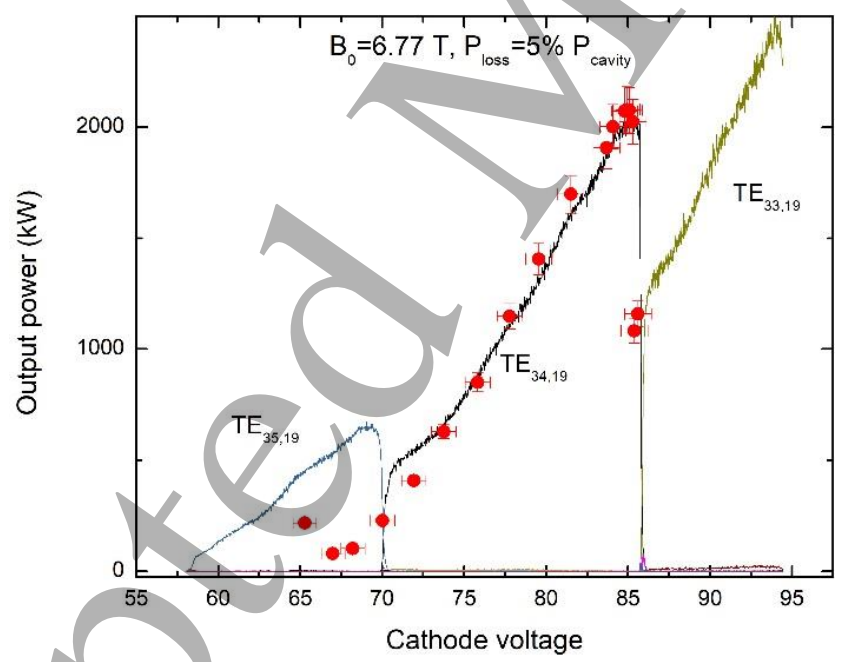

Figure 36. Measured (points) and calculated (solid lines) output power of the KIT coaxial-cavity prototype short-pulse gyrotron vs. beam voltage at $I_{b}=75 \mathrm{~A}$ and cavity magnetic field of $6.77 \mathrm{~T}$.

To support at KIT the future development of CW gyrotrons with an output power of up to $4 \mathrm{MW}$ at frequencies up to $240 \mathrm{GHz}$, the new gyrotron test facility Fusion Long Pulse Gyrotron Laboratory (FULGOR) was installed, which is capable of up to $10 \mathrm{MW} \mathrm{CW}$ operation [119]. The main HV DC power supply, delivered in late 2017 by Ampegon AG (Turgi, Switzerland) and accepted in 2018, provides voltages and currents up to $90 \mathrm{kV} / 120 \mathrm{~A}$ for $3600 \mathrm{~s}$ at $50 \%$ duty cycle and $130 \mathrm{kV} / 120 \mathrm{~A}$ in short pulses $(5 \mathrm{~ms} / 25 \%$ duty cycle). There is the possibility for up to 10 intermediate voltage taps for multi-stage depressed collector operation, freely selectable in $1.2 \mathrm{kV}$ steps. A $10.5 \mathrm{~T}$ cryogen-free gyrotron SCM with $261 \mathrm{~mm}$ warm bore and dipole coils for transverse electron beam alignment was ordered from Tesla Engineering Ltd., Storrington, UK. 


\subsection{Injection locking of gyrotrons}

At IAP Nizhny Novgorod there are new developments in phase locking megawatt-class gyro-oscillators [144-146]. Starting from a $1.5 \mathrm{MW}, 170 \mathrm{GHz}, \mathrm{TE}_{28,12}$-mode tube with $2.5 \mathrm{~s}$ pulse length, $49 \%$ efficiency (with SDC) and $97 \%$ Gaussian-beam output, a gyrotron operating efficiently in modes of both rotations was developed and tested in proof-of-principle experiments. The gyrotron operation can be switched between two modes: co- and counter-rotating $\mathrm{TE}_{ \pm 28,12}$ at $170 \mathrm{GHz}$, by adjusting a cathode coil to select the mode rotation. A new synthesized quasi-optical mode converter composed of 3D metal reflectors provides output coupling for the generated waves in the form of two paraxial Gaussian wave beams, each of them corresponding to a specific direction of mode rotation (see figures 37 and 38). The measured gyrotron output power (up to $2 \mathrm{MW}$ in short-pulse operation), interaction efficiency (34\%, without SDC) and diffraction losses in the mode converter $(<2 \%)$ agree well with the design values (see figure 39). The new gyrotron scheme allows a basic enhancement of the device parameters, the possibility of electronic switching of the output wave beam direction, frequency stabilization by reflection, and the possibility of providing an effective approach to enable frequency and phase locking of a gyrotron-oscillator (injection locking). The latter advance could lead to very efficient single-mode operation in very high order modes (high-frequency 1.5 MW-class gyrotrons with conventional hollow cavity), stabilized by an external signal while the electron beam parameters are not so stable, and the possibility of making several individual gyrotrons coherent. In addition, the possibility of very precise stabilization of a gyrotron-driver was demonstrated [124].

To accomplish phase or frequency locking, the counter-rotating input beam (see figure 37 (b)) is converted to the counter-rotating TE-28,12 mode, which by reflection at the cutoff section of the gyrotron cavity is converted to the operating co-rotating $\mathrm{TE}_{+28,12}$ cavity mode. The input and output wave beams pass through the gyrotron output window at an angle of $\pm 10 \mathrm{deg}$. with respect to the window normal.

The first experiments on gyrotron frequency stabilization by optimum reflection were very encouraging. For a rather high voltage variation of $95-100 \mathrm{kV}$ the frequency was stable to within $2 \mathrm{MHz}$.

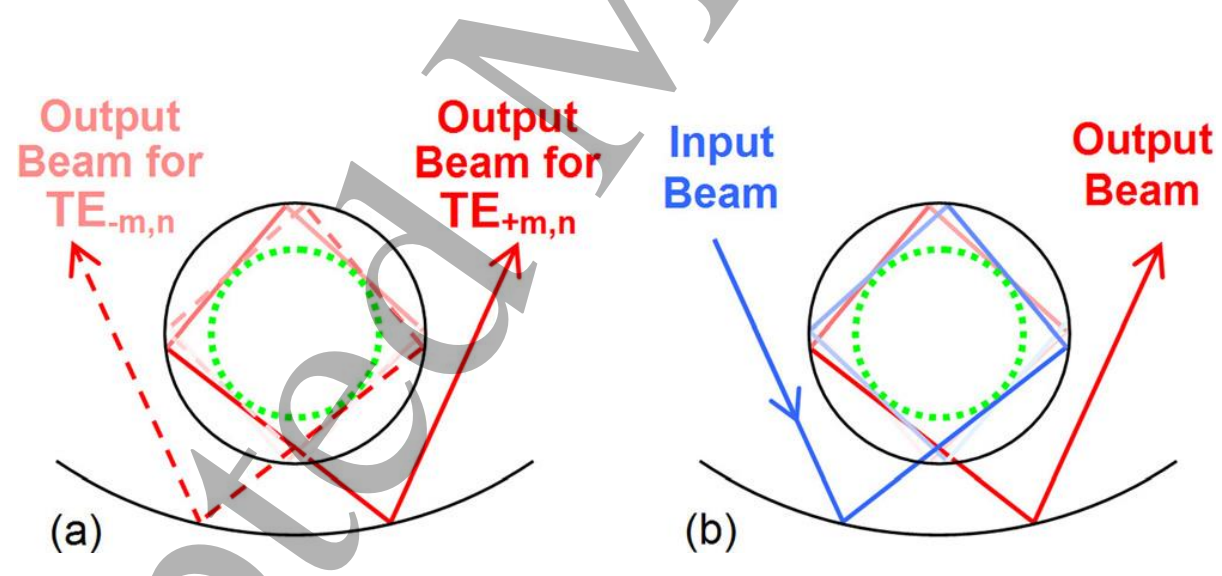

Figure 37. Two operation regimes of mode converter: (a) conversion of both the co- and counter rotating modes and (b) frequency/phase locking regime (Reproduced from [144] Chirkov AV et al 2015, Applied Physics Letters 106, 263501, with permission of AIP Publishing). 

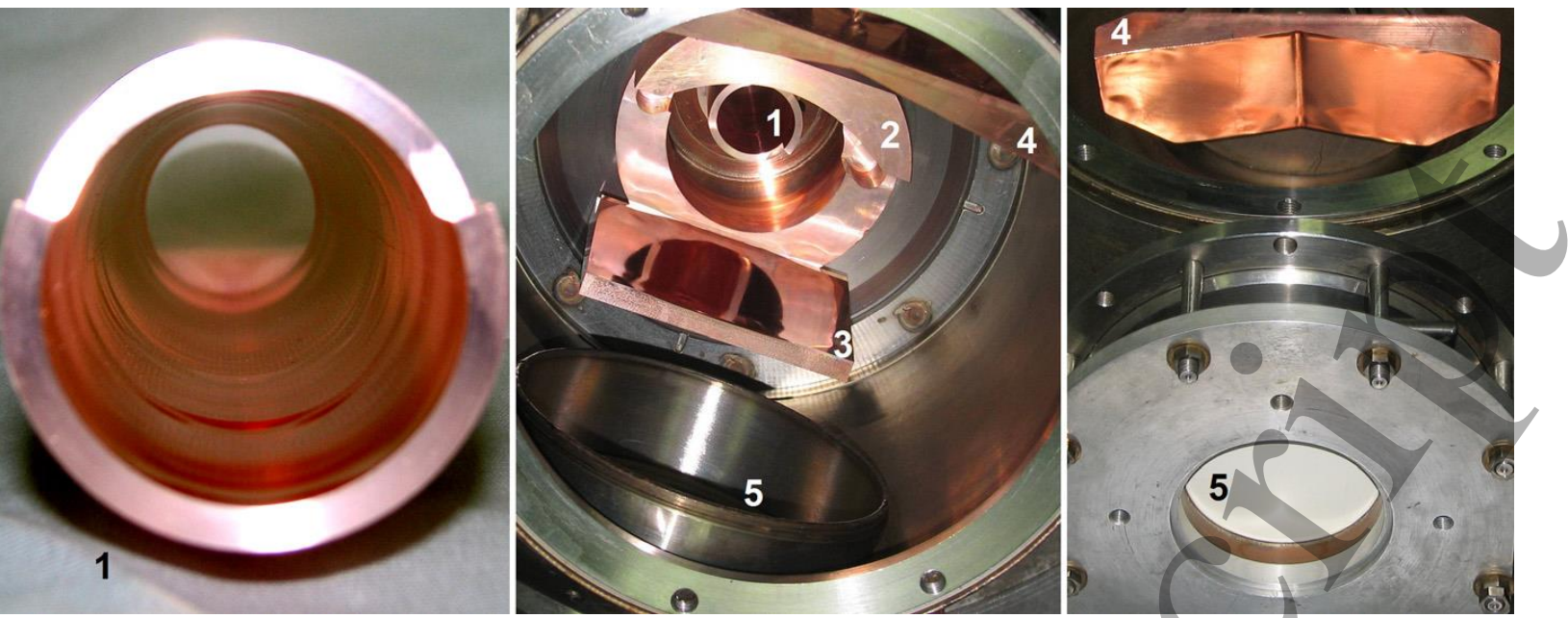

Figure 38. Mode converter for co- and counter-rotating cavity modes: (1) waveguide launcher, that has a vertical plane of symmetry, (2) parabolic mirror, (3) and (4) matching mirrors with non-quadratic surface contour functions, and (5) BN vacuum window (Reproduced from [144] Chirkov AV et al 2015, Applied Physics Letters 106, 263501, with permission of AIP Publishing).

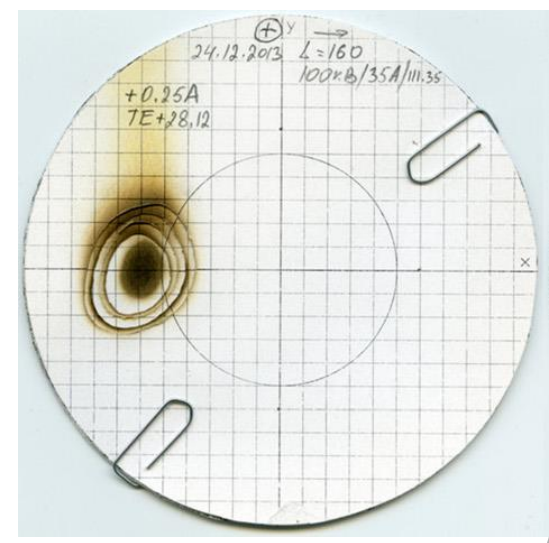

(a)

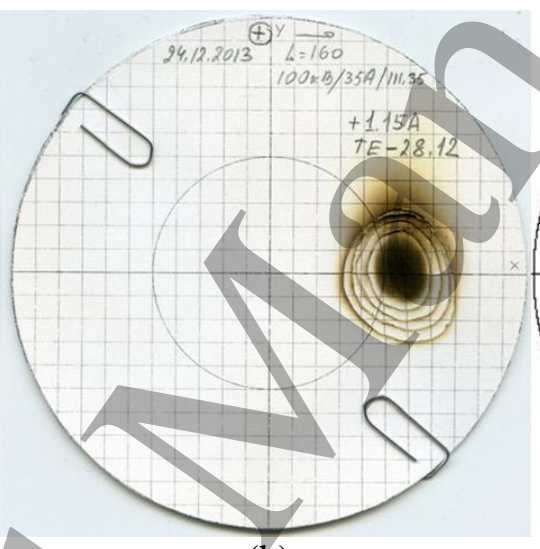

(b)

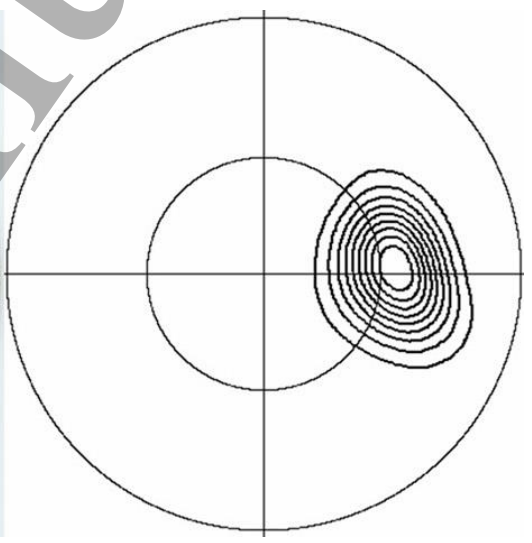

(c)

Figure 39. (a) and (b) Stacks of five burn patterns (with different exposition times) of the gyrotron output beam for co- and counter-rotating cavity modes at the distance of $160 \mathrm{~mm}$ from the gyrotron window, and (c) simulated beam intensity pattern in the same scale (Reproduced from [144] Chirkov AV et al 2015, Applied Physics Letters 106, 263501, with permission of AIP Publishing).

\subsection{Efficiency and RAMI}

Efficiency enhancement via multi-stage depressed collectors, fast oscillation recovery methods and RAMI will be discussed in this section.

\subsubsection{Multi-stage depressed collector}

One promising approach for increasing the total efficiency of fusion gyrotrons above $60 \%$ is to use a multi-stage depressed collector (MDC). That technology is well known from highly efficient traveling wave tubes (TWT) for space applications [147]. Those collectors use electrostatic or magnetic focusing to separate electrons with different energies within the spent electron beam in several intermediate steps of depression voltage along the electron beam axis. For gyrotrons there are also two known theoretical MDC concepts: one is to make use of the non-adiabatic electron trajectories in a strong magnetic field [148]; the other is to utilize the $\boldsymbol{E} \times \boldsymbol{B}$ drift of the electrons in crossed electric and magnetic fields [149]. Even though several considerations for gyrotron MDC designs exist in the literature, there has been no implementation of that technology in an experimental gyrotron. In the frame of EUROfusion, at KIT the 
A realistic and feasible mechanical design is shown in figure 40 [151]. It is based on the typical isolation scheme of fusion gyrotrons, where the cavity is at positive body potential while the mirror-box and the collector outer case (here, the vacuum vessel (b)) are grounded to create a depression voltage for the first stage. Water cooling is considered even in this short-pulse design, in order to increase the duty cycle. The surfaces of the first stage are thin metal plates supported by a metal frame. Beneath the helical electrode insulation gap (c) where slow electrons impact, are the cooling pipes (d) for the first stage. The cooling water is fed through the pipes (a).(e) is the coaxial insert, which is also grounded and hung from the top of the vacuum envelope.

The second stage has a potential of approximately $-12 \mathrm{kV}$. It is supported by several insulators (f). (g) is the "cap" of the second stage, which is also water cooled. The water is fed via the ceramic pipe (h), which also isolates the ground potential from the potential of the second stage. To protect the second stage from harmful transverse motions, which could break the insulators, a few ceramic blocks (i) are installed to fix the transverse position of the second stage.

\subsubsection{Fast oscillation recovery methods (re-start during the shot)}

Maximum possible ECH\&CD system power and operational stability are very important performance parameters. However, approaching the maximum gyrotron output power, undesired satellite modes are excited simultaneously with the operating main cavity mode [51]. This increases the stray radiation inside the tube and loss of the oscillating mode due to mode switching becomes more likely. The usual solution is a trade-off between output power and reliability by operating the gyrotrons below their maximum output power to guarantee a safety margin. An innovative solution has been introduced in the ECH system of W7-X [152,153]. It consists of a fast gyrotron controller (MORE) with a mode-loss precursor feedback and in case this stabilization fails, a fast, automated mode recovery within less than $1 \mathrm{~ms}$ is obtained by reducing the body voltage by approximately $9 \mathrm{kV}$. Then the body voltage is increased

MSDC technology shall be pushed significantly forward. Initial steps towards new, experimentally

Figure 40. Cross section of the mechanical design of the advanced $\mathbf{E}_{\varphi} \times \mathbf{B}_{\mathbf{Z}}$ drift MDC. (a) Water cooling feed through pipes. (b) Grounded vacuum vessel. (c) Helical electrode insulation gap. (d) Water cooling pipes. (e) Grounded coaxial insert. (f) Insulators. (g) Water cooled cap of the second stage. (h) Isolated water feed through. (i) Ceramic stabilization blocks (Reproduced from [151] Wu C et al 2019, Phys. Plasmas 26, 013108, with permission of AIP Publishing).

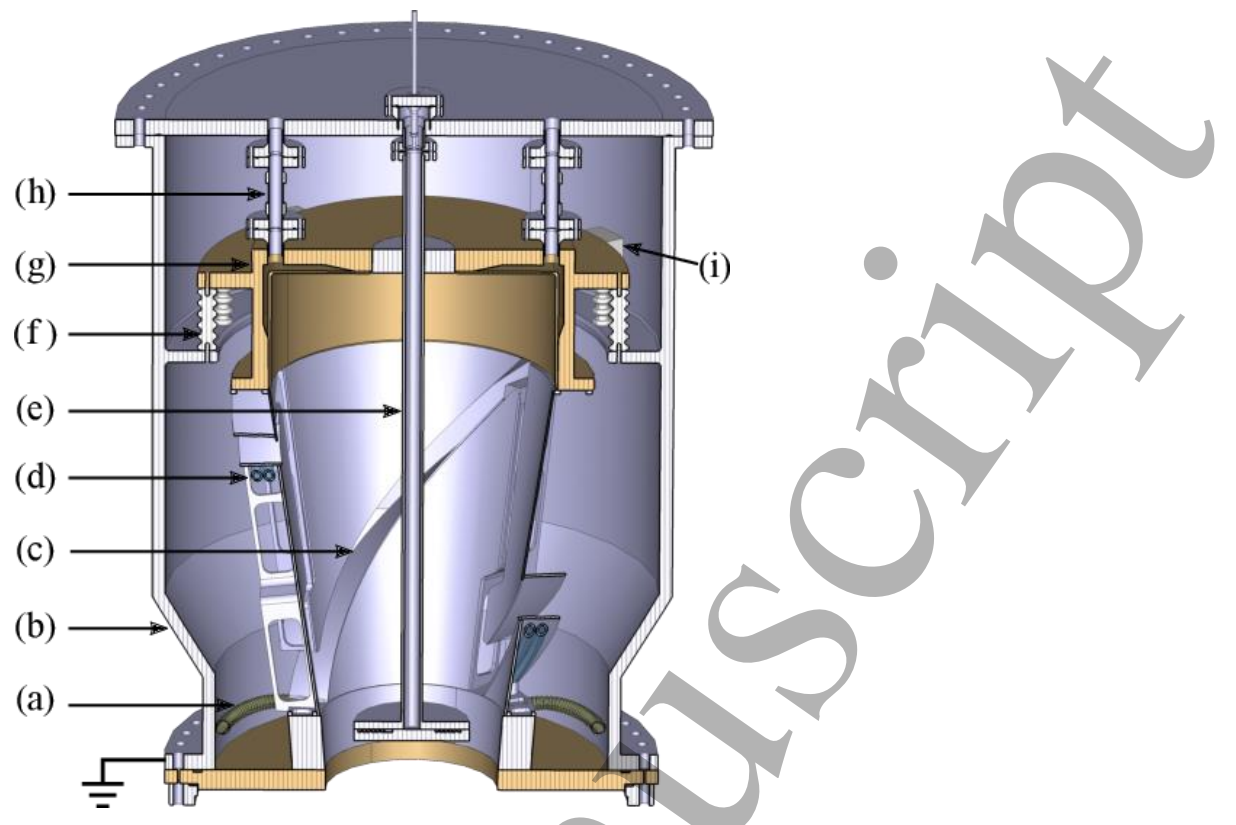


again, to return to the maximum output power. Figure 41 shows a 20 -s pulse with $820 \mathrm{~kW}$ RF power (lower trace). Using the MORE controller, the average output power could be increased to $875 \mathrm{~kW}$ (upper trace).

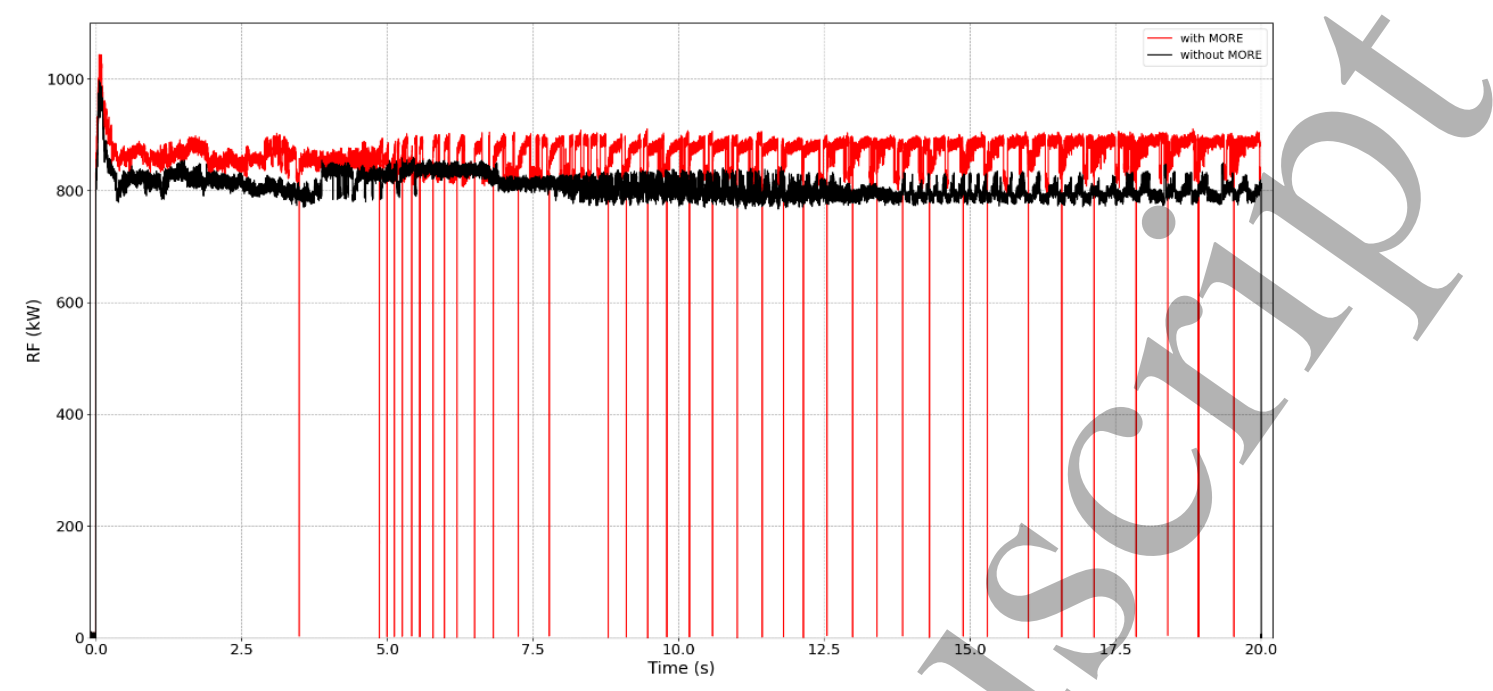

Figure 41. Fast gyrotron oscillation recovery of $140 \mathrm{GHz}$ W7-X gyrotron [153]. Red pulse trace with MORE and black pulse trace without MORE.

\subsubsection{Reliability, Availability, Maintainability and Inspectability (RAMI)}

In a fusion power plant, where all heating and current drive equipment must meet prescribed functions, the issues of RAMI become an integral part of the functional requirement. In present laboratory fusion plasma devices one is usually just performing experiments with whatever power is available on the allocated days: the power requirement is often adapted to the individual gyrotrons of the ECH\&CD system. Of course, fast gyrotron oscillation recovery improves the situation (see 5.7.2). In a fusion power plant, an insufficient $\mathrm{H} \& \mathrm{CD}$ power level may jeopardize the pulse, leading to the premature termination of the plasma discharge (assuming a soft landing is possible) and consequently to the disruption of the electricity supply to the grid.

True RAMI studies on heating systems are scarce due to the non-availability of data on large systems in reactor like environment or even with large systems (many tens of MW of installed power). Experience with the 24 MW ITER ECH\&CD system will be of great importance to realistic RAMI studies.

The present available data on megawatt-class gyrotrons often reports the number of successful shots at prescribed power level and pulse length. For example, the reliability requirement for the ITER tubes is $\geq 95 \%$, defined on 20 pulses of full power and 500 s pulse length. In case of a mode loss occurring during the pulse, this pulse would still be considered successful if full power generation could restart quickly enough to have the nominal output power during a minimum of $95 \%$ of the 500 -s pulse.

For simulation of ITER operation with the Japanese $170 \mathrm{GHz}$ gyrotron, $0.8 \mathrm{MW}$ pulses at $600 \mathrm{~s}$ pulse length were repeated with an interval of $20 \sim 30 \mathrm{~min} .72$ shots of 88 trials were very stable over the full pulse duration. The other pulses were interrupted by internal arcing, etc. (see 4.1.2). Tests at $1 \mathrm{MW}$ output power with the Russian ITER gyrotron at pulse durations of $500 \mathrm{~s}$ and $1000 \mathrm{~s}$ showed a reliability of gyrotron operation $\geq 95 \%$ (see 4.1.3). The $140 \mathrm{GHz}$ THALES gyrotron for W7-X delivered $0.7 \mathrm{MW}$ pulses with 180 s pulse duration at $98 \%$ reliability [90].

The very high RAMI level required for future fusion power plant gyrotrons, e.g. for DEMO, suggests the need for further optimization of all the critical tube components. In addition, advances with respect to robustness against manufacturing tolerances and maintainability are necessary. 


\section{Conclusions}

The state-of-the-art and recent outstanding activities in the field of high-power gyrotron development for magnetic confinement fusion applications have been summarized. Since the early 1990's, gyrotron research and development advanced significantly, and progress is still underway. This is the reason why ECH\&CD mutated from being a stepchild in the family of plasma heating methods to being a major player in the field. Rapid progress in $1 \mathrm{MW}$-class long-pulse operation at 140 and $170 \mathrm{GHz}$ resulted in the facts that ECH is the only $10 \mathrm{MW}$ long-pulse heating system of W7-X, will be the first auxiliary heating method used at ITER ( $24 \mathrm{MW})$, is utilized in all major plasma confinement devices, with the exception of JET, and that ECH\&CD is foreseen in all the different design proposals for a future DEMO reactor. Table 8 summarizes the parameters of running, prepared and foreseen multi-megawatt ECH\&CD systems with frequencies higher than $77 \mathrm{GHz}$. Sub-THz gyrotrons are being used for collective Thomson scattering (CTS) diagnostics. The next targets are tubes with higher frequencies for DEMO, multi-frequency (multi-purpose) gyrotrons, and stepwise frequency tunable tubes for plasma stabilization with

Table 8. Features and parameters of running and foreseen (italic letters) multi-megawatt ECH\&CD systems with frequencies higher than $77 \mathrm{GHz}$.

\begin{tabular}{|c|c|c|c|c|c|c|}
\hline $\begin{array}{c}\text { Plasma Device } \\
\text { Type }\end{array}$ & $\begin{array}{l}\text { Institution } \\
\text { (Site) }\end{array}$ & $\begin{array}{c}\text { ECH Power } \\
{[\mathrm{MW}]}\end{array}$ & $\begin{array}{c}\text { Frequency } \\
{[\mathrm{GHz}]}\end{array}$ & $\begin{array}{c}\text { Pulse } \\
\text { Duration [s] }\end{array}$ & $\begin{array}{c}\text { Energy at Plasma } \\
{[\mathrm{MW} \times \mathrm{x} \text { s] }}\end{array}$ & $\begin{array}{l}\text { Company/ } \\
\text { Institution }\end{array}$ \\
\hline $\begin{array}{c}\text { ASDEX-U } \\
\text { Tokamak [154] }\end{array}$ & IPP Garching & $8.0(8 \times 1.0)$ & $140+105$ & 0.0 & $\begin{array}{l}4.5 \times 10.0 \\
6.4 \times 10.0\end{array}$ & GYCOM/IAP \\
\hline $\begin{array}{c}\text { DIII-D } \\
\text { Tokamak [155] }\end{array}$ & GA San Diego & $\begin{array}{l}3.0(3 \times 1.0) \\
1.5(1 \times 1.5) \\
4.0(4 \times 1.0)\end{array}$ & $\begin{array}{r}110 \\
117.5 \\
110\end{array}$ & $\begin{array}{l}5.0 \\
5.0\end{array}$ & $\begin{array}{c}2.35 \times 5.0 \\
1.0 \times 2.0 \\
3.2 \times 5.0\end{array}$ & $\begin{array}{l}\text { CPI } \\
\text { CPI } \\
C P I\end{array}$ \\
\hline $\begin{array}{c}\text { EAST } \\
\text { Tokamak [156] }\end{array}$ & IPP Hefei & $4.0(4 \times 1.0)$ & 140 & 1000 & $\begin{array}{l}1.4 \times 100 \\
3.6 \times 1000\end{array}$ & $\begin{array}{l}\text { GYCOM/IAP } \\
\text { (2 Tubes) } \\
\text { CPI (2 Tubes) }\end{array}$ \\
\hline ITER Tokamak & Cadarache & $24.0(24 x 1.0)$ & 170 & 1000 & $20.0 \times 1000$ & $\begin{array}{c}G Y C O M / I A P \\
C E T D / Q S T \\
E U, I N D I A\end{array}$ \\
\hline $\begin{array}{l}\text { JT 60SA } \\
\text { Tokamak }\end{array}$ & QST Naka & $\begin{array}{l}4.0(4 \times 1.0) \\
\quad \text { later } \\
9.0(9 \times 1.0)\end{array}$ & $\begin{array}{l}138+110+82 \\
\text { mult-freq. } \\
\text { gyrotron }\end{array}$ & $\begin{array}{c}5.0,100 \\
\text { later } \\
100\end{array}$ & $\begin{array}{c}1.5 \times 5.0+ \\
1.5 \times 100 \\
\text { later } 7.0 \times 100\end{array}$ & $C E T D / Q S T$ \\
\hline $\begin{array}{c}\text { KSTAR } \\
\text { Tokamak [157] }\end{array}$ & NFRI & $\begin{array}{l}0.5(1 \times 0.5) \\
1.0(1 \times 1.0) \\
2.0(2 \times 1.0)\end{array}$ & $\begin{array}{c}84 \\
110 \\
140+105\end{array}$ & $\begin{array}{c}2.0 \\
5.0 \\
300.0\end{array}$ & $\begin{array}{c}0.3 \times 2.0 \\
0.5 \times 2.0 \\
0.7 \times 70.0\end{array}$ & $\begin{array}{c}\text { CPI } \\
\text { GYCOM/IAP } \\
\text { GYCOM/IAP }\end{array}$ \\
\hline $\begin{array}{c}\text { TCV } \\
\text { Tokamak [158] }\end{array}$ & SPC Lausanne & $\begin{array}{l}1.5(2 \times 0.75) \\
1.5(3 \times 0.5) \\
2.0(2 \times 1.0)\end{array}$ & $\begin{array}{c}82.7 \\
118 \\
126+84\end{array}$ & $\begin{array}{l}2.0 \\
2.0 \\
2.0\end{array}$ & $\begin{array}{l}1.3 \times 2.0 \\
1.3 \times 2.0 \\
1.8 \times 2.0\end{array}$ & $\begin{array}{c}\text { GYCOM/IAP } \\
\text { THALES/EGYC } \\
\text { THALES/EGYC }\end{array}$ \\
\hline $\begin{array}{c}\mathrm{T}-10 \\
\text { Tokamak [159] }\end{array}$ & $\begin{array}{l}\text { NRC KI } \\
\text { Moscow }\end{array}$ & $\begin{array}{l}1.0(2 \times 0.5) \\
1.7(2 \times 0.85) \\
1.2(1.2 \times 1.0)\end{array}$ & $\begin{array}{l}129 \\
140 \\
140\end{array}$ & $\begin{array}{l}0.5 \\
0.5 \\
10.0\end{array}$ & $\begin{array}{l}0.8 \times 0.4 \\
1.6 \times 0.4 \\
1.1 \times 1.0\end{array}$ & GYCOM/IAP \\
\hline $\begin{array}{c}\text { T-15MD } \\
\text { Tokamak }\end{array}$ & $\begin{array}{l}\text { NRC KI } \\
\text { Moscow }\end{array}$ & $1.0(1 \times 1.0)$ & 82.9 & 20.0 & $0.95 \times 20.0$ & GYCOM/IAP \\
\hline $\begin{array}{c}\text { LHD Stellarator } \\
{[160]}\end{array}$ & NIFS Toki & $\begin{array}{l}3.9(3 \times 1.3) \\
2.2(2 \times 1.1)\end{array}$ & $\begin{array}{c}77 \\
156\end{array}$ & $\begin{array}{l}5.0 \\
5.0\end{array}$ & $\begin{array}{l}3.5 \times 2.0 \\
1.9 \times 2.0\end{array}$ & $\begin{array}{c}\text { CETD/UNIV. } \\
\text { TSUKUBA }\end{array}$ \\
\hline$\frac{\text { W7-X }}{\text { Stellarator [7] }}$ & IPP Greifswald & $10.0(10 \times 1.0)$ & 140 & $\begin{array}{c}5.0 \\
1800\end{array}$ & $\begin{array}{c}8.0(5.0) \times 5.0(31) \\
8.0 \times 1800\end{array}$ & $\begin{array}{l}\text { THALES/KIT } \\
\text { (9 Tubes) } \\
\text { CPI ( } 1 \text { Tube) }\end{array}$ \\
\hline
\end{tabular}


fixed launching antennas. Injection-locked and coaxial-cavity gyrotrons are candidates for 1.5 - $2 \mathrm{MW}$ output power per tube. Development challenge continue since efficiency enhancement via multi-stage depressed collectors, fast oscillation recovery methods and RAMI are absolutely necessary requirements for future thermonuclear fusion power plants.

\section{Acknowledgments}

The authors would like to thank the members of their related fusion gyrotron research and development teams and companies, EGYC with F4E and THALES in Europe, at IAP with GYCOM in Russia and at QST and University of Tsukuba with CTED in Japan for their continuous excellent R\&D works. We would also like to thank John Lohr from GA for giving us an update of the status of the CPI development of $110 \mathrm{GHz}$ and $117.5 \mathrm{GHz}$ gyrotrons for the ECH\&CD system at DIII-D.

The author's have confirmed that any identifiable participants in this study have given their consent for publication.

\section{References}

[1] Freiberg J 2007, Plasma Physics and Fusion Energy (Cambridge University Press), pages 537-540

[2] Wagner F et al 2010, Plasma Physics and Controlled Fusion 52, 124044

[3] ITER Physics Basis 1999, Nucl. Fusion 39, 2496

[4] ITER Physics Basis 2007, Nucl. Fusion 47, 385

[5] Kikuchi M , Lackner K and Tran MQ, eds, 2012, http://www-pub.iaea.org/books/IAEABooks/ 8879/Fusion-Physics, Chapter 6

[6] Poli E et al 2013, Nucl. Fusion 53, 013011

[7] Wolf RC, 2019, Plasma Physics and Controlled Fusion 61, 014037

[8] Omori T et al 2015, Fusion Eng. and Design 96-97, 547

[9] Martin YR et al 2008, J. Phys. Conf. Ser. 123.1, 012033

[10] Vincenzi P et al 2017, Fusion Eng. and Design 123, 473

[11] Goodman TP et al 2011, Phys. Rev. Lett. 106, 245002

[12] Henderson MA et al 2008, Nucl. Fusion 48, 054013

[13] Granucci G et al 2017, Nucl. Fusion 57, 116009

[14] Alberti S et al 2017, EPJ Web of Conferences 157, 03001

[15] Edgcombe CJ, ed. 1993, Gyrotron oscillators - their principles and practice, Taylor \& Francis, London

[16] Kartikeyan MV, Borie E and Thumm MKA 2004, Gyrotrons - High power microwave and millimeter wave technology, Springer, Berlin

[17] Nusinovich G 2004, Introduction to the physics of gyrotrons, The Johns Hopkins University Press, Baltimore and London

[18] Benford J, Swegle J and Schamiloglu E 2007, High-power microwave sources, 2nd Ed., Taylor \& Francis, New York, London

[19] Litvak A, Sakamoto K and Thumm M 2011, Plasma Physics and Controlled Fusion 53, 124002

[20] Nusinovich GS, Thumm MKA and Petelin, MI 2014, J. Infrared, Millimeter, and Terahertz Waves, 35, 4,325

[21] Thumm M 2014, IEEE Trans. on Plasma Science 42, 3, 590

[22] Thumm M 2014, J. Infrared, Millimeter, and Terahertz Waves, 35, 12, 1011

[23] Tsimring SE 2007, Electron beams and microwave vacuum electronics, John Wiley \& Sons, Hoboken, NJ, USA

[24] Kuftin AN et al 1999, Int. J Infrared and Millimeter Waves 20, 381

[25] Tsimring SE 2001, Int. J Infrared and Millimeter Waves 22, 1433

[26] Pagonakis IGr, Illy S and Thumm M 2016 Physics of Plasmas 23, 083103

[27] Gantenbein G et al. 2010, IEEE Trans. on Plasma Science 38, 1168

[28] Yu J, Antonsen TM and Nusinovich GS 2010 IEEE Trans. on Plasma Science 38, 1193

[29] Sakamoto K et al 2003, Nucl. Fusion 43, 729

[30] Vlasov SN, Zagryadskaya LI and Petelin MI 1975 Radio Eng. Electron. Physics 20, 14

[31] Thumm MK and Kasparek W 2002, IEEE Trans. on Plasma Science 30, 755 
[32] Denisov GG et al 1992, Int. J. Electron. 72, 1079

[33] Bogdashov AA et al 2005, Int. J Infrared and Millimeter Waves 26, 771

[34] Thumm M et al 2007, IEEE Trans. on Plasma Science 35, 143

[35] Neilson JF 2006, IEEE Trans. on Plasma Science 34, 635

[36] Chirkov AV et al 2006, Radiophys. Quantum Electron. 49, 344

[37] Jin J, et al 2009, IEEE Trans. on Microwave Theory and Techniques 57, 1661

[38] Neilson JF and Bunger R 2002 IEEE Trans. on Plasma Science 30, 794

[39] Jin J et al 2017, IEEE Trans. on Microwave Theory and Techniques 65, 3, 699

[40] Thumm M 1998, Int. J. Infrared and Millimeter Waves 19, 3

[41] Braz O et al 1997, Int. J. Infrared and Millimeter Waves 18, 1495

[42] Kasugai A et al 1998, Rev. Sci. Instruments 69, 2160

[43] Sakamoto K et al 1999, Rev. Sci. Instruments 70, 208.

[44] Sakamoto K et al 1994, Phys. Rev. Lett. 73, 3532

[45] Piosczyk B et al 1996, IEEE Trans. on Plasma Science 24, 579

[46] Denisov G et al 2017, EPJ Web of Conferences 147, 04003

[47] Schmid M, Illy S, Dammertz G, Erckmann V and Thumm M 2007 Fusion Eng. Design 82, 744

[48] Thumm M et al. 2008, IEEE Trans. on Plasma Science 36, 341

[49] Ives RL et al 1999, IEEE Trans. on Plasma Science 27, 2, 531

[50] Bruschi et al 2003, Nucl. Fusion 43, 1513

[51] Schlaich A et al 2013, IEEE Trans. on Microw. Theory and Techniques 61, 4660

[52] Chirkov AV, Denisov GG and Aleksandrov NL 1995 Opt. Commun. 115, 449

[53] Darbos C et al 2015, J. Infrared, Millimeter, and Teraherz Waves 37, 4

[54] Bigot B 2018, 27th IAEA Int. Conf. on Fusion Energy (Gandhinagar, India, 2018) [OV/1-2]

[55] Sakamoto K. et al 1996, J. Phys. Soc. Japan 65, 1888.

[56] Sakamoto K. et al 1997, Int. J. Infrared and Millimeter Waves 18, 1637.

[57] Sakamoto K et al 2007, Nature Physics 3, 411

[58] Kasugai A et al 2008, Nucl. Fusion 48, 054009

[59] Sakamoto K et al 2009, Nucl. Fusion 49, 095019

[60] Kajiwara K et al 2013, Nucl. Fusion 53, 043013

[61] Kajiwara $\mathrm{K}$ et al 2011, J. Infrared, Millimeter and Terahertz Waves 32, 329

[62] Kajiwara $\mathrm{K}$ et al 2011, Fusion Eng. and Design 86, 955

[63] Ikeda $\mathrm{R}$ et al 2015, Fusion Eng. and Design 96-97, 482

[64] Oda $\mathrm{Y}$ et al 2018, 27 $7^{\text {th }}$ IAEA Int. Conf. on Fusion Energy (Gandhinagar, India, 2018) [FIP/P1-56]

[65] Zapevalov VE et al 2001, Fusion Eng. and Design 53, 377

[66] Denisov GG et al 2003, Radiophysics and Quantum Electronics 46, 757

[67] Denisov GG et al 2008, Nucl. Fusion 48, 054007

[68] Litvak AG et al 2011, J. Infrared, Millimeter and Terahertz Waves 32, 337

[69] Krasilnikov AV et al 2015, Nucl. Fusion 55, 10, 104007

[70] ITER Newsline, 26 February 2018, https://www.iter.org/newsline/-/2931

[71] Darbos C et al 2019, J. Infrared, Millimeter and Terahertz Waves, in press

[72] Hogge J-P et al 2009, Fusion Science and Technology 55, 204

[73] Pagonakis IGr et al 2015, Fusion Eng. and Design 96-97, 149

[74] Rzesnicki T et al 2017, Fusion Eng. and Design 123, 490

[75] Gantenbein $\mathrm{G}$ et al 2017, EPJ Web of Conferences 157, 03016

[76] Ioannidis ZC et al 2017, IEEE Trans. on Electron Devices 64, 9, 3885

[77] Imai T et al 2010, $23^{\text {rd }}$ IAEA Int. Conf. on Fusion Energy (Daejeon, South Korea, 2010)TP/P6-12

[78] Minami R et al 2013, Nucl. Fusion 53, 063003

[79] Kariya Tet al 2017, Nucl. Fusion 57, 066001

[80] Kariya T et al 2018, 27 ${ }^{\text {th }}$ IAEA Int. Conf. on Fusion Energy (Gandhinagar, India) [FIP/P1-56]

[81] Moriyama S et al 2009, Nucl. Fusion 49, 085001

[82] Kobayashi T et al 2015, Nucl. Fusion 55, 063008

[83] Denisoy GG et al 2017, $18^{\text {th }}$ IEEE Int. Vacuum Electron. Conf. (IVEC 2017), London, UK, GI-1

[84] Erckmann V et al 2007, Fusion Science and Technology 52, 291

[85] Felch K et al 2005, J. of Physics: Conference Series 25, 13

[86] Cauffman et al 2015, $40^{\text {th }}$ Int. Conf. Infrared, Millimeter and Terahertz Waves, Hong Kong, M1E5 [87] Alberti $\mathrm{S}$ et al 2001, Fusion Eng. and Design 53, 387 
[88] Dammertz G et al 2002, IEEE Trans. on Plasma Science 30, 808

[89] Dammertz G et al 2005, Fusion Eng. and Design 74, 217

[90] Gantenbein G et al 2011, J. of Infrared, Millimeter, and Terahertz Waves, 32, 320

[91] Thumm $M$ et al 2005, IEEE Trans. on Electron Devices 52, 818

[92] Dammertz G et al 2003, Fusion Eng. and Design 66-68, 497

[93] Darbos C et al 2009, Fusion Science and Technology 56, 1205

[94] Wagner D. et al 2015, J. Infrared, Millimeter and Terahertz Waves 37, 1, 45

[95] Alberti S et al 2017, EPJ Web of Conferences 157, 03001

[96] Rodolphe $\mathrm{M}$ et al 2019, $20^{\text {th }}$ Int. Conf. Vacuum Electronics (IVEC 2019), Busan, South Korea

[97] Felch K, Huey H, and Jory H 1990, J. Fusion Energy 9, 59

[98] Felch K et al 1996, IEEE Trans. on Plasma Science 24, 558

[99] Felch K et al 2008, Nucl. Fusion 48, 054008

[100] Lohr J et al 2011, J. Infrared, Millimeter and Terahertz Waves 32, 253

[101] Choi EM et al 2006, Phys. Plasmas 13, 023103

[102] Felch K et al 2015, EPJ Web of Conferences 87, 04006

[103] Felch K et al 2017, 42 ${ }^{\text {nd }}$ Int. Conf. Infrared, Millimeter, and THz Waves, Cancun, Mexico, WC2.3

[104] Zohm H and Thumm M 2005, J. Phys.: Conf. Ser. 25, 274

[105] Piosczyk B et al 2000, IEEE Trans. on Plasma Science 28, 918

[106] Zapevalov VE et al 2004, Radiophysics and Quantum Electronis 47, 396

[107] Kazansky IV et al 2009, $7^{\text {th }}$ Int. Workshop Strong Microwaves: Sources and Applications 1, 100

[108] Sakamoto K et al 2017, 42 ${ }^{\text {nd }}$ Int. Conf. Infrared, Millimeter, and THz Waves, Cancun, Mexico, RA2.3

[109] Morozkin M et al 2018, EPJ Web of Conferences 195, 01008

[110] Denisov GG et al 2018, Review of Scientific Instruments 89, 084702

[111] Garavaglia S et al 2018, Fusion Eng. and Design 136, 1173

[112] Franck J et al 2015, Nucl. Fusion 55, 013005

[113] Thumm M et al 2015, Terahertz Science and Technology 8, 3, 85

[114] Kalaria PC et al 2016, Phys. Plasmas 23, 092503

[115] Kalaria PC et al 2017, Frequenz 71, 3-4, 161

[116] Jelonnek J et al 2017, Fusion Eng. and Design 123, 241

[117] Thumm M et al 2018, Terahertz Science and Technology 11, 1, 1

[118] Ruess T et al 2019, $20^{\text {th }}$ Int. Conf. Vacuum Electronics (IVEC 2019), Busan, South Korea

[119] Schmid M et al 2017, Fusion Eng. and Design 136, 485

[120] Saito T et al 2012, Phys. Rev. Lett. 109, 15, 155001

[121] Saito T et al 2013, $38^{\text {th }}$ Int. Conf. Infrared, Millimeter, and THz Waves, Mainz, Germany, Mo5-3

[122] Saito T et al 2017, Plasma and Fusion Res.: Rapid Communications 12, 1206013

[123] Glyavin MY et al 2012, Appl.Phys. Lett. 101, 15, 153503

[124] Fokin A et al 2018, Scientific Reports 8, 4317

[125] Kajiwara K et al 2011, Appl. Phys. Express 4, 126001

[126] Sakamoto K et al 2012, 37 Int. Conf. Infrared, Millimeter, and THz Waves, Wollongong, Australia, Tue-A-3-1

[127] Ikeda $\mathrm{R}$ et al 2017, J Infrared Millimeter and Terahertz Waves 38, 531

[128] Oda Y et al 2018, Nucl. Fusion 58, 106041

[129] Braz O et al 1997, Int. J. Infrared and Millimeter Waves 18, 1465

[130] Thumm M et al 2001, Fusion Eng. and Design 53, 407

[131] Hirose R et al 2008, IEEE Trans. Applied Superconductivity 18, 2, 920

[132] Litvak AG et al 2012, EPJ Web of Conferences 32, 04003

[133] Koppenburg K et al 2001, IEEE Trans. on Electron Devices 48, 101

[134] Gantenbein G et al 2014, IEEE Trans. on Electron Devices 61, 6, 1806

[135] Samartsev A et al 2015, IEEE Trans. on Electron Devices 62, 7, 2317

[136] Piosczyk B et al 2004, IEEE Trans. on Plasma Science 32, 853

[137] Zapevalov VE et al 2000, Radiophysics and Quantum Electronics 43, 671

[138] Piosczyk B et al 1997, IEEE Trans. on Plasma Science 25, 460

[139] Rzesnicki T et al 2010, IEEE Trans. on Plasma Science 38, 1141

[140] Ruess S et al 2018, Int. J. Microwave and Wireless Technologies 10, 547

[141] Gantenbein G et al 2019, Fusion Eng. and Design, doi.org/10.1016/ j.fusengdes.2018.12.063 
[142] Flyagin VA et al 2003, Int. J. Infrared and Millimeter Waves 24, 1

[143] Ioannidis ZC et al 2016, IEEE Trans. on Electron Devices 63, 3, 1299

[144] Chirkov AV, Denisov GG and Kuftin AN 2015, Applied Physics Letters 106, 263501

[145] Denisov GG 2017, EPJ Web of Conferences 149, 01001

[146] Bakunin VL et al 2018, Technical Physics Letters 44, 6, 473

[147] Faillon G et al 2008, "Microwave Tubes", "Vacuum Electronics - Components and Devices", Eichmeier JA and Thumm M, eds., Springer, Berlin Heidelberg New York, 1-84 (2008)

[148] Ives RL et al 1999, IEEE Trans. on Plasma Science 27, 503

[149] Pagonakis IGr et al 2008, IEEE Trans. on Plasma Science 36, 469

[150] Wu C et al 2018, Phys. Plasmas 25, 033108

[151] Wu C et al 2019, Phys. Plasmas 26, 013108

[152] Wilde $\mathrm{F}$ et al 2017, $18^{\text {th }}$ IEEE Int. Vacuum Electron. Conf. (IVEC 2017), London, UK, GII-1

[153] Wilde $\mathrm{F}$ et al 2018, $20^{\text {th }}$ Joint Workshop on ECE and ECRH (EC20), Greifswald, Germany, S4.4.

[154] Wagner D et al 2017, EPJ Web of Conferences 149, 03004

[155] Cengher $\mathrm{M}$ et al 2019, EPJ Web of Conferences 203, 02006

[156] Wang X et al 2019, EPJ Web of Conferences 203, 02012

[157] Park HK et al 2018, 27 $7^{\text {th }}$ IAEA Int. Conf. on Fusion Energy (Gandhinagar, India) [OV/2-3]

[158] Coda $\mathrm{S}$ et al 2018, 27 ${ }^{\text {th }}$ IAEA Int. Conf. on Fusion Energy (Gandhinagar, India) [OV/5-2]

[159] Borschegovskiy A et al 2019, EPJ Web of Conferences 203, 02004

[160] Igami, H et al 2019, EPJ Web of Conferences 203, 02001 